Portland State University

PDXScholar

Spring 5-8-2018

\title{
Impacts of Mindfulness Training on Mechanisms Underlying Stress Reduction in Teachers: Results from a Randomized Controlled Trial
}

Jaiya Rae Choles

Portland State University

Follow this and additional works at: https://pdxscholar.library.pdx.edu/open_access_etds

Part of the Psychology Commons

Let us know how access to this document benefits you.

Recommended Citation

Choles, Jaiya Rae, "Impacts of Mindfulness Training on Mechanisms Underlying Stress Reduction in Teachers: Results from a Randomized Controlled Trial" (2018). Dissertations and Theses. Paper 4468. https://doi.org/10.15760/etd.6352

This Thesis is brought to you for free and open access. It has been accepted for inclusion in Dissertations and Theses by an authorized administrator of PDXScholar. Please contact us if we can make this document more accessible: pdxscholar@pdx.edu. 
Impacts of Mindfulness Training on Mechanisms

Underlying Stress Reduction in Teachers:

Results from a Randomized Controlled Trial

by

Jaiya Rae Choles

A thesis submitted in partial fulfillment of the requirements for the degree of

\author{
Master of Science \\ in \\ Psychology
}

Thesis Committee:

Andrew Masburn, Chair

Ellen Skinner

Joel Steele

Portland State University

2018 


\begin{abstract}
A teacher's ability to foster and sustain high quality learning environments for their students relies largely on their own coping abilities and mental health (e.g., Montgomery \& Rupp, 2005). However, due to the emotionally taxing nature of their profession, teachers are at increased risk for developing elevated levels of occupational stress and burnout (Skinner \& Beers, 2016). To help teachers cope with their occupational stress and other negative emotions related to their occupation, mindfulness-based stress reduction programs for teachers have been introduced through schools (Roeser, 2014). Evidence for the effectiveness of such programs is promising (see Jennings, Frank, Snowberg, Coccia, \& Greenberg, 2013; Taylor et al., 2016), however few studies have considered underlying mechanisms that may be driving these effects.

Using data collected as part of a randomized controlled trial, this thesis examines the impact of mindfulness training on three coping resources, namely, somatic body awareness, executive function, and emotion regulation. Additionally, this thesis examines whether development of these resources translate into improvements in teachers' occupational well-being — specifically indicated through reductions in their anxiety, depression, stress, and burnout. Results suggest that the mindfulness training significantly improves teachers' somatic body awareness, with evidence for improvements in teachers' emotion regulation reappraisal as well. Additionally, some mediation results were promising, however, no significant mediations were found for any of the coping resources on any of the well-being outcomes for teachers. By addressing these topics, the results of this thesis contribute to the current field's understanding of how mindfulness training works to improve well-being in teachers.
\end{abstract}




\section{Acknowledgements}

I would like to sincerely thank my advisors on this project, Drs. Andrew Mashburn, Robert Roeser, Ellen Skinner, and Joel Steele, for their guidance and support on this immensely challenging and rewarding project. I would also like to acknowledge the William T. Grant Foundation, the Spencer Foundation, the Mind and Life Institute, Portland State University, and the teachers and students of Portland Public Schools for making this study possible. I would also like to mention, with great gratitude, my student colleagues, my family, and most importantly my partner Jim Goodman, for their encouragement and unwavering support. 


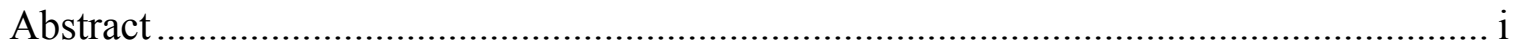

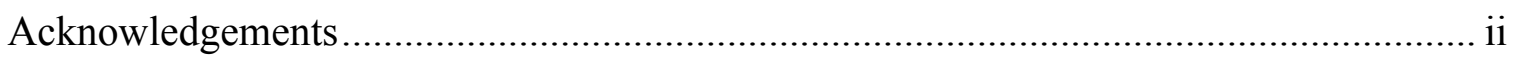

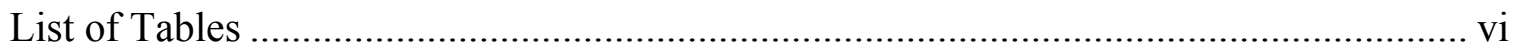

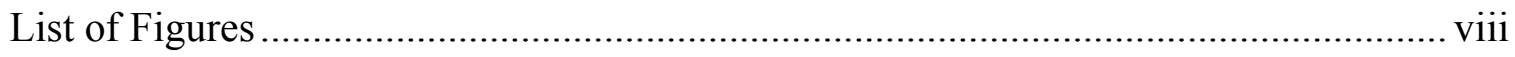

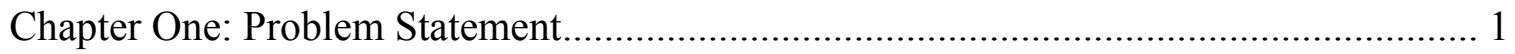

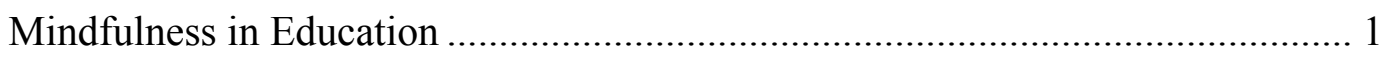

Chapter Two: Literature Review …………………….......................................... 5

Theoretical Framework for Assessing Teacher Stress ........................................... 6

Levels of the Stress-coping Process........................................................ 7

Levels of Coping and Mindfulness ............................................... 8

Flexibility of Coping Repertoires ........................................................... 9

Flexibility of Coping Repertoires and Mindfulness........................ 9

Coping as Reactivity and Regulation.................................................... 10

Reactivity, Regulation, and Mindfulness...................................... 11

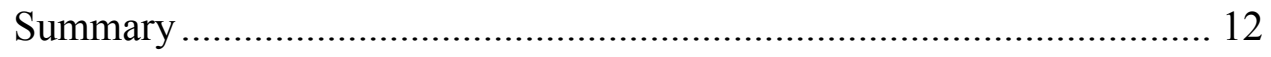

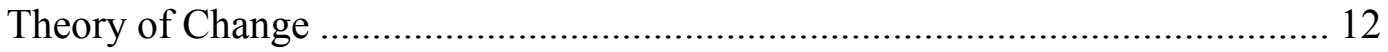

Proposed Mechanisms Underlying the Stress Reducing Effects of Mindfulness

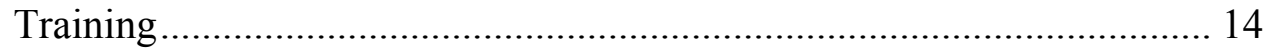

Somatic Body Awareness .................................................................. 14

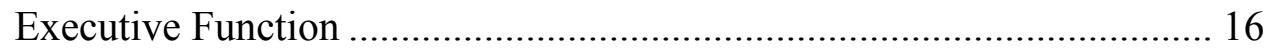

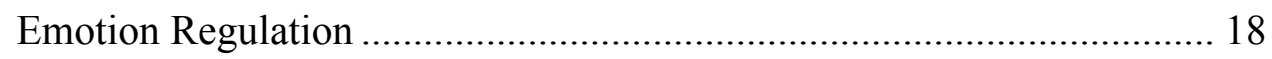

Effects of Mindfulness Training on the Proposed Mechanisms ........................... 21

Somatic Body Awareness in the Context of Mindfulness Interventions .. 22

Executive Function and Emotion Regulation in the Context of

Mindfulness Interventions ................................................................... 23

Effects of Mindfulness Training on Executive Function and Emotion Regulation in Teachers................................................ 28

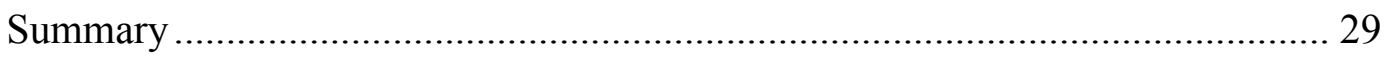

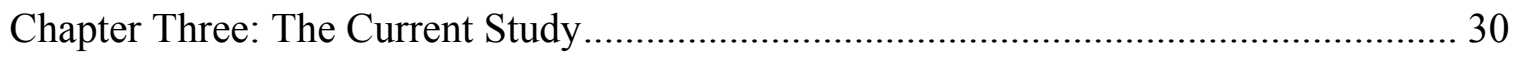

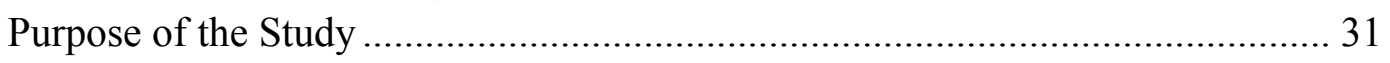

Research Questions and Hypotheses ....................................................... 31

Chapter Four: Research Design and Methods ............................................................. 34

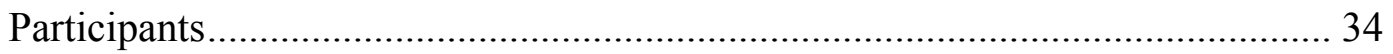

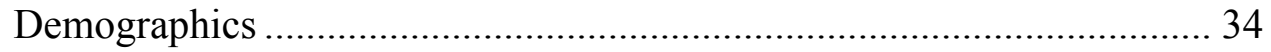

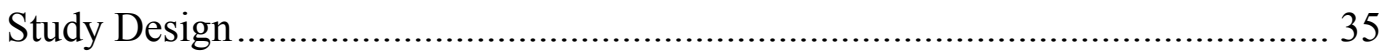




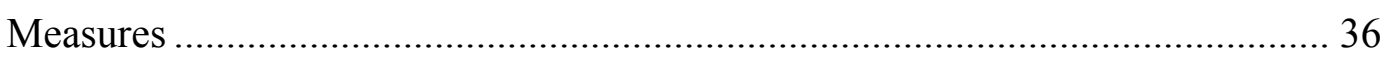

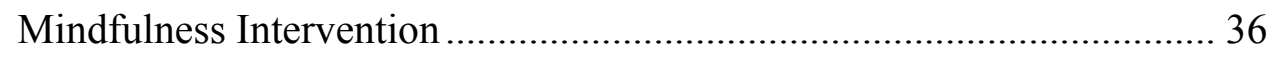

Somatic Body Awareness ................................................................... 36

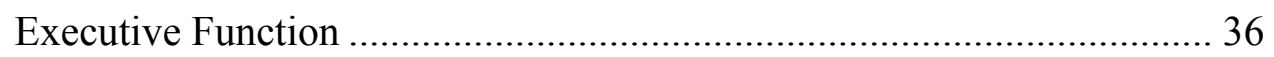

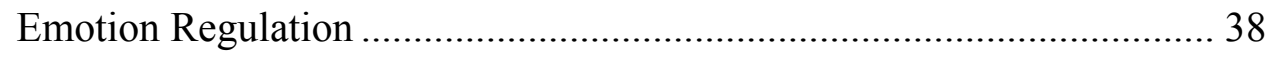

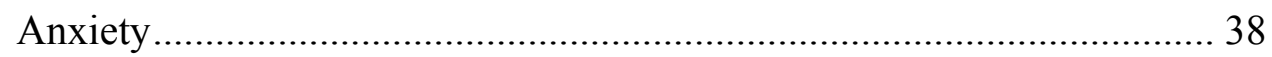

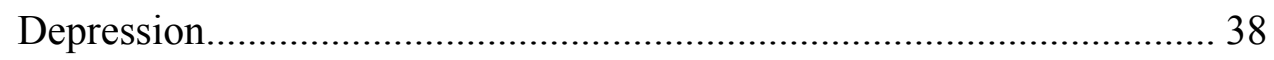

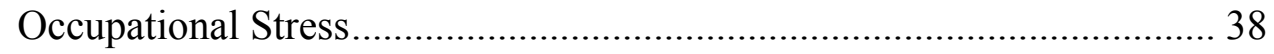

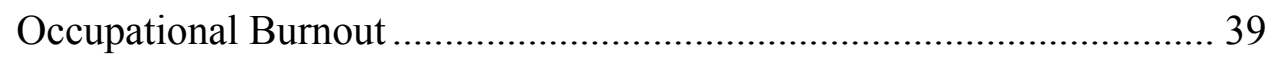

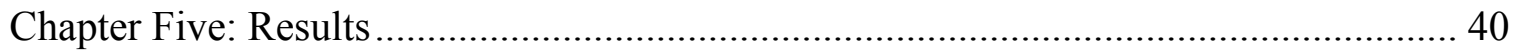

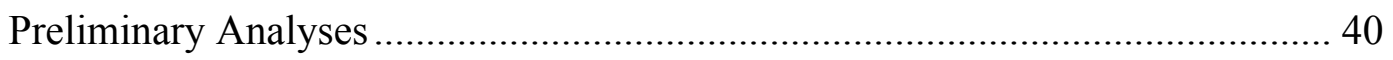

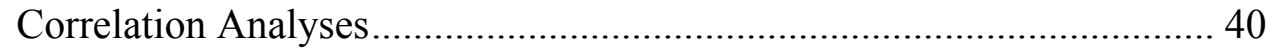

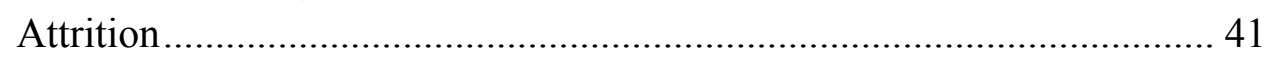

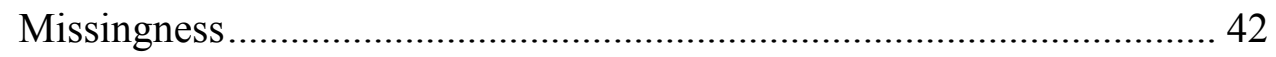

Baseline Equivalence ………………………………..................... 42

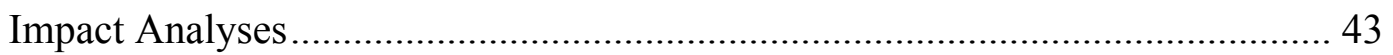

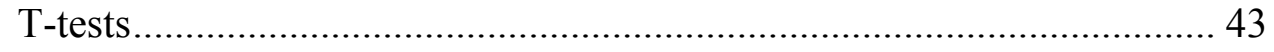

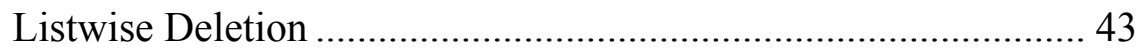

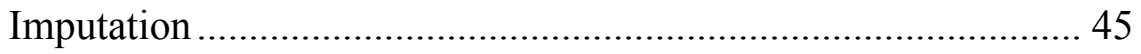

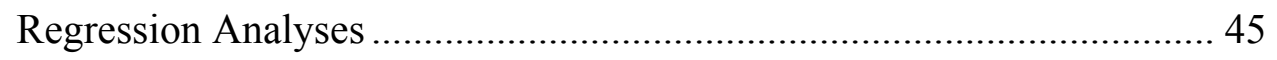

Mediation Analyses .......................................................................... 46

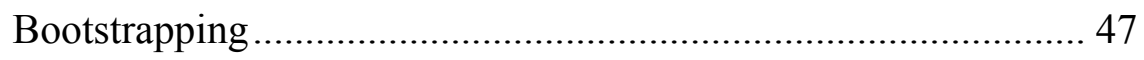

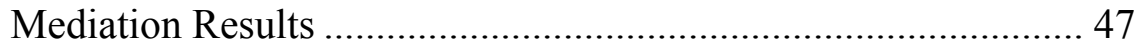

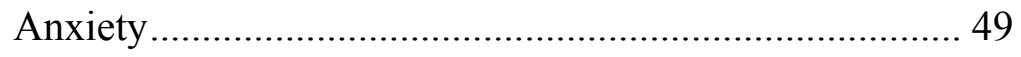

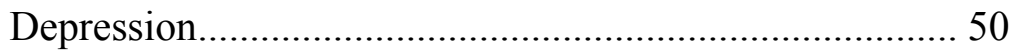

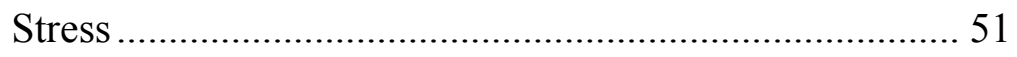

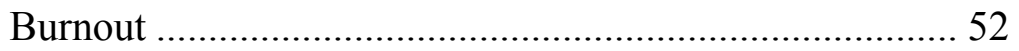

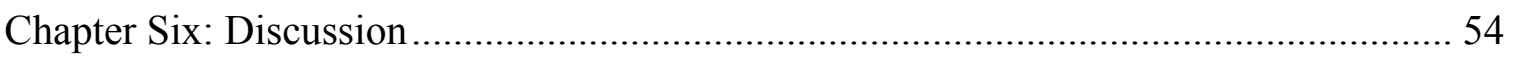

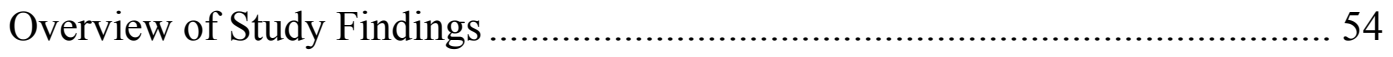

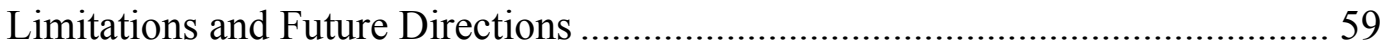

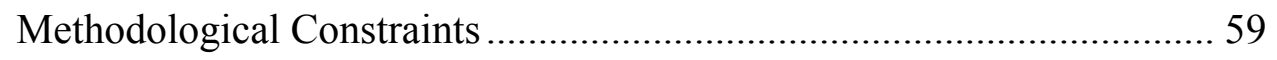

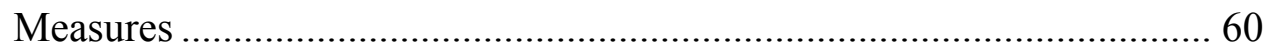

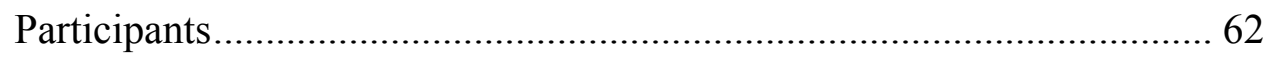

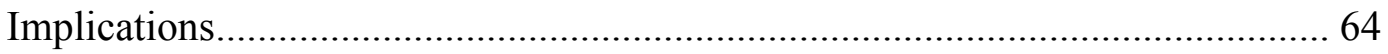

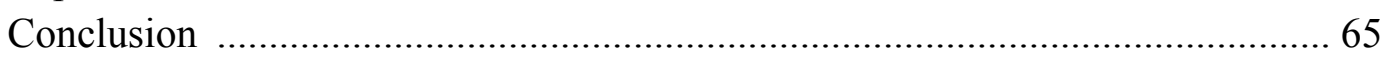

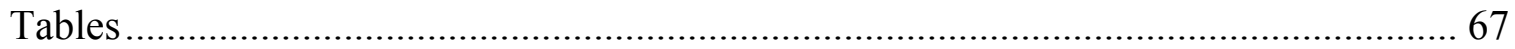

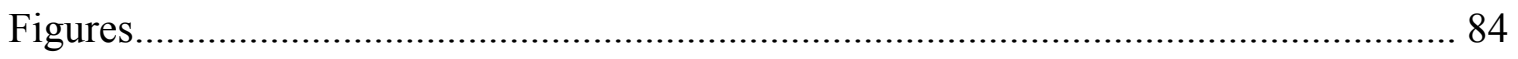

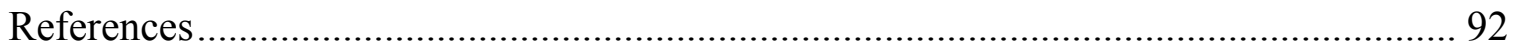

Appendix A. Literature Review Tables …………………...................................... 107 


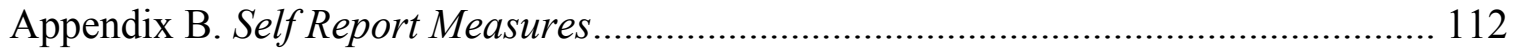




\section{List of Tables}

\section{Table}

Page

Table 1. Sample Sizes by Intervention Group and Assessment Period

Table 2. Descriptive Statistics of Study Measures at Baseline, Post-intervention, and 4-month Follow-up......

Table 3. Pre-intervention Bivariate Correlations among Variables................................. 68

Table 4. Characteristics of Teachers Assigned to MBEB and Waitlist Control Groups .. 68

Table 5. Descriptive Statistics and Tests of Differences between Groups at Baseline..... 69

Table 6. Imputed Descriptive Statistics and Tests of Differences between Groups at

Baseline

Table 7. Descriptive Statistics and Tests of Differences between Groups at

Post-intervention 70

Table 8. Descriptive Statistics and Tests of Differences between Groups at 4-month

Follow-up. 70

Table 9. Imputed Descriptive Statistics and Tests of Differences between Group at

Post-intervention.

Table 10. Imputed Descriptive Statistics and Tests of Differences between Groups at

4-monthFollow-up

Table 11. Regressions of Intervention Group Predicting Mechanisms at

Post-intervention and Follow-up.

Table 12. Imputed Regressions of Intervention Group Predicting Mechanisms at Post-intervention and 4-month Follow-up 72

Table 13. Intervention Group Predicting Anxiety Mediated by Somatic Body

Awareness 73

Table 14. Intervention Group Predicting Depression Mediated by Somatic Body

Awareness..... 73

Table 15. Intervention Group Predicting Stress Mediated by Somatic Body

Awareness 73

Table 16. Intervention Group Predicting Burnout Mediated by Somatic Body

Awareness. 74

Table 17. Intervention Group Predicting Anxiety Mediated by Executive Function ....... 74

Table 18. Intervention Group Predicting Depression Mediated by Executive Function .. 74

Table 19. Intervention Group Predicting Stress Mediated by Executive Function .......... 75

Table 20. Intervention Group Predicting Burnout Mediated by Executive Function....... 75

Table 21. Intervention Group Predicting Anxiety Mediated by Reappraisal .................. 75

Table 22. Intervention Group Predicting Depression Mediated by Reappraisal ............. 76

Table 23. Intervention Group Predicting Stress Mediated by Reappraisal..................... 76 
Table 24. Intervention Group Predicting Burnout Mediated by Reappraisal ................... 76

Table 25. Intervention Group Predicting Anxiety Mediated by Suppression................... 77

Table 26. Intervention Group Predicting Depression Mediated by Suppression............... 77

Table 27. Intervention Group Predicting Stress Mediated by Suppression ...................... 77

Table 28. Intervention Group Predicting Burnout Mediated by Suppression .................. 78

Table 29. Imputed Intervention Group Predicting Anxiety Mediated by Somatic Body

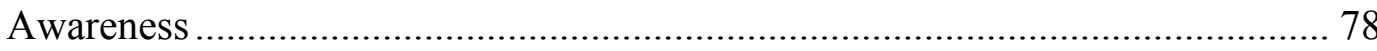

Table 30. Imputed Intervention Group Predicting Depression Mediated by Somatic

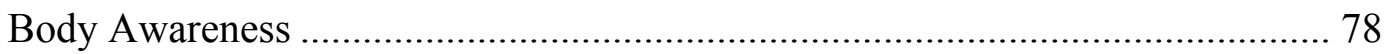

Table 31. Imputed Intervention Group Predicting Stress Mediated by Somatic Body

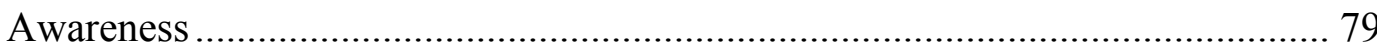

Table 32. Imputed Intervention Group Predicting Burnout Mediated by Somatic Body

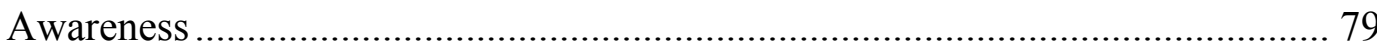

Table 33. Imputed Intervention Group Predicting Anxiety Mediated by Executive

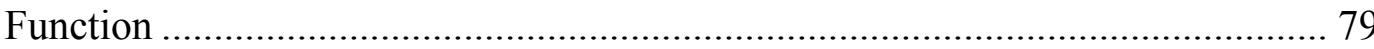

Table 34. Imputed Intervention Group Predicting Depression Mediated by Executive

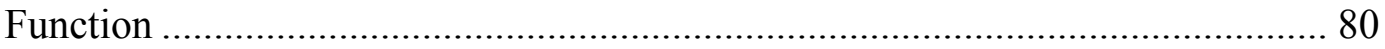

Table 35. Imputed Intervention Group Predicting Stress Mediated by Executive Function 80

Table 36. Imputed Intervention Group Predicting Burnout Mediated by Executive

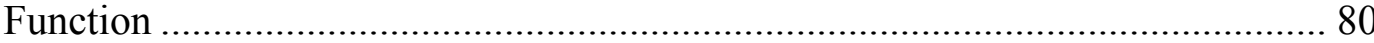

Table 37. Imputed Intervention Group Predicting Anxiety Mediated by Reappraisal ..... 81

Table 38. Imputed Intervention Group Predicting Depression Mediated by

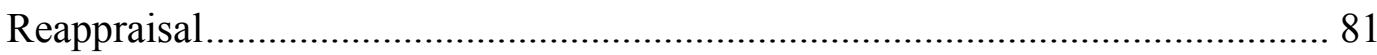

Table 39. Imputed Intervention Group Predicting Stress Mediated by Reappraisal ........ 81

Table 40. Imputed Intervention Group Predicting Burnout Mediated by Reappraisal..... 82

Table 41. Imputed Intervention Group Predicting Anxiety Mediated by Suppression .... 82

Table 42. Imputed Intervention Group Predicting Depression Mediated by

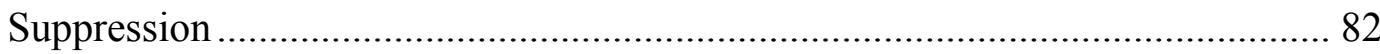

Table 43. Imputed Intervention Group Predicting Stress Mediated by Suppression........ 83

Table 44. Imputed Intervention Group Predicting Burnout Mediated by Suppression .... 83 


\section{List of Figures}

$\begin{array}{lll}\text { Figure } & \text { Page }\end{array}$

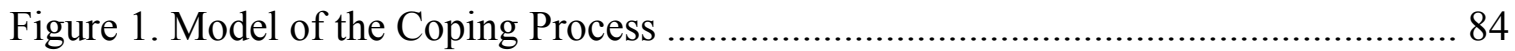

Figure 2. Coping Resources as Situated within the Coping Process ............................... 85

Figure 3. Comprehensive Theory of Change Model ....................................................... 86

Figure 4. Conceptual Models for Research Question One ............................................. 87

Figure 5. Conceptual Models for Research Question Two .............................................. 88

Figure 6. Consort Diagram of Teachers' Attrition and Migration Throughout the

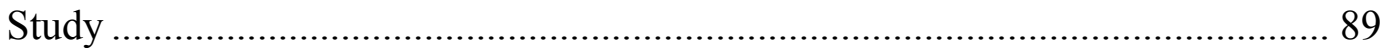

Figure 7. Statistical Model for Research Question One ............................................... 90

Figure 8. Statistical Model for Research Question Two ..................................................... 91 


\section{Chapter One}

\section{Problem Statement}

Despite the fact that teachers play a critical role in fostering the development of academic and social-emotional skills in their students, they face high levels of occupational stress and burnout (Chang, 2009; Pas, Bradshaw, \& Hershfeldt, 2012). Research has attributed this increased risk to work-related demands, such as time pressure and workload, teaching evaluations, parent and administration interactions, and classroom problems such as working with unmotivated or misbehaving students (Flook, Goldberg, Pinger, Bonus, \& Davidson, 2013; Montgomery \& Rupp, 2005). To help teachers manage high levels of stress and burnout, researchers have begun adapting Mindfulness-Based Stress Reduction (MBSR) programs as unique professional development opportunities to help teachers cope with daily occupational stressors (Roeser, 2014; Roeser, Skinner, Beers, \& Jennings, 2012). And evidence for the efficacy of such programs for teachers is promising (Gold et al., 2010; Jennings et al., 2013; Roeser et al., 2013; Taylor et al., 2016; see Table A1 for comprehensive results). Despite such evidence, however, little research has explored underlying mechanisms that may be driving mindfulness-training benefits in teachers. Therefore, the principal aim of this study is to elucidate if three key processes, somatic body awareness, executive function, and emotion regulation, serve as likely candidate mechanisms that can explain the stressreducing effects of mindfulness training for teachers.

\section{Mindfulness in Education}

Broadly, mindfulness can be defined as paying attention in a purposeful and nonjudgmental manner to present moment experience (Kabat-Zinn, 1998). Definitions of 
mindfulness such as this include two components: self-regulation of attention (i.e. sustained attention and attention shifting) and an open, non-judgmental orientation to experience (Bishop et al., 2004). So defined, mindfulness can be trained and used to enhance awareness and attention regulation in order to promote more skillful responses to emotional distress or other maladaptive behavioral tendencies (Bishop et al., 2004).

Developing these regulatory skills is of particular importance for teachers due to the high emotional demands of the profession (Hargreaves, 2000). Emotion regulation, in which appropriate displays of emotion are key, facilitates both high quality teaching and high quality learning (Hargreaves, 2000), and is closely tied to a teacher's ability to develop rich and meaningful relationships with their students as a means to deliver social-emotional and academic skills to support their success (Jennings \& Greenberg, 2009). However, teachers' abilities to regulate their emotions in classrooms are often undermined by manifestations of student misbehavior, disaffection, and immaturity (Skinner \& Beers, 2016), and teachers report that continual repetitions of minor student disruptions are among the leading instigators of negative emotions, such as anger, frustration, anxiety, and depression (Kyriacou, 2001). The constant need to regulate such negative emotions is a form of emotional labor that can have deleterious effects on the overall health and well-being of teachers (Hargreaves, 2000). Additionally, chronically masking negative emotion (e.g. utilizing suppression as a regulatory strategy) to meet classroom goals can decrease teachers' energy and enthusiasm for teaching and increase their likelihood of developing stress and burnout (Chang, 2009).

The extent to which teachers productively regulate their emotions on the job, and therefore the amount of job-related anxiety, depression, stress and/or burnout they 
experience, depends largely on the interaction between their personality characteristics (e.g., tendency to experience distress due to stress), skills and coping abilities (e.g., emotion regulation, executive function), and environmental factors (e.g., job demands see Montgomery \& Rupp, 2005). Specifically, teachers' negative emotions and experienced stress and burnout are thought to develop due to various factors: the level of actual stressors they experience (e.g. student disruptions, work demands, relationship or home life conflicts); their awareness and appraisals of those stressors; their availability and use of effective coping mechanisms (e.g. setting work limitations, calming oneself); and/or through the use of maladaptive coping mechanisms (e.g. drinking, avoidance behaviors; Montgomery \& Rupp, 2005).

Both awareness of stress arising in the body, as well as the regulatory strategies teachers utilize to cope with ongoing stressors, influence the types of emotional reactions they have to stress - whether it be in a positive manner such as hope and passion, or in a negative manner, expressed through anxiety, depression, and frustration. The adaptive or maladaptive emotional responses teachers' use directly affects important outcomes such as life satisfaction, work commitment, well-being, and burnout (Chang, 2009; Montgomery \& Rupp, 2005).

There is some evidence that teacher-related stressors, especially around the management of student behavior, may be particularly salient in middle school classrooms due to the heightened social immaturity and emotional reactivity of adolescents going through puberty (see Anderson \& Teicher, 2008; Eccles \& Roeser, 2009). At the same time, evidence suggests teacher-student relationships become more distant in middle school classrooms and opportunities for social-emotional learning decrease as children 
begin to enter bigger schools and rotate between teachers for their various classes (Hargreaves, 2000). The organizational pattern of middle school and the timetables associated with changing classrooms reportedly fosters professional distance between teachers and students (Sizer, 1992), perhaps at a time when students need regulation mentorship most (Eccles \& Roeser, 2016). Thus, mindfulness training may be particularly useful for teachers in middle school contexts, helping to bolster both teacher attunement to the emotional needs of students and the cultivation of positive classroom climates to better support students' academic and social-emotional success (Roeser, 2014).

Therefore, the purpose of this thesis is to examine the impact of mindfulness training on middle school teachers' development of somatic body awareness, executive function, and emotion regulation. Specifically, data collected as part of a Randomized Controlled Trial (RCT) experimental study of the impact of MBEB (Cullen \& Wallace, 2010), a Mindfulness-Based Emotional Balance program developed for teachers, will be used to examine whether mindfulness training improves teachers' somatic body awareness, executive function, and emotion regulation skills, as well as whether improvement in these mechanisms translates to increased well-being in teachers over time. By addressing these topics, the results of this thesis will better elucidate whether teachers can develop these coping resources through mindfulness training, and whether these resources serve as the intermediary step driving the relation between mindfulness training and decreased anxiety, depression, stress, and burnout in teachers. 
Chapter Two

\section{Literature Review}

Despite robust evidence indicating mindfulness training is a successful tool to alleviate a series of negative outcomes, research has yet to pinpoint mechanisms of action that may be driving these effects for teachers in educational settings (see Schussler, Jennings, Sharp, \& Frank, 2016; Taylor et al., 2016). Previous research has demonstrated significant reductions in teachers' anxiety, depression, stress, and burnout in teachers randomized to mindfulness training and that increases in mindfulness and selfcompassion mediate these relations (Roeser et al., 2013). However, mindfulness trainings are complex, multifaceted programs that incorporate various practices (e.g. breath awareness, body scans, mindful walking practices, etc.) and establishing the various causal mechanisms by which this diversity of practices affects outcomes remains difficult (Perlman, Salomons, Davidson, \& Lutz, 2010). Therefore, the current study extends previous work in this area by examining somatic body awareness, executive function, and emotion regulation as three potential key coping mechanisms responsible for the effects of mindfulness training on reducing negative well-being outcomes in teachers.

In the following literature review I begin by first providing a theoretical framework of how stress develops, how stress relates to coping, and how each of the three proposed mechanisms contributes to this process. Second, I define each of the three mechanisms in detail. Lastly, I provide a summary of empirical evidence of the effects of mindfulness training on these processes in general populations and in teachers specifically. 


\section{Theoretical Framework for Assessing Teacher Stress}

In this thesis, Lazarus and Folkman's (1984) theoretical framework and a broader developmental view of coping are used to conceptualize how mindfulness training may reduce stress in teachers via enhancement of their somatic body awareness, executive function, and emotion regulation. Lazarus and Folkman (1984) describe stress as transactional in nature: a reciprocal process between the person and environment, defined specifically as " a relationship with the environment that the person appraises as significant for his or her well-being and in which the demands tax or exceed available coping resources" (Lazarus \& Folkman, 1984, p. 63). Due to its dynamic nature, coping in this framework is defined as "constantly changing cognitive and behavioral efforts to manage specific external and/or internal demands that are appraised as taxing or exceeding the resources of the person" (Lazarus \& Folkman, 1984, p. 141). These dynamic interactions are shaped by both individual factors (e.g. action tendencies, attitudes, appraisals) and those related to the greater social and environmental contexts (e.g. the actual stressor, perceived supports; Compas, Connor, Saltzman, Harding Thomesen, \& Wadsworth, 2001; Lazarus \& Folkman, 1984). As such, events are appraised in terms of their demands for adaptation, where adaptation is conditioned on both person-factors and the actual situational demands, as well as the generation of an appraisal which denotes the person's implicit belief as to whether they have resources available to meet that stressor/set of demands in a given time and place (Lazarus \& Folkman, 1984).

This multifaceted view of how stress is experienced can be supplemented and extended using a developmental perspective (Aldwin, 2007). For developmentalists, the 
dynamic process of coping situates itself within the context of human development: emphasizing not only how coping processes play out in any given situation, but also considering how coping is shaped by individuals' past experiences, current developmental status, and ongoing developmental growth over time (Skinner \& ZimmerGembeck, 2016). Additionally, this conceptualization examines coping within a multilevel ("under the skin" genetics up through societal interactions and structures) and dynamic (iterative) framework, whose underlying assumptions allow coping to be viewed as malleable across time and therefore as a skill that can be cultivated through intervention and/or experience (Skinner \& Zimmer-Gembeck, 2016).

Levels of the stress-coping process. The view that coping functions at multiple levels allows researchers to better understand how coping processes are situated between stressors and the multitude of disorder and well-being outcomes. Specifically, deconstructing the complex construct into real time, episodic time, and developmental time provides a more complete picture of how ongoing interactions translate into episodes of coping, which subsequently protect from or intensify stressors over time (Skinner \& Zimmer-Gembeck, 2016). In real time, coping is considered a "coordinating concept" (p. 11) such that it constitutes the simultaneous coordination and regulation of physiological experiences, action tendencies (temperamental factors), emotion, attention, motivation, and behavior. The coordination of these various aspects of regulation occurs in the moment-to-moment transactions between an individual and environment. In real time, individuals may be generating new stress appraisals or modifying current appraisals. At the next level, episodic time captures "the story" or entire cycle of coping that progresses across calendar time (i.e. days, weeks, or months). As can be found in 
Figure 1, the coping cycle includes the components of: the stressor, the appraisal of available resources and supports, the implementation of various coping strategies and/or management of any setbacks, and finally ends with a resolution or outcome that then feeds back into perceived demands and resources for subsequent episodes. Lastly, developmental time comprises the slow process of adaptation that is most directly associated with long-term outcomes of risk and resilience, considering the accumulation of resources and coping development across the lifespan (Skinner \& Zimmer-Gembeck, 2016).

Levels of coping and mindfulness. Mindfulness training may intersect with coping processes at the moment-to-moment "real time" level; helping to strengthen personal resources during the stress appraisal and subsequent coping process phases (see Figure 2 for a depiction of how these coping resources are situated within the coping process). Specifically, mindfulness training may provide additional resources to draw on (i.e. greater awareness of physiological reactivity, increased executive function, and positive emotion regulation strategies), in moments of stress (see Teper et al., 2013). First, this greater number of overall perceived resources might reduce the total number of experiences primarily appraised as stressful. Second, once stress has been appraised, practicing present moment awareness and non-reactivity may be a useful stand-alone coping strategy, as it may reduce physiological reactivity and cognitive elaboration associated with stress and counteract secondary appraisals of the stress event (Gross, 1998). By intervening at the moment-to-moment level and reducing the number of stressful experiences appraised as stressful, mindfulness training may help to reduce the total number and/or duration of coping episodes. This impact may then cascade across 
developmental time, translating into increased resilience and reduced negative long-term health and well-being outcomes, and ultimately an internalization of increased coping capacity that can be applied to future stressful scenarios.

Flexibility of coping repertoires. A wide variety of coping strategies with different target outcomes can be implemented across these time levels in both the Lazarus and Folkman (1984) framework and more current developmental conceptualizations (see Compas, et al., 2017). For example, both conceptualizations organize coping strategies into those that target the source of stress directly (i.e. problem-focused and primary control) with actions such as information seeking or problem-solving, and those that target subsequent experiences evoked by the stressor (emotion-focused and secondary control) in which individuals can, for example, reappraise or accept the situation to modify their experience of the stressor (Compas, et al., 2001; Lazarus \& Folkman, 1984). Additionally, many more coping strategies have been observed, for instance, Compas and colleagues (1997) include disengagement as a third category of coping. Disengagement can be defined as actions individuals take, such as distraction or avoidance, to orient away from stressors. In all cases, these coping strategies are considered active or effortful means of coping. However, the wide variety of strategies available to draw upon gives rise to many possible outcomes-some more successful than others. In particular, coping strategies that mask or attempt to ignore the stressor, such as emotional suppression, avoidance, and/or denial, have been shown to be associated with higher levels of stress and psychopathology (Compas et al., 2017).

Flexibility of coping repertoires and mindfulness. Mindfulness training may be a particularly important strategy in shifting individuals' coping repertoires to include a 
greater number of strategies that promote well-being. For example, practicing selfcompassion and acceptance (central practices of mindfulness) may help individuals cope with events outside of their control. Indeed, research on emotional approach and accommodation coping processes indicate that actions such as accepting emotions, letting emotions go, or neutralizing a stressor by adjusting goals to fit situational constraints are associated with positive well-being over time (Brandtstadter \& Renner, 1990; Stanton, Danoff-Burg, Cameron, \& Ellis, 1994). Furthermore, this emotional processing has been show to be particularly useful for women, functioning to change cognition related to stress and emotion, increase self-compassion, enhance or promote cognitive reorganization, release physiological and psychological tension associated with the stressor, and to motivate behavior (Stanton et al., 1994; Pennebaker, Kiecolt-Glaser, \& Glaser, 1988). Therefore, through mindfulness training individuals may be able to shift their coping repertoire to predominantly problem-focused/primary control strategies and emotion-based strategies that are associated with positive outcomes, while simultaneously reducing their use of disengagement forms of coping, such as avoidance, that are associated with negative health outcomes.

Coping as reactivity and regulation. When studying how the active coping strategies described above translate environmental stressors into positive or negative well-being outcomes, it becomes additionally important to consider the role of automatic, involuntary, or habitual response tendencies (see Figure 2 for a depiction of how these relate to the coping process). These individual differences in reactivity are not goaloriented or effortful, however, they influence coping processes by utilizing the same regulatory resources required for successful coping (Compas et al., 1997) and by 
interacting dynamically with coping strategies as the coping process unfolds (Skinner \& Zimmer-Gembeck, 2016). Specifically, involuntary habitual response tendencies may play a crucial role in the transformation of acute stressors into chronic stressors. Acute stressors by definition are those that do not last; however, certain habitual response tendencies, such as worry or rumination, may exacerbate the original stressor through continued cognitive exposure (Compas et al., 1997). Continued involuntary interaction with a stressor can drain regulatory resources that could otherwise be allocated to effective coping processes, potentially causing a deficit in resources and increased difficulty to initiate positive coping processes over time. Therefore, how successfully (or unsuccessfully) all effortful coping and habitual tendency components are coordinated contributes significantly to either positive health and well-being, or distress and disorder, over time (Skinner \& Zimmer-Gembeck, 2016).

Reactivity, regulation, and mindfulness. Previous research has demonstrated that mindfulness training can reduce reactivity through increased cognitive control and focused attention on the present moment (Carmody \& Baer, 2007; Kumar, Feldman, \& Hayes, 2008). Specifically, increased attunement to physiological sensations coupled with increased regulatory capacity may help individuals detect reactivity earlier in a stress reaction phase, as well as inhibit or intervene on subsequent elaborative processing through successful redirection of attention toward actual present moment events (Lutz, Slagter, Dunne, \& Davidson, 2008; Tang, Hölzel, \& Posner, 2015). Additionally, present moment focus and reappraisal of one's thoughts and emotions as transient may assist in breaking down learned habitual response tendencies by disrupting the reactivity cascade (Perlman, Salomons, Davidson, \& Lutz, 2010; Wenk-Sormaz, 2005; see Figure 2). A 
reworking of the relationship between reactivity and regulation in this way may promote greater flexibility in behavior and shift habitual response tendencies to be productively informative (helping individuals to recognize when action is needed) without invoking a stress response that exceeds their coping resources.

Summary. Based on this developmental framework of coping, it is posited that teachers can develop coping resources through mindfulness training. A primary goal of mindfulness training is to support the development of various positive coping resources, and is implemented with the prospect that teachers may draw upon these newfound strategies during stressful scenarios, and thus shift their perspective and perception from an appraisal of uncontrollable "stress" to a positive perception of surmountable "challenge". Targeting how teachers relate to stress in the moment-to-moment interactions that constitute the teaching day is thought to initiate a cascade effect: subsequently reducing the overall effect of stress on coping episodes and bolstering teacher well-being over time. In the next section, the theory of change of how mindfulness training may impart various coping resources is summarized. Specifically, describing how three specific coping resources, namely, somatic body awareness, executive function, and emotion regulation may serve as pathways through which mindfulness training shapes teachers' subsequent stress and well-being.

\section{Theory of Change}

Events appraised as stressful are, by definition, those that exceed coping resources (Montgomery \& Rupp, 2005). Such events and appraisals, therefore, are coupled with physiological stress reactions in the central and peripheral nervous systems that serve to motivate the organism to address the perceived challenge or threat quickly (Davidson \& 
McEwen, 2012; Teper, Segal, \& Inzlicht, 2013). The subtle distress cues arising from such appraisals begin in sensory and somatic awareness (e.g. rapid breathing, increased heart rate) and function to alert an individual of the need to initiate regulatory control (e.g., emotion regulation and/or another coping response) of something emotionally relevant (see Primary Appraisal in Figure 2). In essence, if individuals perceive they are under threat or challenge, they are motivated to act in ways that not only help them to return to a state of less stress (those of surmountable challenge), but also to continue to persist in a goal-oriented manner (Skinner \& Zimmer-Gembeck, 2016). In this way, the detection of an unfolding stress reaction can be operationalized as occurring when obstacles impede progress towards desired states/goals.

Such monitoring of goal-directed progress is a process associated with an individual's executive function, or one's ability to solve problems, plan and execute complex actions, and inhibit pre-potent emotional and behavioral responses (Williams et al., 2009). In the presence of such an obstacle, if the individual is not "caught in bottomup stress reactivity," then top-down executive control processes can initiate regulatory responses to mitigate the threat by activating plans and coping resources or through seeking social support (see Secondary Appraisal in Figure 2). However, if the bottom-up inputs are particularly powerful, as in the case of imminent danger to physical well-being, or if an individual's top-down regulatory abilities are not well developed, then automatic stress reactivity rather than regulation will occur in response to the situation (Davidson et al., 2012; see Reactivity in Figure 2).

Mindfulness training and its emphasis on present moment awareness and nonjudgmental acceptance may bolster somatic awareness, attentional, and emotional 
regulatory processes via several pathways. First, with the development of somatic body awareness through mindfulness training (e.g., body scan, focused attention on the breath), individuals may detect subtle distress signals with refined attunement, and as such, detect the need for control earlier in the stress reaction phase (Teper et al., 2013). Second, by attending to such primary sensations with an open and nonjudgmental attitude, an individual may counteract secondary appraisals of the stress event, therefore hindering reactive elaborative processing (Gross, 1998). Third, by practicing acceptance of afflictive emotions during a reactivity phase, individuals may be "cognitively reappraising" stressful events, which subsequently allows them to bring their attention back to their present moment experience in a reciprocal fashion to once again begin monitoring progress towards goals (see Regulation in Figure 2; Inzlicht, Legault, \& Teper, 2014; Teper et al., 2013).

Given this framework, it is hypothesized that mindfulness practice cultivates three coping resources_-somatic body awareness, executive function, and emotion regulation - and that these resources positively influence the appraisal and coping components of the stress-coping process. These strengthened coping resources are then hypothesized to produce more successful and positive coping episodes for teachers, thus reducing teachers' negative experiences of anxiety, depression, stress, and burnout over time (see Figure 3 for a comprehensive depiction of this study's theoretical model).

\section{Proposed Mechanisms Underlying the Stress Reducing Effects of Mindfulness}

\section{Training}

Somatic body awareness. Somatic body awareness, or "the ability to notice subtle bodily sensations" (Mehling et al., 2009, as cited in Hölzel et al., 2011 p. 541) is 
thought to be a "coordinating concept" (Skinner \& Zimmer-Gembeck, 2016) occurring in real-time that is closely tied to higher order cognitive operations and whose function is to motivate behavior and initiate regulatory control (Farb et al., 2015). Specifically, an iterative process associating physiological sensations with goals, previous life experiences, and/or environmental cues is thought to give rise to appraisals of experiences and motivate behavior to obtain wanted goals and maintain desired physiological states (Craig, 2009; Farb et al., 2015). In this way, somatic body awareness is closely connected with regulatory and coping processes, as it provides preliminary information of a need to initiate regulation, likely evolving to aid in adaptation (Craig, 2013).

Neuroanatomical evidence identifies a unified pathway associated with somatic body awareness beginning with peripheral sensory receptors (incorporating all five senses), moving to spinal cord projections, brainstem, and ultimately dispersing into multiple areas of the brain including (but not limited to) insular (integration), limbic (emotion), and executive function areas (Bush, Luu, \& Posner, 2000; Farb, Segal, \& Anderson, 2013). Examples of sensations associated with somatic body awareness are heart beat detection, pain sensitivity, temperature, and respiration (Farb et al., 2015). In some cases, somatic body awareness definitions even extend to "deep body receptors," such as those associated with internal feelings of pleasure and warmth (Bjornsdotter, Loken, Olausson, Vallbo, \& Wessberg, 2009). These internal sensations function as signals to self-regulatory systems, communicating moment-to-moment information about the body's response to current contextual factors (Farb et al., 2015). As such, somatic body awareness is intimately linked to an individual's well-being; helping to define both 
an individual's existence in the present moment and ability to effect change through action (Farb et al., 2015).

Individual differences in somatic body awareness sensitivity have not been widely studied, yet, are important to consider given that such signals assist in decision making processing (Farb et al., 2015), likely influencing individuals' approach and avoidance tendencies, broader mood states, and emotional balance (Craig, 2007; Farb et al., 2015). For example, heightened sensitivity to bodily sensations without adequate contextual accuracy or regulation ability may underlie 'false alarms' characteristic of anxiety disorders. Specifically, associating physiological sensations such as increased heart rate or rapid breathing with negative appraisals of those feelings can create negative selfbeliefs such as "there's something wrong with my heart" or "I can't breathe" (Paulus \& Stein, 2010). As such, assisting individuals in developing greater body awareness is considered an appropriate component of treatment for psychological disorders (Hölzel et al., 2011), however, more research is needed to understand how these differences are connected to regulatory processes and well-being.

Executive function. Executive function, also called cognitive control, is defined as a family of mental operations associated with "an individual's capacity to adaptively regulate his or her thoughts, emotions, instincts, and actions" (Tang, Yang, Leve, \& Harold, 2012, p. 361). Executive function has been shown to be comprised of both "cool" and "hot" subcomponents: "cool" executive function describes regulatory behaviors employed in response to challenging stimuli that lacks emotional content, and encompasses cognitive processes such as attentional control, cognitive flexibility, selfmonitoring, response inhibition, planning, and working memory (Chiesa, Calati, \& 
Serretti, 2011; Tang et al., 2012), whereas "hot" executive function describes regulatory behaviors employed in response to emotionally salient stimuli (Zelazo \& Carlson, 2012). "Hot" executive function is thought to require more regulatory effort due to increased motivational salience associated with emotionally relevant content. A classic example of such is delay of gratification, in which an individual must inhibit the pre-potent desire for an immediate reward in order to obtain a more meaningful reward at some point in the future (Zelazo \& Carlson, 2012).

Neuroanatomical evidence supports this theoretical understanding, implicating distinct yet interrelated prefrontal cortex regions and the anterior cingulate cortex specifically, as key anatomical components responsible for the regulation of attention and emotion (Davidson, Pizzagalli, Nitschke, \& Putnam, 2002; Devinsky, Morrell, \& Vogt, 1995). For example, Bush and colleagues (2000) demonstrated that two distinct subcomponents of the anterior cingulate cortex complement the theoretical "hot" and "cool" components of executive function. Specifically, the authors found that the dorsal component of the anterior cingulate cortex functions as a mechanism of effortful control (e.g. "cool" executive function) whereas the ventral component is critical in conflict monitoring (i.e. monitoring the organisms current state and comparing it to incoming relevant information that may have emotional consequences, a "hot" function). Additionally, the two subcomponents of the anterior cingulate cortex, although distinct, have been shown to interact in a reciprocal manner, such that when the dorsal/control component is active the ventral/affective component is not, and vice versa. This can be considered anatomical evidence that attention shifts between being effortfully and emotionally controlled, such that individuals must simultaneously learn how to down 
regulate "bottom-up" stress response tendencies, while strengthening "top-down" executive function regulation abilities simultaneously (Davidson et al., 2012; Miyake et al., 2000). Furthermore, anterior cingulate cortex activation has been demonstrated to occur when effortful emotion regulation is necessary, such as when an individual's current behavior is failing to successfully achieve a desired outcome (Davidson et al., 2012). Thus, both cool and hot forms of executive function are considered neurological precursors to emotion regulation processes (Davidson et al., 2012; Teper et al., 2013).

Emotion regulation. Emotion regulation, the final mechanism posited here to underlie the stress reducing effects of mindfulness training in teachers, is defined as "attempts individuals make to influence which emotions they have, when they have them, and how these emotions are experienced and expressed" (Gross, Richards, \& John, 2006, p. 14). Successful emotion regulation requires awareness of, and a suitable response to, emotionally evocative stimuli in order to bring conscious intentions to fruition in action. The ability to be aware of emotionally evocative cues requires attention and somatic awareness. For instance, distress cues arising from the body represent one means by which monitoring of behavior-intention congruency may be activated (Teper et al., 2013). When detecting signs of emerging stress reactions in the body, for instance, individuals also begin to appraise their available resources as either being sufficient for managing the challenge/situation or not. If current resources are deemed insufficient for addressing demands, 'bottom-up" stress reactivity processes may override "top-down” regulatory abilities, causing a stress response (Davidson et al., 2012). Once appraisal of stress occurs, continued awareness and attention regulation might still disrupt these automatic processes or make possible many regulation tools to help mitigate the stress effects. 
At the broadest level, Gross and John's (2003) model of emotion regulation distinguishes between antecedent- and response- focused emotion regulation techniques. Through situational awareness, antecedent-focused strategies allow individuals to regulate emotions prior to full activation of an emotion (i.e. noticing reactivity and reframing of an event to alter the original response trajectory of the emotion), whereas response-focused strategies are used to manage an emotional experience once it has already progressed through its developing phase (i.e. not displaying anger outwardly, despite internal feelings of anger). Together these strategies form a process account, or timeline, of possible emotion regulation techniques that may be initiated after stress appraisal (Gross \& John, 2003).

Flexibility in emotion regulation is therefore dependent on attention and awareness, and there are substantial individual differences in behaviors and strategies that people use to regulate emotion. For example, situation selection (e.g. approaching or avoiding individuals or places), situation modification (e.g., choosing whether to engage in certain interactions), deploying attention in different ways (e.g., examining the details of a rug), or using cognitive change methods to alter the meaning of a situation, are all forms of cognitive reappraisal, or antecedent-focused strategies that alter the meaning of a situation that may evoke an emotional reaction (Gross, 2001; Gross et al., 2006). These may be more common among individuals who have calmer temperaments, or significantly less life stress (Williams, et al., 2009). However, individuals may also modify their emotional responses through expressive suppression, a response-focused strategy that involves attempting to inhibit the expression of ongoing emotional reactions (Gross, 2001; Gross et al., 2006). Such strategies may be more common among those 
who work in settings where suppression is perhaps readily used (e.g. teachers) or for those with a history of trauma or significant life stress (Williams et al., 2009).

The regulation strategies individuals choose to employ can directly impact their level of stress exposure, the magnitude of the physiological and emotional responses evoked in response to stress, and/or the duration of time it takes to recover from a stressful event (Williams et al., 2009). For example, cognitive reappraisal has been shown to be associated with better outcomes as compared to expressive suppression, such as decreases in negative emotion experiences and fewer cognitive, physiological, and interpersonal costs associated with regulating (Gross \& John, 2003). In contrast, expressive suppression is considered a less effective regulation strategy because despite its association with successful down-regulation of emotional expression, it does not relieve the user from their internal experience of the emotion. Indeed, expressive suppression has been associated with higher physiological and cognitive costs, such as increases in activation of the cardiovascular system and poorer working-memory capacity (Gross \& John, 2003; Gross et al., 2006). Additionally, chronic use of suppression techniques has been found to be associated with worse overall functioning in emotional, well-being, and interpersonal domains (Gross et al., 2006). The negative health-related outcomes that are associated with suppression highlight the importance of teaching individuals effective emotion regulation strategies to protect their health and promote well-being (Chang, 2009). Specifically, it may be particularly useful to promote the use of reappraisal strategies to help regulate stress, while simultaneously reducing reliance on the use of expressive suppression as an emotion regulation strategy. 
In sum, somatic body awareness, executive function, and emotion regulation can be thought of as three interrelated coping resources functioning to detect and regulate stress reactivity processes. Within the coping framework provided above, each is considered a "coordinating concept" occurring in real-time and representing resources individuals may draw on when environmental cues of stress are perceived. Successful allocation of resources during these real-time interactions feed into and influence how coping episodes play out, which then subsequently influence well-being across developmental time. Through the lens of this framework, it is hypothesized that mindfulness training will strengthen these real-time resources, which will in turn, translate to better well-being over time. Next, I describe how mindfulness training might impact somatic body awareness, executive function, and emotion regulation, and then review relevant research that demonstrates the impact of mindfulness training on these mechanisms.

\section{Effects of Mindfulness Training on the Proposed Mechanisms}

Mindfulness practice may promote somatic body awareness, executive function, and emotion regulation skills by enhancing attention to emotionally evocative cues in the environment or the body that signal demands and potential stress; as well as inhibiting or intervening in the automatic affective processing associated with a single stress response and/or habitual response tendencies (Lutz, Slagter, Dunne, \& Davidson, 2008; Tang, Hölzel, \& Posner, 2015). By requiring practitioners to focus on their breath (a sustained attention task) and to bring their attention back to the breath when the mind wanders (an attention switching task; Bishop et al., 2004) individuals may improve their ability to focus their attention on stimuli, and to disengage from negative thoughts or feelings. 
Additionally, mindfulness teaches individuals to pay attention to moment-to-moment sensations through a lens of non-judgmental acceptance (Kabat-Zinn, 1998) and as such, has been theorized to be a unique cognitive reappraisal technique that occurs during the attentional deployment phase of affective experiences (Farb, Anderson, Irving, \& Segal, 2014). Specifically, shifting attention away from self-referential thoughts to the present moment experience may hinder further elaborative processing and subsequently decrease the intensity or duration of an affective or stress experience (Lutz et al., 2008).

Additionally, continued focus on present moment sensations associated with emotions can "free up" attentional and emotional resources that might otherwise be used in the stress-related cognitive elaboration process. Reappraising one's thoughts and emotions as transient assists in desensitization of habitual responses, promotes flexibility in behavior, and therefore increases the total number of possible behavioral outcomes (e.g. choosing not to react when otherwise one would have; Wenk-Sormaz, 2005). Now, I transition to previous research examining the impacts of mindfulness training on somatic body awareness, executive function, and emotion regulation.

Somatic body awareness in the context of mindfulness interventions. Several studies have identified changes in somatic body awareness following mindfulness training in both self-report and neuroscience domains (see Table A2). Evidence from qualitative interviews in a study examining experienced meditation practitioners indicated seven out of 10 participants spontaneously reported increased ability to detect bodily sensations and four out of 10 indicated improved emotional awareness in a similar manner (Hölzel, Ott, Hempel, \& Stark, 2006 as cited in Hölzel et al., 2011). Results from 
another study also found improved self-report body awareness following a mindfulnessbased stress reduction course (Carmody \& Baer, 2008).

Additionally, functional Magnetic Resonance Imaging (fMRI) studies have demonstrated greater activation in regions of the brain associated with body awareness following mindfulness training. Specifically, the insula, which is known to be active in tasks of somatic body awareness (Craig, 2003), has shown increased activation in individuals following a MBSR program (as compared to controls) when they focused their attention on their present moment experience (Farb et al., 2007). In another study fMRI data indicated increased somatic body awareness via greater activation in several areas of the insula and significantly decreased activity in areas of the prefrontal cortex associated with narrative processing (a counterfactual to present moment experience; Farb et al., 2013) in MBSR participants as compared to controls.

These few studies provide promising evidence supporting increased somatic body awareness through mindfulness practice. Despite this evidence, however, more studies are needed to understand the impacts of mindfulness training on somatic body awareness and how somatic body awareness is related to regulatory processes. Additionally, the development of somatic body awareness through mindfulness training in teachers has yet to be examined.

\section{Executive function and emotion regulation in the context of mindfulness}

interventions. Due to the interrelated nature and anatomical neural circuitry overlap of executive function and emotion regulation (Davidson et al., 2012), researchers testing the effects of mindfulness training on these regulatory abilities often do not make a distinction between them. As such, the below review encompasses a summary of 
literature focusing on behavioral measures of inhibitory control and negative emotion symptom reduction as evidence to support the effect of mindfulness training on these regulatory processes.

In order to study these cognitive processes behaviorally, researchers have employed "conflict" paradigms using behavioral computer tasks such as the Flanker task (see Eriksen \& Eriksen, 1974) and the Stroop task (see Stroop, 1935). In the framework of these paradigms responses to incongruent conditions (e.g., a target left-facing arrow surrounded by distracting right-facing arrows) reportedly requires conflict-monitoring abilities (anterior cingulate cortex activation) in order to suppress pre-potent response tendencies associated with a correct task response (Fan, Flombaum, McCandliss, Thomas, \& Posner, 2003). Researchers utilizing these tasks to test the impacts of mindfulness training build on theoretical assumptions that executive function and emotion regulation skills are adaptable cognitive regulatory mechanisms that can be strengthened through mindfulness practice, and that change in behavioral measures of conflict-monitoring reflect that assumption (Jha, Krompinger, \& Baime, 2007; Rueda, Posner, \& Rothbart, 2004).

An initial review of existing evidence of the impact of mindfulness training improves executive function and emotion regulation is mixed. In a review of 12 studies (see Table A3 for literature review summary), several studies found improved conflictmonitoring abilities in participants of MBSR programs of various lengths (Chan \& Woollacott, 2007; Moore \& Malinowski, 2009; Tang, Ma, Wang, \& Fan, 2007; Teper \& Inzlicht, 2013; Wenk-Sormaz, 2005), however others did not (Semple, 2010). In these 
studies individuals demonstrated greater regulatory abilities following mindfulness training, as seen through reductions in conflict task interference.

Several studies found practice time dependent effects, such that minutes spent meditating per day was more strongly related to conflict-monitoring abilities as compared to total hours spent meditating in one's lifetime (Chan \& Woollacott, 2007) or significant effects were found only for those in the MBSR group with high practice times (Jha, Stanley, Kiyonaga, Wong, \& Gelfand, 2010). Additionally, several studies found shortterm mindfulness trainings (4 to 5 days) predicted significant changes in conflictmonitoring abilities (Tang et al., 2007; Zeidan, Johnson, Diamond, David, \& Goolkasian, 2010). These distinctions may suggest a practice threshold, or indicate an active practice is required, to meaningfully impact conflict-monitoring abilities. Moreover, these results may indicate that conflict-monitoring enhancements due to mindfulness training do not last if meditation practice ceases.

To better understand the underlying attentional processes associated with improved conflict monitoring abilities (e.g., cool executive function), Jha and colleagues (2007) utilized the Attention Network Task (Jin Fan, McCandliss, Sommer, Raz, \& Posner, 2002). The Attention Network Task distinguishes between attentional alerting, orienting, and conflict-monitoring. Jha and colleagues (2007) compared controls to both an eight-week MBSR group and advanced meditators undergoing a one-month intensive meditation course. Significant differences in conflict-monitoring in the advanced meditation group at baseline mimic the findings of the previously described studies. At follow-up, however, these authors found improved orienting abilities in the MBSR group (as compared to the advanced and control groups), as well as increased alerting abilities 
in the advanced group following the retreat. Additionally, they found no significant MBSR and advanced group differences in conflict monitoring following mindfulness training. These results indicate the possibility that varying levels of exposure to mindfulness practices may differentially affect unique components of the underlying attentional and executive processes. It also remains unclear as to whether conflict abilities continue to develop with more rigorous training, or if improvement plateaus.

Testing such differences using computerized cognitive tasks provides one line of evidence implicating the effect of mindfulness training on executive function and emotion regulation. However, to better understand underlying neurological activity associated with these processes researchers have employed Electroencephalography (EEG) measures. EEG measures isolate event related potentials, in other words, isolated brain activity associated with responses on conflict-monitoring tasks (Dehaene, Posner, \& Tucker, 1994). This area of research has demonstrated that mindfulness training is associated with increased error related negativity (Teper \& Inzlicht, 2013), an event related potential generated by the anterior cingulate cortex and a neurophysiological indication of conflict-monitoring abilities (Dehaene et al., 1994). Also, Teper \& Inzlicht (2013) found that self-report indications of mindful acceptance directly predicted error related negativity amplitudes — suggesting that mindfulness training may increase neural correlates associated with error detection and greater executive function abilities. Moreover, studies utilizing fMRI technology have found similar results of meditation training on executive function and its underlying neural correlates. Research, for instance, has shown increased activation in the anterior cingulate cortex following meditation practice of a short duration (Posner, Rothbart, Sheese, \& Tang, 2007). These 
results provide further evidence to support neurological changes in conflict-monitoring abilities due to mindfulness training.

To connect conflict-monitoring results to more meaningful changes in the construct of emotion regulation, researchers have tested whether changes in conflictmonitoring abilities are associated with reductions in negative emotions, as well as other indications of reactivity, such as physiological levels of cortisol. Evidence indicates that mindfulness training is associated with decreased reports of anxiety, depression, anger, fatigue, decreased stress-related cortisol, and increased immunoreactivity (Tang et al., 2007), as well as decreased EEG reactivity to aversive images (Brown, Goodman, \& Inzlicht, 2013). Additionally, Kumar and colleagues (2008) demonstrated that increases in mindfulness were linearly associated with decreases in depression and reductions in avoidance and rumination tendencies. Moreover, similar reductions in negative emotions following mindfulness training have been found for various affective disorders such as generalized anxiety disorder (Kabat-Zinn et al., 1992) and major depression (Segal, Williams, \& Teasdale, 2002) in clinical populations, and decreases in anxiety and depression (Shapiro et al., 1998); mood disturbance and stress (Brown \& Ryan, 2003); and distress (Grossman, Niemann, Schmidt, \& Walach, 2004) in nonclinical populations. Taken together, this evidence supports the idea that mindfulness training may strengthen executive function and emotion regulation abilities, and subsequently reduce negative emotions.

In sum, these results of the effect of mindfulness training on somatic body awareness, executive function, and emotion regulation suggest mindfulness training may increase individuals' awareness of bodily sensations, enhance attentional resources 
available to support regulation, and subsequently reduce the deautomatization of learned behavioral responses associated with stress and reactivity (e.g. Vago \& Silbersweig, 2012) in general populations and some clinical populations.

\section{Effects of mindfulness training on executive function and emotion regulation}

in teachers. Despite the above reported evidence, research testing the effects of mindfulness training on executive function and emotion regulation in teachers is still nascent; and almost no studies have examined somatic body awareness or used behavioral measures (but see Roeser et al., 2013) to assess these relations. Only two studies are known at this time to have examined emotion regulation in teacher populations. Specifically, Taylor and colleagues (2016) report increases in teachers' selfreported emotion regulation efficacy (i.e. how competent teachers feel regulating their emotions) following a MBSR intervention. Using self-report and interview data, results indicated that at post-intervention teachers felt more efficacious for regulating their emotions in the classroom, as well as significantly decreased their use of negative emotion words when describing work-related stressors.

Additionally, Jennings and colleagues (2013) report increases in reappraisal emotion regulation techniques following an intervention of CARE (Cultivating Awareness and Resilience in Education) mindfulness training as well as a trending towards significance decrease in expressive suppression use. These results on regulation outcomes provide evidence supporting the idea that mindfulness trainings improve teachers' regulation abilities, at least as measured by self-reports. Additionally, these results suggest the possibility that mindfulness training may be particularly useful in helping teachers to regulate stress by promoting the use of reappraisal strategies while 
MINDFULNESS AND MECHANISMS OF STRESS REDUCTION

simultaneously reducing reliance on the use of suppression as an emotion regulation strategy. However, given the sparseness of these findings, it is important to continue investigating these processes in new samples of teachers using diverse measures.

\section{Summary}

Individual differences exist in stress exposure, stress appraisal, magnitude of emotional reactivity, and the duration of stress recovery. Successful regulation of stress relies heavily on individuals' coping abilities (including their somatic body awareness, executive function, and emotion regulation) and teacher stress specifically has been linked to a lack of adequate emotion regulation abilities (see Montgomery \& Rupp, 2005). Somatic body awareness, or one's ability to detect subtle physiological sensations, is key for the detection of a discrepancy between one's current and desired states. This discrepancy signals the need for individuals to initiate "top-down" regulatory control when stress reactivity occurs. Refined somatic body awareness, executive function, and emotion regulation skills have been shown to be cultivated through mindfulness training. As such, this thesis examines whether somatic body awareness, executive function, and emotion regulation develop through mindfulness training. Additionally, it examines whether these three coping resources are necessary precursors to reductions in anxiety, depression, stress, and burnout in teachers, as previous research has found (Roeser, 2013; 2018). 


\section{Chapter Three}

\section{The Current Study}

The data utilized for this project are part of a larger RCT testing the effects of mindfulness training on middle school teachers' well-being. Specifically, this project tests the effects of MBEB, a Mindfulness Based Emotional Balance program (Cullen \& Wallace, 2010) created for teachers and educators and adapted from Kabat-Zinn's (1990) MBSR program. The purpose of this RCT was to utilize the fully manualized, eight-week long MBEB professional development program to support teachers in developing mindfulness skills (e.g. attention and emotion regulation, self-compassion, empathy, forgiveness, compassion for others, etc.) in order to promote well-being in a variety of settings and situations. It is theorized that by fostering this unique set of skills and practices teachers will a) be better able to support their own well-being, b) cultivate positive interactions in both their personal and professional lives, and c) apply what they have learned in classroom settings to better meet the needs of their students.

The MBEB program comprises approximately 50\% MBSR content (e.g. mindfulness contemplative and movement practices; Kabat-Zinn, 1990), 30\% mindfulness-based emotional skill and theory, and 20\% mindfulness-based prosociality (e.g. kindness, compassion, forgiveness). Participants experience these program foci through a series of group activities, personal mindfulness practice sessions, and homework assignments. Group activities are comprised of guided mindfulness sessions, lectures targeting topics such as stress or forgiveness, as well as relevant discussions and question/answer sessions with the facilitator. Personal mindfulness practice sessions emphasize moment-to-moment awareness of the breath or the body as a means of 
cultivating concentrative skills. And homework assignments included daily mindfulness practices at home and reflection through journaling.

MBEB training emphasizes emotion regulation to a greater extent than some MBSR programs in order to help teachers manage stress in their profession. Specifically, MBEB emphasizes how mindfulness training can be used to disrupt automatic emotional triggers as well as provide skills for effective regulating once an emotion has been activated. These topics are explored in depth throughout the eight-week program through lectures on emotion, emotion regulation, and how mindfulness training can be used to reduce negative tendencies such as rumination and stress reactivity. Additionally, teachers participate in guided visualizations to explore inner emotional experiences and participate in weekly discussions that focus on applying these techniques in their daily lives.

\section{Purpose of the Study}

The purpose of this study is to test (1) the effect of mindfulness training on somatic body awareness, executive function, and emotion regulation in teachers, and (2) whether the development of somatic body awareness, executive function, and emotion regulation mediate the relations between mindfulness training and the well-being outcomes of anxiety, depression, stress, and burnout in teachers (see Figure 3 for conceptual model, and Figures 4 and 5 for research question depictions).

Research questions and hypotheses. Specifically, the current study seeks to address the following research questions:

Research question 1.a. Does mindfulness training impact teachers' development of somatic body awareness? 
Hypothesis 1.a. Mindfulness training will significantly increase teachers' somatic body awareness.

Research question 1.b. Does mindfulness training impact teachers' development of executive function?

Hypothesis 1.b. Mindfulness training will significantly improve teachers' executive function.

Research question 1.c. Does mindfulness training impact teachers' development of emotion regulation strategies?

Hypothesis 1.c. Mindfulness training will significantly increase teachers' use of reappraisal strategies and significantly decrease teachers' use of suppression strategies.

Research question 2.a. Is the impact of mindfulness training on the well-being outcomes of anxiety, depression, stress, and burnout mediated by teachers' somatic body awareness?

Hypothesis 2.a. Mindfulness training will significantly increase teachers' somatic body awareness post-program, which will partially mediate the relations between mindfulness training and decreased anxiety, depression, stress, and burnout at follow-up.

Research question 2.b. Is the impact of mindfulness training on the well-being outcomes of anxiety, depression, stress, and burnout mediated by teachers' executive function?

Hypothesis 2.b. Mindfulness training will significantly increase teachers' executive function post-program, which will partially mediate the relations between mindfulness training and decreased anxiety, depression, stress, and burnout at follow-up. 
Research question 2.c. Is the impact of mindfulness training on the well-being outcomes of anxiety, depression, stress, and burnout mediated by teachers' emotion regulation?

Hypothesis 2.c. Mindfulness training will significantly change teachers' emotion regulation post-program, specifically increasing teachers' reappraisal and decreasing teachers' suppression, which will partially mediate the relations between mindfulness training and decreased anxiety, depression, stress, and burnout at follow-up. 


\section{Chapter Four}

\section{Research Design and Methods}

\section{Participants}

The sample of teachers was drawn from the larger population of teachers within a large metropolitan public school system located in the Pacific Northwest. Teachers were recruited using a variety of methods such as through emails sent to district administrators, word of mouth, and fliers put on school message boards. Teachers who contacted the research team were asked a series of questions to determine their eligibility to participate. The eligibility criteria were: the teacher taught middle school $\left(6^{\text {th }}, 7^{\text {th }}\right.$, and/or $8^{\text {th }}$ grades $)$, taught a specific subject (e.g. language arts, math) that is appropriate to observe using an educational observational measure (e.g. excluding physical education, school counselors, etc.) and taught the same students for the duration of an entire semester or year. Teachers that met these three criteria were informed of the demands and nature of the projectincluding the randomized waitlist control design of the research study—prior to consenting to participate. Teachers consented to participate with the knowledge that they would receive a mindfulness intervention meant to reduce stress, as well as several gift cards and/or continued education credits as compensation for their time.

Demographics. The final sample of participants included 58 teachers who were recruited in two waves of data collection to create two cohorts of teachers (cohort 1: $n=$ 30 , cohort 2: $n=28$ ) who were then randomized into treatment or waitlist control groups (MBEB: $n=29$, WLC: $n=29$ ). Teachers came from 24 urban schools in the Pacific Northwest that were either K-8 (60.3\%) or 6-8 in structure. Based on self-reports, participants were on average 41 years of age $(M=41.23, S D=8.66), 69.4 \%$ female, 
$81.8 \%$ White $(n=42)$; and 96\% reported having a master's degree. Additionally, years of teaching experience ranged from .25 to 37 years $(M=9.71, S D=7.45 ;$ Median $=8$; Mode =4). Participants were measured at three time points: baseline, immediately after the intervention, and at a 4-month follow-up that took place after summer during the fall of the following school year. At each time of measurement they completed a battery of tests including self-report questionnaires, computerized cognitive tasks, third-party classroom observations, and physiological measures of stress reactivity. For the purposes of this study, only self-report and cognitive task data will be utilized.

\section{Study Design}

A randomized controlled trial (RCT) experimental design was used to test the efficacy of the MBEB program for teachers. A block randomization procedure of subject taught and school type was used for each cohort. The block randomization ensured the treatment and control groups would be balanced with regard to teachers' subject taught and when possible, their school structure (K-8 or 6-8; see Bloom, 2005). Baseline data for cohort one was collected in the Fall of 2013, followed by randomization to treatment and waitlist control conditions. Program implementation for cohort one took place for eight weeks in February and March of 2014. Post-program assessments were conducted in April of 2014 and the 4-month follow-up was conducted in September of 2014. The waitlist control group of cohort one then participated in the intervention in October and November of 2014. The same procedures and timeline were replicated across the second cohort of teachers starting in the fall of 2015. 


\section{Measures}

Mindfulness intervention. Teachers were offered a 28-hour, 10-session

mindfulness professional development program (MBEB) spanning eight weeks. The program comprises activities such as guided mindfulness practice, small group activities and discussions, as well as homework assignments promoting everyday use of techniques taught in the intervention. Program dosage was assessed through attendance at each of the sessions. Of the teachers randomized to the program (including those who were randomized but dropped from the study, $n=29$ ), teachers attended 6.5 out of 10 sessions on average. Of the teachers who did not drop from the study and completed the mindfulness training $(n=23)$, teachers attended 8.3 out of 10 sessions on average.

Somatic body awareness. Somatic awareness of the body and bodily sensations was measured by an adapted short-form of the Body Awareness Scale (Porges, 1993; T1 $\alpha=.79$, T2 $\alpha=.89, \mathrm{~T} 3 \alpha=.87)$. Teachers are asked to report on their general awareness of their body while teaching, by answering questions such as "I am aware of my mouth becoming dry" or "I am aware of muscle tension in my body" on a Likert scale measured from 1 (never) to 5 (always). Upon close scrutiny of item content, one can see that this scale measures somatic body awareness of typical stress responses emerging in the body.

Executive function. Executive function is measured by the Flanker Task, a computerized behavioral measure of inhibitory control and focused attention (Eriksen \& Eriksen, 1974). Participants are instructed to attend to the central target letter on a computer screen and are directed to press a button that corresponds with the central target letter (either $\mathrm{H}$ or $\mathrm{N}$ ) under certain conditions. In the congruent condition, the central target letter is the same as the distracting stimuli (peripheral letters). In the incongruent 
condition, the central target letter is different than the distracting stimuli (i.e. HHHHH or HHNHH). Participants find it more difficult to inhibit the distracting stimuli on incongruent trials (a conflict monitoring test), which is reflected in longer reaction times for those trials.

Prior to conducting analyses, preliminary data processing is required to prepare these data. Validity of this task depends on the speed accuracy tradeoff (see Wickelgren, 1976). The speed accuracy tradeoff suggests that when participants either slow down significantly to improve accuracy, or speed up significantly to improve speed, they compromise the ability of the task to validly capture their executive function. Because of this, a series of preliminary filters are used on the data to exclude individual data that do not meet these speed and accuracy criteria. First, incorrectly responded to trials are filtered out and mean reaction time congruent and incongruent scores are calculated for each participant. Next, accuracy and response times of these data are examined to ensure the data are valid. Overall accuracy scores (collapsed across study conditions) were calculated to ensure high correct response rates. Participants who fell below a standard cutoff point of $80 \%$ accuracy (Zelazo et al., 2013), or whose reaction times were less than or greater than three standard deviations from the mean, were excluded from all analyses involving these data. Forty-one participants of the 58 randomized met these criteria and were included in the executive function analyses reported in this study. Lastly, a conflict score, indicative of the participant's executive function, was calculated by subtracting the mean congruent trial reaction time from the mean incongruent trial reaction time. Conflict scores that are closer to zero are considered indicative of stronger executive 
function abilities, such that they demonstrate an individual is able to direct attention away from the distracting stimuli more efficiently.

Emotion regulation. Self-report emotion regulation was measured using a revised short form of the Gross and John (2003) Emotion Regulation Questionnaire. This scale is comprised of two subscales, reappraisal and suppression, with items measured on a Likert (1-5) scale. Reappraisal was measured by three questions (T1 $\alpha=.84$, T2 $\alpha=$ $.83, \mathrm{~T} 3 \alpha=.78$ ), with items such as "I control my emotions by changing the way I think about the situation I'm in". Suppression was measured with three questions (T1 $\alpha=.65$, T2 $\alpha=.65$, T3 $\alpha=.81$ ), with questions such as "When I am feeling negative emotions, I make sure not to express them."

Anxiety. Anxiety was measured using a Likert (1-4) revised 20-question version of the State-Trait Anxiety Inventory (Spielberger, Gorsuch, Lushene, Vagg, \& Jacobs, 1983), self-report questionnaire (T1 $\alpha=.93, \mathrm{~T} 2 \alpha=.95$, T3 $\alpha=.95$ ), consisting of questions such as "I feel frightened" or reverse coded "I feel calm."

Depression. Depression was measured using a revised short version of the Beck Depression Inventory (Beck, Steer, \& Carbin, 1988), a 12-question scale (T1 $\alpha=.84$, T2 $\alpha=.80, \mathrm{~T} 3 \alpha=.87)$. Questions have participants check one of four options that best describes how they feel, an example of which is "(1) I do not feel sad. (2) I feel sad. (3) I am sad all the time and I can't snap out of it. Or (4) I am so sad or unhappy that I can't stand it."

Occupational stress. Teacher stress was measured using a series of questions including both revised questions from Lambert, McCarthy, and Abbott-Shim (2001) and Roeser and Midgley (1997). Teachers were asked seven questions (T1 $\alpha=.63$, T2 $\alpha=$ 
.63, T3 $\alpha=.70)$ on a Likert scale (1-5), with questions such as "I find dealing with student motivational and disciplinary problems to be very stressful", or "I find trying to be attentive to the needs of fellow teachers is very stressful".

Occupational burnout. Teacher occupational burnout was measured using a revised short-form of the Maslach Burnout Inventory (Maslach, Jackson, \& Leiter, 1996), an 18-question Likert (1-7) scale (T1 $\alpha=.86, \mathrm{~T} 2 \alpha=.87$, T3 $\alpha=.90)$. Teachers were asked how often they felt each experience, with questions such as "feel used up at the end of the work day?" or "feel fatigued when you get up in the morning and have to face another day on the job?". See Appendix B for all survey items. 


\section{Chapter Five}

\section{Results}

\section{Preliminary Analyses}

Descriptive information of the composite scores of all measures described above can be found in Table 2, including baseline means and standard deviations for the entire sample. Distributions of all variables were inspected for any potential outliers histograms, boxplots, and normal Q-Q plots indicated variables were normally distributed with several variables exhibiting only minor skew (e.g., depression and executive function). However, all variables had skew and kurtosis estimates within acceptable range (i.e. skew values below the absolute value of three and kurtosis values less than the absolute value of 10; Kline, 2016). Data visualization techniques also showed several variables had outliers, however, each of these fell within the range of possible scores on each scale and were therefore retained.

Correlation analyses. Correlations among study variables at baseline are reported in Table 3. Significant negative relations were found between anxiety and reappraisal $(r=-.57)$; depression and reappraisal $(r=-.55)$; and burnout and reappraisal $(r=-.29)$. Although not causally examined yet, these negative relations suggest teachers who more often use reappraisal as an emotion regulation strategy have significantly lower concurrent levels of anxiety, depression, and burnout. Additionally, a significant positive relation was found between burnout and suppression $(r=.35)$, which suggests that teachers who more often use suppression as an emotion regulation strategy also report higher levels of burnout. 


\section{MINDFULNESS AND MECHANISMS OF STRESS REDUCTION}

There were also significant positive relations among the well-being outcomes, specifically, burnout and anxiety $(r=.45)$; burnout and depression $(r=.30)$; burnout and stress $(r=.53)$; and depression and anxiety $(r=.65)$, and a trending toward significant positive relation between stress and anxiety $(r=.26)$. These relations indicate that teachers who experience higher levels of one of these negative well-being outcomes are also more likely to report higher levels of the others. There were no significant relations between somatic body awareness or executive function and any well-being outcomes.

Attrition. Program attrition was also inspected to determine whether individuals within the treatment and control groups differentially dropped out of the program - as differential attrition may cause post-test non-equivalence (see Hansen, Collins, Malotte, Johnson, \& Felding, 1985). Upon inspection, two treatment teachers dropped from the study after randomization but prior to baseline assessment (i.e. complete data possible for only $n=56$ of those randomized) and several other teachers in both the treatment and control groups dropped or migrated between groups between the baseline and follow-up time points of the study. Figure 6 depicts the attrition and migration flow of participants through the study.

Despite these changes due to attrition and migration, total numbers between groups remained relatively stable across time, with six out of the 29 treatment teachers missing data across both cohorts and four out of the 29 control teachers missing data across both cohorts (see Table 1 for valid data per group across time points). Also, despite having several teachers migrate between groups, all analyses map back to the randomization of the project, such that teachers who migrated or dropped were still 
considered members of the group they were randomly assigned to at the start of the project.

Missingness. To address the missing data issue due to the study's attrition, multiple imputation was utilized. First, Little's MCAR Test (Little, 1988) was used to test for systematic missingness bias. Results of this test were not significant; indicating missingness within this sample was randomly distributed. As such, multiple imputation was employed to impute the missing data, with 10 imputations created by using all variables of interest in this study and additional related auxiliary variables (see Schafer \& Graham, 2002). All of the following analyses were conducted and reported using both the original (listwise deletion) and imputed data.

Baseline equivalence. Due to the fact that this study utilizes data from a RCT, preliminary analyses were conducted to check for baseline equivalence between treatment and control groups. Independent t-tests between groups for each of the study's key variables (i.e. somatic body awareness, executive function, both sub-scales of emotion regulation, and all well-being outcomes) as well as several demographic variables established baseline equivalence, using both listwise original and imputed data (see Table 4 for baseline equivalence of teacher demographics and Tables 4 and 5 for listwise and imputed baseline equivalence of the variables of interest). No significant differences between groups were found for any of the variables of interest within this study or demographic characteristics. These results, as well as the randomization component of the study design, suggest that no additional covariates need to be included for any subsequent analyses. This is because randomly assigning teachers to either the treatment or waitlist control group distributes all possible systematic differences between 
MINDFULNESS AND MECHANISMS OF STRESS REDUCTION

groups equally at the start of the study. Establishing equivalent groups at the start of the study allows researchers to make causal claims about an intervention if differences between groups are found after the intervention. However, some possible differences might still occur by chance after randomization, which is why baseline equivalence is used to test that the groups are not statistically different from each other before intervention implementation.

\section{Impact Analyses}

Standard hypothesis testing parameters were utilized (i.e. alpha level of .05) for all analyses. SPSS version 22 was used for preliminary data descriptives and to examine group differences. The statistical software package R version 1.0.153 (R Core Team, 2013) was used to conduct the Ordinary Least Squares regressions and mediation analyses. Mindfulness training (condition) was dummy coded as treatment (1) and control (0) for all analyses.

T-tests. T-tests were conducted on all post-intervention and follow-up outcomes to examine differences between groups on all variables of interest. Listwise deleted results at post-intervention and 4-month follow-up can be found in Tables 7 and 8, and imputed post-intervention and 4-month follow-up results can be found in Tables 9 and 10.

Listwise deletion. Listwise results indicate teachers in the mindfulness intervention significantly increased in somatic body awareness at post-intervention $(M=$ $3.13, S D=.64)$ as compared to the waitlist control group $(M=2.72, S D=.97), t(47)=$ $1.74, p<.05, d=.49$. No statistically significant executive function or emotion regulation differences were found at post-intervention between groups. However, a small effect size 
in the unexpected direction was found for suppression $(d=.23)$ and a small/medium effect size was found for reappraisal $(d=.44)$. Cohen's (1988) effect size $(d)$ standardizes mean group differences by dividing them by the groups' pooled standard deviation. These effect sizes indicate that teachers in the mindfulness training group reported somatic body awareness scores that were one half of a standard deviation above waitlist control teachers on average. Mindfulness training group teachers reported similar increases in emotion regulation reappraisal, and almost a quarter of a standard deviation increase in emotion regulation suppression scores as compared to controls.

As can be found in Roeser and colleagues (2018) statistically significant between group differences were found for anxiety $(t(47)=-2.91, p<.01, d=-.85)$ and stress $(t$ $(47)=-2.02, p<.05, d=-.59)$ at post-intervention. And although not statistically significant, the effect size estimates for depression $(d=-.35)$ and burnout $(d=-.48)$ were also medium in size. Additionally, reductions in anxiety among treatment group teachers $(M=1.94, S D=.50)$ remained stable at follow-up in comparison to waitlist controls $(M=$ $2.49, S D=.70 ; t(44)=-3.03, p<.01, d=-.89)$. Teachers in the mindfulness group also had significantly reduced levels of burnout $(M=3.08, S D=.93)$ as compared to waitlist controls $(M=3.76, S D=.93 ; t(44)=-2.51, p<.05, d=-.74)$ at follow-up. And although not statistically significant, medium effect sizes between groups were also found for stress $(d=-.50)$ and depression $(d=-.43)$.

Lastly, exploratory t-tests at the 4-month follow-up were also conducted on the coping resources proposed in this project to examine whether positive effects on these mechanisms persisted. Results suggest somatic body awareness improvements at postintervention did not maintain at follow-up, with results indicating a small effect size in 
the opposite direction $(d=-.18)$. However, the small effect on teachers' suppression in the unexpected direction was maintained at follow-up $(d=.27)$ and so was the medium effect size for reappraisal $(d=.34)$.

Imputation. Post-intervention imputed results mirror the listwise results described above, with slightly more conservative estimates and effect sizes among significant variables. Specifically, differences between groups at post-intervention remained significant for somatic body awareness $(t(56)=1.74, p<.05, d=.45)$, anxiety $(t(56)=-$ 2.27, $p<.05, d=-.68)$, and stress $(t(56)=-2.02, p<.05, d=-.53)$. Small to medium effect sizes were still present for reappraisal $(d=.37)$ and burnout $(d=-.33)$, and in the opposite direction than was expected for suppression $(d=.29)$. However, the effect size for depression reduced significantly with imputation $(d=-.13)$.

Imputation results at follow-up also mirrored the listwise results reported above, with more conservative estimates for each of the outcomes. Results indicate significant reductions in anxiety $(t(56)=-2.21, p<.05, d=-.68)$ and burnout $(t(56)=-2.51, p<.05$, $d=-.56$ ) for teachers in the mindfulness training group. Additionally small to medium effect sizes between groups were found for depression $(d=-.27)$, stress $(d=-.35)$, and reappraisal $(d=.38)$; and also in the unexpected direction for suppression $(d=.24)$ and somatic body awareness $(d=-.22)$.

Regression Analyses. The first research question examined the impact of mindfulness training on somatic body awareness, executive function, and emotion regulation. For these regressions, the baseline measure of the outcome was used as a covariate to isolate change over time. Each of these covariates was mean-centered to increase precision and interpretability. As is shown in equation one, each analysis tested 
the effect of the mindfulness intervention (MT) on the mechanisms of interest at postintervention $\left(\mathrm{M}_{\mathrm{T} 2}\right)$, controlling for baseline measures of the mechanism $\left(\mathrm{M}_{\mathrm{T} 1}\right)$ (see Figure 6 for statistical model).

$$
\mathrm{M}_{\mathrm{T} 2} \sim \mathrm{MT}+\mathrm{M}_{\mathrm{T} 1}
$$

Results of the listwise deleted data indicate that the mindfulness intervention significantly improved teachers' somatic body awareness $(\mathrm{b}=.50, \mathrm{SE}=.22, \beta=.29, p$ $<.05)$ and teachers' emotion regulation reappraisal $(\mathrm{b}=.44, \mathrm{SE}=.18, \beta=.27, p<.05$; see Table 11 for listwise mechanism regression results). These results indicate that teachers in the mindfulness training group are predicted to report approximately a half of a point higher (Likert 1-5) on somatic body awareness and reappraisal after mindfulness training, compared to the control group. However no significant changes in teachers' executive function or suppression were found at post-intervention. Results from the imputed data were similar, however, more moderate, indicating a trending toward significant improvement in somatic body awareness at post-intervention $(b=.45, \mathrm{SE}$ $=.21, \beta=.26, p<.10)$, and no significant improvement in teachers' reappraisal $(b=.30$, $\mathrm{SE}=.19, \beta=.18, p=.16)$. Imputed data similarly showed no significant improvement in teachers' executive function or suppression (see Table 12).

Mediation Analyses. Mediation analyses on teachers' well-being were conducted in the statistical software package R version 1.0.153 (R Core Team, 2013) using a mediation package (Revelle, 2017) equivalent to Hayes’ PROCESS Macro (Hayes, 2013; 2018). These mediation techniques are path analysis tools that estimate the direct and indirect effects of a mediation model simultaneously, as well as use bootstrapping to increase power in detecting the indirect effect (Hayes, 2013). This method does not 
require significant main effects to be established prior to testing mediation and has been shown to have a lower type I error rate as compared to the Baron and Kenny method (Hayes, 2013).

Bootstrapping. Bootstrapping is a procedure that assumes a sample of data is representative of the greater population. This assumption allows the sample data to be resampled with replacement, calculating a different but equally as plausible sample estimate repeatedly on the scale of thousands of times. In mediation, the repeated calculation of the indirect pathway estimate is used to create a sampling distribution in which confidence intervals of the indirect effect are derived. No assumptions about the shape of the indirect effect sampling distribution are made, which therefore increases the likelihood that the estimates are accurate, not biased, and estimated with greater power due to the resampling process (Hayes, 2013). For the purposes of this study 10,000 bootstraps were used for all mediation analyses to account for the small sample size of the study and because evidence indicates that the benefit of going beyond this amount is limited (Hayes, 2013). Additionally, there are several types of bootstrapping (percentile, bias-corrected, bias-corrected accelerated) and while there are benefits and drawbacks to each, percentile bootstrapping was chosen for this study as it is the recommended bootstrapping method for simple mediations (Hayes, 2018).

Mediation Results. Mediation analyses in this study were longitudinal in nature, and tested whether somatic body awareness, executive function, and emotion regulation at post-intervention mediate the relations between mindfulness training and teachers' well-being outcomes of anxiety, depression, stress, and burnout at follow-up. Below is a set of simultaneous equations that represent the mediation models of this study (see 
Figure 8 for basic mediation diagram). Equation two tests the effect of the independent variable (MT) on the mediating variable (M; path a on the diagram). Equation three represents the effect of the independent variable (MT) on the dependent variable (D; path c' on the diagram) as well as the effect of the mediating variable (M) on the dependent variable ( $\mathrm{D}$; path $\mathrm{b}$ on the diagram). The prime notation on the independent variable (MT') in the third equation represents the effect of MT on D not accounted for by the indirect mediation pathway (paths a and b), whereas MT without prime notation represents the total effect of the mediation model. The indirect effect of the mediation model is calculated by multiplying the estimate derived from the second equation and the mediation $(\mathrm{M})$ estimate from the third equation (the combined $\mathrm{a}^{*} \mathrm{~b}$ path). A significant mediation is determined by a statistically significant indirect effect, which occurs if the confidence interval for the indirect effect does not include zero. Partial or full mediation is determined depending on whether the direct effect of MT on D is statistically significant.

$$
\begin{gathered}
\mathrm{M} \sim \mathrm{MT} \\
\mathrm{D} \sim \mathrm{MT}^{\prime}+\mathrm{M}
\end{gathered}
$$

Mediation results using listwise deleted data can be found in Tables 13-28. Imputed mediation results can be found in Tables 29-44. Confidence intervals of the indirect effect estimates of the mediations using both listwise deleted and imputed data indicate no significant mediations of any of the mechanisms on any of the well-being outcomes for teachers. To explore these questions further, several other mediation specifications were conducted as well, using post-intervention scores for both the mediator and outcome, and using baseline to post-intervention change scores for the 
mediators. No significant results were found for either of these additional mediation specifications.

Partially standardized effect sizes were calculated for the total $\left(\mathrm{c}_{p s}\right)$, indirect $\left(a b_{p s}\right)$, and direct $\left(c^{\prime}{ }_{p s}\right)$ effects and can be found in each mediation table. The partial standardization consists of dividing each of the above-mentioned path estimates by the standard deviation of the outcome variable (i.e. $\mathrm{ab} / \mathrm{SD}_{\mathrm{y}}$ ). Effect sizes of this nature are considered useful because they contextualize the path estimates based on the level of variability in the outcome (Hayes, 2013). The partial standardization is appropriate for this study given the dichotomous nature of the grouping variable. These partial effect sizes can be interpreted as average group differences in standard deviations in the outcome for each mediation path.

Close examination of effect size and path estimates suggest some mediations may be pertinent to consider despite not reaching statistical significance as measured by the indirect effect confidence interval. Specifically, and in congruence with the t-test and regression analyses above, only somatic body awareness and reappraisal mediations yielded path and effect size estimates that may be meaningful to mention. All listwise and imputed results of these mediations are reported below.

Anxiety. Listwise results of group predicting anxiety mediated by somatic body awareness show a significant total effect of group on anxiety $\left(b_{c}=-.55, \beta=-.42, p=\right.$ $\left..001, c_{p s}=-.82\right)$, a significant direct effect of group on anxiety $\left(b_{c},=-.48, \beta=-.36, p<\right.$ $\left..01, c_{p s}^{\prime}=-.72\right)$, a marginal effect of group on somatic body awareness $\left(b_{a}=.40, \beta=.24\right.$, $p=.07)$, a marginal effect of somatic body awareness on anxiety $\left(b_{\mathrm{b}}=-.17, \beta=-.22, p=\right.$ $.08)$, and a non-significant total indirect effect $\left(\mathrm{b}_{\mathrm{ab}}=-.06,95 \% \mathrm{CI}:[-.25, .05], a b_{p s}=-\right.$ 
.10). The effect size of the total effect indicates that the overall mediation model explains approximately $80 \%$ of the variance in anxiety. The effect size of the indirect effect indicates that approximately $10 \%$ of that total variance explained is due to the mediation path (see Table 13). However, results using imputed data were different, indicating no significant effect of somatic body awareness on anxiety, and an effect size of the indirect effect of only .04 (see Table 29).

The listwise mediation results with group predicting anxiety mediated by reappraisal showed a significant total effect of group on anxiety $\left(b_{c}=-.55, \beta=-.42, p=\right.$ $\left..001, c_{p s}=-.82\right)$, a significant direct effect of group on anxiety $\left(b_{c},=-.44, \beta=-.33, p<\right.$ $\left..01, c_{p s}^{\prime}=-.66\right)$, a non-significant effect of group on reappraisal $\left(b_{\mathrm{a}}=.34, \beta=.21, p=\right.$ $.11)$, a significant effect of reappraisal on anxiety $\left(b_{b}=-.32, \beta=-.39, p=.001\right)$, and a non-significant total indirect effect $\left(\mathrm{b}_{\mathrm{ab}}=-.11,95 \% \mathrm{CI}:[-.27, .03], a b_{p s}=-.16\right)$. Effect sizes indicate that approximately $16 \%$ of the total variance in anxiety explained by the model is due to the mediation pathway of reappraisal (see Table 21). Imputed results were similar, however, the direct effect of group on anxiety was only marginally significant, with a .11 effect size of the indirect effect (see Table 37).

Depression. Listwise results of the mediation model with mindfulness training group predicting depression through somatic body awareness suggests a marginal total effect of group on depression $\left(b_{c}=-.19, \beta=-.22, p=.10, c_{p s}=-.43\right)$. The model also indicated a non-significant direct effect of group on depression $\left(b_{\mathrm{c}},=-.14, \beta=-.15, p=\right.$ $\left..25, \mathrm{c}_{\mathrm{ps}}=-.30\right)$, a marginal effect of group on somatic body awareness $\left(\mathrm{b}_{\mathrm{a}}=.40, \beta=.24\right.$, $p=.07)$, a significant effect of somatic body awareness on depression $\left(b_{b}=-.14, \beta=-.26\right.$, $\mathrm{p}<.05)$, and a non-significant indirect effect $\left(\mathrm{b}_{\mathrm{ab}}=-.06,95 \% \mathrm{CI}:[-.16, .01], a b_{p s}=-.13\right)$. 
The effect size of the indirect effect indicates that approximately $13 \%$ of the variance explained in depression by the model is due to the mediation pathway (see Table 14). Imputed results of the mediation of group predicting depression through somatic body awareness did not have any significant model pathways, however the effect size of the indirect effect still accounted for $9 \%$ of the variance explained in the outcome (see Table $30)$.

The listwise mediation results of group predicting depression as mediated by reappraisal indicates a marginal total effect of group on depression $\left(b_{c}=-.19, \beta=-.22, p\right.$ $\left.=.10, c_{p s}=-.43\right)$, a non-significant direct effect of group on depression $\left(b_{c},=-.13, \beta=\right.$ $\left..15, p=.25, c_{p s}^{\prime}=-.29\right)$, a non-significant effect of group on reappraisal $\left(b_{\mathrm{a}}=.34, \beta=.21\right.$, $p=.11)$, and a significant effect of reappraisal on depression $\left(\mathrm{b}_{\mathrm{b}}=-.18, \beta=-.33, p=.01\right)$. The total indirect effect was not significant $\left(b_{a b}=-.06,95 \%\right.$ CI: $\left.[-.17, .01]\right)$, with an effect size of .14 (see Table 22). Imputed results of this mediation model determined no significant model path estimates, with the effect size of the indirect effect accounting for $9 \%$ of the explained variance in depression (see Table 38 ).

Stress. The listwise mediation model examining stress predicted by group through somatic body awareness determined the total effect of group on stress was marginal $\left(b_{c}=\right.$ $\left.-.30, \beta=-.24, p=.07, c_{p s}=-.47\right)$. Additionally, the direct effect was not significant $\left(b_{\mathrm{c}},=\right.$ $\left.-.23, \beta=-.18, p=.18, c_{p s}^{\prime}=-.35\right)$, the effect of group on somatic body awareness was marginal $\left(b_{\mathrm{a}}=.40, \beta=.24, p=.07\right)$, a marginal effect of somatic body awareness on stress $\left(b_{b}=-.19, \beta=-.25, p=.06\right)$, and a non-significant indirect effect $\left(b_{a b}=-.08,95 \%\right.$ CI: $\left.[-.27, .02], a b_{p s}=-.12\right)$. The effect size of the indirect effect suggests that approximately $12 \%$ of the total variance in stress explained by the model is due to the 
mediation pathway through somatic body awareness (see Table 15). Imputed results of the same mediation model yielded no significant path estimates, with an effect size of the indirect effect explaining $7 \%$ of the total variance in stress accounted for by the model (see Table 31).

The listwise mediation model of group predicting stress, as mediated by reappraisal suggests a marginal total effect of group on stress $\left(b_{c}=-.30, \beta=-.24, p=.07\right.$, $\left.c_{p s}=-.48\right)$. The model's direct effect of group on stress was not significant $\left(\mathrm{b}_{\mathrm{c}},=-.24, \beta=\right.$ $\left.-.19, p=.15, c_{p s}^{\prime}=-.38\right)$. Also, the effect of group on reappraisal was not significant $\left(\mathrm{b}_{\mathrm{a}}=\right.$ $.34, \beta=.21, p=.11)$ and the effect of reappraisal on stress was marginal $\left(b_{b}=-.18, \beta=-\right.$ $.22, p=.09)$. The total indirect effect of the model was not significant $\left(b_{a b}=-.06,95 \%\right.$ CI: $\left.[-.23, .03], a b_{p s}=-.10\right)$, indicating that $10 \%$ of the total variance in stress explained by the model is due to the mediation pathway of reappraisal (see Table 23). The imputed results of this same mediation model produced no significant model path estimates and a .05 effect size of the indirect effect (see Table 39).

Burnout. The listwise results of the mediation model of group predicting burnout through somatic body awareness indicated a significant total effect of group on burnout $\left(b_{c}=-.69, \beta=-.35, p<.01, c_{p s}=-.71\right)$, a significant direct effect of group on burnout $\left(b_{c}\right.$ ' $=-.65, \beta=-.34, p=.01, c^{\prime}{ }_{p s}=-.67$ ), also a marginal effect of group on somatic body awareness $\left(\mathrm{b}_{\mathrm{a}}=.40, \beta=.24, p=.07\right)$, a non-significant effect of somatic body awareness on burnout $\left(b_{\mathrm{b}}=-.09, \beta=-.08, p=.55\right)$, and the total indirect effect was not significant $\left(b_{a b}=-.04,95 \%\right.$ CI: $[-.29, .18], a b_{p s}=-.04 ;$ see Table 16). Imputed results of the same model were more conservative with a non-significant effect of group on somatic body 
MINDFULNESS AND MECHANISMS OF STRESS REDUCTION

awareness and an effect size of the total indirect effect accounting for only $2 \%$ of the explained variance in burnout (see Table 32).

Lastly, listwise results of the mediation model with group predicting burnout through reappraisal showed a significant total effect of group on burnout $\left(b_{c}=-.69, \beta=-\right.$ $\left..35, p<.01, c_{p s}=-.70\right)$. The model also indicated a significant direct effect of group on burnout $\left(b_{\mathrm{c}}{ }^{\prime}=-.52, \beta=-.27, p<.05, c^{\prime}{ }_{p s}=-.53\right)$, a non-significant effect of group on reappraisal $\left(b_{\mathrm{a}}=.34, \beta=.21, p=.11\right)$, and a significant effect of reappraisal on burnout $\left(b_{b}=-.51, \beta=-.42, p<.001\right)$. The total indirect effect of the model was not statistically significant $\left(b_{a b}=-.17,95 \%\right.$ CI: $\left.[-.46, .04], \mathrm{ab}_{\mathrm{ps}}=-.17\right)$. The effect size of the indirect effect indicates that approximately $17 \%$ of the variance of burnout explained by the model is due to the mediation pathway (see Table 24). Imputed results of the same mediation model provided similar results with the exception of a non-significant direct effect of group on burnout and a .06 effect size of the indirect effect (see Table 40). 


\section{Chapter Six}

\section{Discussion}

The main purpose of this project was to examine several possible mechanisms underlying the stress-reducing effects of the MBEB mindfulness program for teachers. Research has previously demonstrated that teachers randomized to MBEB show significant reductions in stress, burnout, anxiety, and depression, and that the cultivation of key mindfulness-based skills may mediate these relations (Roeser et al., 2013). However, no other studies are known to have examined other mechanisms of action that explain these positive effects in teachers. Therefore, the current study examined somatic body awareness, executive function, and emotion regulation as three possible coping resources that develop through mindfulness training, as well as whether the development of these resources explains the long-term reduction of anxiety, depression, stress, and burnout found in teachers after MBEB training.

\section{Overview of Study Findings}

In the first aim of this study, it was hypothesized that teachers would significantly improve their somatic body awareness, executive function, and reappraisal abilities, and would significantly reduce their use of suppression as an emotion regulation technique following mindfulness training. Results indicate that these hypotheses were only partially supported. Preliminary listwise deletion t-tests examining post-intervention effects on each of these mechanisms indicated that teachers significantly improved in their somatic body awareness, and marginally improved in their reappraisal, however imputed data ttests were more conservative - supporting only marginal improvements in teachers' somatic body awareness. Contrary to what was expected, there was also a non-significant 
but small positive effect of mindfulness training on teachers' suppression at postintervention.

To isolate development of these mechanisms over time, OLS regressions were conducted testing the impact of the mindfulness training on teachers' post-intervention somatic body awareness, executive function, and emotion regulation, controlling for teachers' baseline scores. Again, hypotheses were only partially supported. Listwise regression results indicated that teachers in the mindfulness training group significantly improved in their somatic body awareness and reappraisal. However, there was no significant change on teachers' executive function or suppression. Imputed data of these same analyses indicated a trending toward significant improvement in teachers' somatic body awareness, but no significant improvements in teachers' reappraisal, executive function, or suppression. Additionally, there was only a marginal improvement in teachers' reappraisal still present at follow-up, indicating that somatic body awareness improvements did not persist over time.

The evidence supporting significant increases in teachers' somatic body awareness and reappraisal replicates previous research in general samples for somatic body awareness (see Table A2) and teacher-specific samples for reappraisal (Jennings et al., 2013). Our finding that the MBEB program improves teachers' somatic body awareness suggests that teachers who notice ongoing physiological sensations in the body with greater attunement may be able to recognize the need to regulate earlier in a stress reaction phase (Lutz et a., 2008; Tang et al., 2015). Enhanced somatic body awareness may also allow teachers to recognize when stressful experiences in the classroom are occurring and help them to initiate regulation with greater success. The MBEB program 
also instructs teachers to focus on the present moment experience with an open and nonjudgmental orientation (Cullen \& Wallace, 2010). Therefore, developing somatic body awareness during training may provide teachers with a new regulation strategy focusing on their physiological sensations instead of engaging in elaboration of the stress response. By disrupting stress-reactivity processes in this way, teachers may be breaking down learned action tendencies that lead to stress and by doing so, reduce the total number of stress-coping episodes they must engage in (Perlman et al., 2010).

Similarly, increasing teachers' use of reappraisal as a strategy for regulating emotion while teaching may help teachers to reconsider difficult students or other challenging classroom experiences in ways that include more contextual information. Reconsidering stressful experiences by taking the perspective of the student or drawing on additional knowledge may reduce teachers' own negative reactions, while simultaneously allowing them to engage more constructively with the student or problem. This may positively impact classroom experiences overall by reducing teachers' time spent managing their own stress and therefore allow them to be more present and available to their students and the teaching task at hand. Additionally, increased reappraisal capabilities may positively influence the transactional coping process for teachers (see Skinner \& Zimmer-Gembeck, 2016). By reappraising stressful scenarios teachers may be reconstructing their perceptions of current demands, negative relationships with students, or their perception of available coping resources. These positive changes may influence various aspects of the stress-coping process, such as reduce the amount of time teachers experience stress during an episode, reduce the total 
number of coping episodes, or change the trajectory of an ongoing coping episode (Skinner \& Zimmer-Gembeck, 2016; Williams, 2009).

Unexpectedly, somatic body awareness improvements in treatment teachers did not persist, and a small reversal of group differences was found at follow-up. The extinction of this effect over time might indicate that an active mindfulness practice is necessary for enhanced somatic body awareness to persist. This is particularly plausible given that an increase in somatic body awareness is thought to develop through mindful attention practices focused on the breath or body (Bishop et al., 2004). In order to maintain increased somatic body awareness, teachers may need to continue an active mindfulness practice. A fruitful next step to clarify these relations would be to examine whether teachers who maintained a personal practice throughout the four months after the intervention still report increased somatic body awareness at follow-up. Furthermore, despite being small in magnitude, it still remains unclear why a reverse effect of treatment teachers' somatic body awareness was found at follow-up.

Lastly, the unexpected lack of evidence supporting the positive impact of the mindfulness intervention on teachers' executive function and suppression may be due to study-specific methodological issues (see limitations below). Indeed, previous studies have demonstrated significant improvements in each of these coping resources after mindfulness training (see Appendix A for overview of previous studies). However, the small but positive impact of the MBEB on teachers' suppression warrants further discussion. Middle school teachers must teach multiple classes a day and have very limited time to teach students in each class. Thus, suppression of one's feelings may sometimes be a useful tool for teachers to reach educational goals in classroom settings 
with misbehaving students. This may be true despite the fact that suppression has been linked to negative well-being outcomes in both previous literature (Gross \& John, 2003) and in the current study's baseline correlation between suppression and burnout. It is still unknown whether suppression in combination with positive coping strategies (i.e. reappraisal) has similar long-term negative consequences to suppression alone. Future studies should continue exploring both suppression and executive function in middle school teacher samples to better understand these unexpected results.

The second aim of this study was to examine whether teachers' development of these coping resources explain the reductions in anxiety, depression, stress, and burnout found in previous studies of mindfulness training for teachers. Mediation analyses using listwise deleted and imputed data both suggest that reductions in anxiety, depression, stress, and burnout are not due to increases in somatic body awareness, executive function, and emotion regulation. Indirect effect confidence intervals of the mediation pathways using both listwise deleted and imputed data indicated no significant mediations. The indirect effect quantifies the influence of the intervention on teacher well-being that flows through the mediating coping resources. Despite not reaching statistical significance in these confidence intervals, the partially standardized effect sizes and direct path estimates within the listwise deleted mediation models that included somatic body awareness and reappraisal seemed promising - particularly those with burnout and anxiety mediated by reappraisal. Even though no casual claims can be made using these data, future research should continue examining these relations because determining whether mindfulness training reduces negative well-being outcomes in teachers through these coping resources remains an important line of inquiry. 
The coping framework used in this study may also inform these mediation results. The mechanisms proposed here are theorized to be coping resources that teachers can draw on during real-time stress encounters. However, somatic body awareness, executive function, and emotion regulation are only pieces within the greater 'coordinating concept' that is considered coping at the moment-to-moment level (Skinner \& Zimmer-Gembeck, 2016). Testing each as separate mechanisms of action, although an appropriate first step, may not directly align with this theory. For example, it may be that reappraisal as a standalone strategy does not explain teachers' reductions in anxiety or burnout, but rather that the teacher's perception of a holistic increase in possible resources to draw on during moments of stress appraisal that explain improved well-being. This suggests the need for further analyses that include all proposed coping resources in a single model. Such analyses will clarify the combined effect of these coping resources on teacher well-being and eliminate one possible reason why the current study's mediation results lacked statistical significance.

\section{Limitations and Future Directions}

Methodological Constraints. The biggest limitation to this study is the small sample size of the data. Detecting significant longitudinal mediation effects with such a small sample requires a very robust effect. For example, Fritz and MacKinnon (2007) found through simulation studies that only when the mediation pathway estimates (a and b respectively) are approximately .39 and .59 would a significant mediation effect be detected using percentile bootstrapping and confidence intervals. Although one mediation analysis reported here comes close to these estimates (burnout mediated by reappraisal, with $b_{a}=.34$ and $b_{b}=-.51$ ), most are smaller. Fritz and MacKinnon (2007) state that 
when path estimates are more moderate in nature (i.e. between .14 and .39), a sample size between 126 and 406 would be required to detect significant indirect effects. Therefore, the current study provides promising preliminary evidence in support of several meditational relations and future research should replicate this study with a sample size within this suggested range in order to better determine whether these coping resources explain increases in teachers' well-being after mindfulness training.

Due to the same sample size constraints, we could not incorporate an active waitlist control group in the research design of this study. This may affect our ability to elucidate what components of mindfulness training cause changes in coping resources and teacher well-being. For example, we may be attributing all changes in teacher stress to the mindfulness training, when in fact changes might have resulted from the 28 hours of additional time teachers spent away from work and other obligations. For these reasons, future research endeavors should include an active waitlist control research group in the design to account for this uncertainty and to decrease the likelihood of a type I error.

Measures. Several measures used in this study have several important limitations, including teachers' executive function, suppression, and stress. Specifically, conducting teachers' cognitive tasks in their classrooms after school may have introduced method bias into teachers' executive function scores. Researchers responsible for these testing sessions reported many interruptions across testing sessions (e.g., students or other faculty entering the room to ask questions, phones ringing, etc.). Because of this, the executive function scores captured in this study may not be as valid as those captured in other studies using laboratory-based settings. Indeed, previous studies have found 
significant increases in executive function scores following mindfulness training (see Table A3) and in teacher samples specifically (Roeser et al., 2013). Future research should consider replicating this RCT with cognitive tasks conducted in a more controlled setting to better understand these effects.

The suppression subscale of the emotion regulation survey did not meet a satisfactory reliability $(\alpha=.65)$, nor did the occupational stress survey $(\alpha=.63)$. This indicates uncertainty that suppression and stress were adequately captured in this sample of teachers. Reliability analyses conducted as part of the preliminary data analysis process indicated that excluding a single item from the stress survey would not improve reliability and removing a single item from the suppression scale was not possible because the short-form used in this study included only three questions. Future research should consider replicating this study with a larger sample size to better test reliability of these scales, as well as examine the role of suppression in middle school teacher samples in greater detail, given the small but positive effect of MBEB on suppression found in the current study.

Lastly, this study examined multiple coping resources and multiple well-being outcomes, however future studies should continue expanding measures in these areas to gain a more comprehensive understanding of these processes. Specifically, next steps should include consideration of other factors that influence stress appraisal and coping such as involuntary response tendencies and context about the stressor - and other coping strategies. Future studies should also include the previously established mechanisms of self-compassion and mindfulness (Roeser et al., 2013) in these combined mediation 
models. Results from these inquiries may provide a more holistic picture of how coping resources are coordinated in moments of stress.

Furthermore, future research should also consider including relevant covariates within these models, quantifying motivations and reasons for attending the program, and include measures of actual program participation. These measures would help to determine whether teachers with specific motivations, or those who practice more diligently, receive greater program benefits. Also, although covariates were not necessary for these analyses, adding theoretically related covariates to these models would provide a more precise understanding of these relations and help us to detect possible subgroups of individuals who might benefit most from mindfulness training. For the same reasons, future research should consider moderated mediation or a person-centered framework to examine how combinations of demographic variables, coping resources, and automatic response tendencies interact within individuals and influence well-being over time.

Participants. Due to the nature of intervention research, this study is subject to selection bias and social desirability. Program participation was voluntary and as such, our sample is only representative of teachers who were interested in exploring mindfulness practices. This may be particularly important given the examination of stress and well-being as outcomes of this study and that the intervention is advertised as a stress-reduction and wellness program. It may be that this study's sample of teachers consented to participate because of greater stress or negative emotions, or that teacher with the most stress were not interested. Therefore, this sample may not be truly representative of the greater teacher population. 


\section{MINDFULNESS AND MECHANISMS OF STRESS REDUCTION}

Similarly, it is difficult to parse out true intervention effects from response biases due to social desirability. Since participants were aware that the intervention focuses on the development of emotion regulation skills, their responses likely reflect a self-reported increase in such measures. In contrast, utilizing a behavioral measure of executive function helped to ameliorate this issue, however, the issue still stands because significant intervention effects were only found on self-report measures. As such, future research should consider employing additional behavioral cognitive tasks, physiological indicators of stress, and/or electroencephalography or fMRI technology in controlled laboratory settings to better determine neurological changes and plasticity related to somatic body awareness, executive function, and emotion regulation.

Likewise, we also had some teachers drop out of the program or migrate between groups throughout the study. Although these attrition issues do not impact the randomization of the study, it may impact study conclusions due to the potential for posttest nonequivalence. It may be that the teachers who left the program, or otherwise needed to adjust their group, are systematically different than those who completed the study. For instance, the demands of the eight-week program were too extensive for some teachers who were more burned out than the others who remained. Having those teachers systematically drop from the program would introduce bias between groups that the randomization component of the study could not control for. This possible attrition bias may be one explanation for why the imputed results of this study were in all cases different than the original listwise deleted data. 


\section{Implications}

This study informs the current field of mindfulness research and education by examining several potential underlying mechanisms that might explain the positive impact of mindfulness training on teachers' well-being. Specifically, results of this study have improved our understanding of the effects of the MBEB program on somatic body awareness, executive function, and emotion regulation. Despite only partial support for the stated hypotheses, this study is the first known to establish significant positive change in teachers' somatic body awareness following mindfulness training. Additionally, our finding that MBEB increased teachers' reappraisal abilities is consistent with previous research in teachers (Jennings et al., 2013). These findings are of stand-alone importance because increases in teachers' coping resources can positively impact their own wellbeing and the quality of their interactions with students.

Next, this study's application of the randomized controlled trial methodology allows causal claims to be made about the impact of mindfulness training on teachers' development of coping resources and well-being. Randomizing teachers to MBEB and waitlist control groups and ensuring these groups were similar at the start of the study allows us to determine with high confidence that the MBEB program is an effective intervention for teachers. Although it is still unclear whether the development of coping resources causes improved teacher well-being, this study demonstrates the potential of this path of inquiry and the need for further exploration of coping resources as mechanisms driving positive outcomes in teachers.

The use of mindfulness interventions as professional development programs for teachers may be particularly beneficial in generating whole-school and community-wide 
positive change. Specifically, this study and others examining mindfulness training in teacher samples have been celebrated for establishing multifaceted benefits for teachers and students. Unlike many other professional development programs, the MBEB program prioritizes teacher well-being first, with a "broaden and build" theoretical framework (see Fredrickson, 2001). In this framework, enhanced teacher well-being translates into more supportive interactions with students through a reduced need for teachers to utilize available coping resources to regulate their own stress. Thus, the positive impact of mindfulness interventions does not halt at improving teachers' personal experiences, but also translates into increased positive classroom interactions (Roeser et al., 2018).

\section{Conclusion}

In conclusion, this randomized controlled trial study tested the impact of the MBEB mindfulness intervention on teachers' development of several coping resources, namely, somatic body awareness, executive function, and emotion regulation (reappraisal and suppression). Also, this study examined whether positive development of these resources accounted for the decreases in teachers' anxiety, depression, stress, and burnout, that has been described previously (Roeser et al., 2013; 2018). Results of this project suggest that the MBEB program significantly improves teachers' somatic body awareness, with some evidence indicating improvements in teachers' reappraisal. However, there was not sufficient evidence to conclude that improvement in these coping resources explain teachers' reduction in anxiety, depression, stress, and burnout. Nevertheless, the effect of these coping resources on teacher well-being is promising, indicating that further research is needed in this area. Methodological limitations including the study's small sample size, reliability of several survey scales, and the 
validity of doing executive function tests in applied settings are some potential reasons these results were found. As such, future research endeavors should continue to explore these processes in tandem, as well continue to implement mindfulness programs to improve both the well-being of teacher participants and to create positive change in classrooms and schools. 
Table 1.

Sample Sizes by Intervention Group and Assessment Period

\begin{tabular}{lcccccc}
\hline & \multicolumn{4}{c}{ No. of Participants } \\
\cline { 2 - 3 } \cline { 5 - 6 } Study Phase & \multicolumn{2}{c}{ Cohort 1 } & & \multicolumn{2}{c}{ Cohort 2 } \\
\cline { 2 - 3 } \cline { 5 - 7 } Randomization $(n=58)$ & MBEB & WLC & & MBEB & WLC \\
Baseline Assessment $(n=55)$ & 13 & 15 & & 13 & 14 \\
Post-Intervention Assessment $(n=50)$ & 11 & 14 & & 12 & 13 \\
4-month Follow-up Assessment $(n=48)$ & 12 & 14 & & 11 & 11 \\
\hline
\end{tabular}

Note. $\mathrm{MBEB}=$ Treatment Group; WLC $=$ Control Group

Table 2.

Descriptive Statistics of Study Measures at Baseline, Post-intervention, and 4-month Follow-up

\begin{tabular}{lccccccc}
\hline & $\mathrm{N}$ & $\mathrm{M}$ & $\mathrm{SD}$ & $\mathrm{Min}$ & $\mathrm{Max}$ & Skew & Kurtosis \\
\hline Baseline & & & & & & & \\
$\quad$ Somatic Body Awareness & 54 & 2.92 & .70 & 1.11 & 4.44 & -.15 & -.17 \\
Executive Function & 41 & 54.19 & 36.13 & -8.62 & 175.76 & 1.20 & 2.84 \\
ER - Reappraisal & 54 & 3.35 & .87 & 1.33 & 4.67 & -.55 & -.61 \\
ER - Suppression & 54 & 2.26 & .67 & 1.00 & 4.00 & .31 & -.05 \\
Anxiety & 54 & 2.40 & .57 & 1.20 & 3.85 & .14 & -.08 \\
Depression & 54 & 1.53 & .39 & 1.00 & 2.67 & 1.12 & 1.20 \\
Stress & 54 & 3.43 & .54 & 2.00 & 4.57 & -.29 & -.14 \\
Burnout & 54 & 3.68 & .92 & 1.72 & 5.61 & .00 & -.63 \\
Post-intervention & & & & & & & \\
Somatic Body Awareness & 49 & 2.91 & .85 & 1.00 & 5.00 & .03 & .02 \\
Executive Function & 41 & 48.30 & 33.64 & -13.22 & 136.94 & .54 & .03 \\
ER - Reappraisal & 50 & 3.51 & .81 & 1.00 & 5.00 & -.96 & .92 \\
ER - Suppression & 50 & 2.37 & .71 & 1.00 & 4.00 & .54 & -.09 \\
4-month Follow-up & & & & & & & \\
Anxiety & 46 & 2.23 & .67 & 1.00 & 3.85 & .37 & -.53 \\
Depression & 46 & 1.47 & .45 & 1.00 & 2.92 & 1.31 & 1.39 \\
Stress & 46 & 3.32 & .65 & 1.71 & 4.71 & -.33 & .36 \\
Burnout & 46 & 3.43 & .98 & 1.17 & 5.78 & .04 & -.14 \\
\hline
\end{tabular}

Note. Descriptives prior to imputation; ER = Emotion Regulation. 
Table 3.

Pre-intervention Bivariate Correlations among Variables

\begin{tabular}{lcccccccr}
\hline & 1 & 2 & 3 & 4 & 5 & 6 & 7 & 8 \\
\hline 1. Somatic Body Awareness & - & & & & & & \\
2. Executive Function & -.12 & - & & & & & \\
3. ER - Reappraisal & .18 & -.18 & - & & & & \\
4. ER - Suppression & -.02 & .05 & -.13 & - & & & & \\
5. Anxiety & .03 & .08 & $-.57 * * *$ & .20 & - & & \\
6. Depression & -.12 & .09 & $-.55^{* * *}$ & .22 & $.65^{* * *}$ & - & & \\
7. Stress & .09 & .11 & -.19 & .05 & $.266^{\dagger}$ & .12 & - & \\
8. Burnout & .15 & .15 & $-.29 *$ & $.35 *$ & $.45^{* *}$ & $.30 *$ & $.53 * * *$ & - \\
\hline
\end{tabular}

Note. $n=37-55 ;{ }^{\dagger} \mathrm{p}<.10 .{ }^{*} \mathrm{p}<.05 . * * \mathrm{p}<.01 . * * * \mathrm{p}<.001 ; \mathrm{ER}=$ Emotion Regulation.

Table 4.

Characteristics of Teachers Assigned to MBEB and Waitlist Control Groups

\begin{tabular}{|c|c|c|c|c|c|}
\hline & \multirow[t]{2}{*}{$\begin{array}{l}\text { Total } \\
\text { Sample }\end{array}$} & \multirow[t]{2}{*}{ MBEB } & \multirow[t]{2}{*}{ WLC } & \multicolumn{2}{|c|}{$\begin{array}{l}\text { Test of Difference } \\
\text { Between Groups }\end{array}$} \\
\hline & & & & $\mathrm{t}$ & $d$ \\
\hline Sex (\% female) & $69 \%$ & $69 \%$ & $69 \%$ & .00 & .00 \\
\hline Ethnicity (\% White) & $82 \%$ & $79 \%$ & $85 \%$ & -.55 & -.16 \\
\hline $\begin{array}{l}\text { Level of Education } \\
\text { (\% Master's degree) }\end{array}$ & $96 \%$ & $96 \%$ & $96 \%$ & .08 & .00 \\
\hline $\begin{array}{l}\text { Mean Years of Age } \\
\text { (SD) }\end{array}$ & $\begin{array}{l}41.23 \\
(8.66)\end{array}$ & $\begin{array}{l}40.80 \\
(7.85)\end{array}$ & $\begin{array}{l}41.63 \\
(9.48)\end{array}$ & -.34 & -.10 \\
\hline $\begin{array}{l}\text { Mean Years of } \\
\text { Teaching Experience } \\
\text { (SD) }\end{array}$ & $\begin{array}{c}9.71 \\
(7.45)\end{array}$ & $\begin{array}{l}10.18 \\
(7.79)\end{array}$ & $\begin{array}{c}9.30 \\
(7.27)\end{array}$ & .42 & .12 \\
\hline $\begin{array}{l}\text { School structure } \\
(\% \mathrm{~K}-8)\end{array}$ & $60 \%$ & $66 \%$ & $55 \%$ & .80 & .23 \\
\hline
\end{tabular}

Note. $\mathrm{MBEB}=$ Treatment $(n=25-29)$, WLC $=$ Waitlist Control $(n=29)$;

No test statistic was significant at $p<.05$. 
Table 5.

Descriptive Statistics and Tests of Differences between Groups at Baseline

\begin{tabular}{|c|c|c|c|c|c|c|}
\hline & \multicolumn{2}{|c|}{ MBEB } & \multicolumn{2}{|c|}{ WLC } & \multicolumn{2}{|c|}{ Test of Difference } \\
\hline & M & SD & M & SD & $\mathrm{t}$ & $\mathrm{d}$ \\
\hline \multicolumn{7}{|l|}{ Mechanisms } \\
\hline Somatic Body Awareness & 2.83 & .65 & 3.00 & .75 & -.91 & -.26 \\
\hline Executive Function & 55.29 & 38.39 & 52.79 & 33.33 & .22 & .07 \\
\hline ER - Reappraisal & 3.35 & .81 & 3.36 & .93 & -.04 & -.01 \\
\hline ER - Suppression & 2.29 & .61 & 2.24 & .73 & .24 & .08 \\
\hline \multicolumn{7}{|l|}{ Well-being } \\
\hline Anxiety & 2.35 & .61 & 2.44 & .54 & -.54 & -.16 \\
\hline Depression & 1.56 & .46 & 1.50 & .33 & .58 & .15 \\
\hline Stress & 3.45 & .53 & 3.41 & .56 & .29 & .07 \\
\hline Burnout & 3.69 & .95 & 3.67 & .91 & .09 & .02 \\
\hline
\end{tabular}

Note. MBEB $=$ Treatment $(n=25)$, WLC $=$ Waitlist Control $(n=29)$; No test statistic was significant at $p<.05 ; \mathrm{ER}=$ Emotion Regulation.

Table 6.

Imputed Descriptive Statistics and Tests of Differences between Groups at Baseline

\begin{tabular}{|c|c|c|c|c|c|c|}
\hline & \multicolumn{2}{|c|}{ MBEB } & \multicolumn{2}{|c|}{ WLC } & \multicolumn{2}{|c|}{ Test of Difference } \\
\hline & M & SD & M & SD & $\mathrm{t}$ & $\mathrm{d}$ \\
\hline \multicolumn{7}{|l|}{ Mechanisms } \\
\hline Somatic Body Awareness & 2.84 & .68 & 3.00 & .75 & -.91 & -.23 \\
\hline Executive Function & 56.16 & 37.44 & 52.21 & 32.54 & .37 & .11 \\
\hline ER - Reappraisal & 3.36 & .81 & 3.36 & .93 & -.04 & .00 \\
\hline ER - Suppression & 2.32 & .63 & 2.24 & .73 & .24 & .12 \\
\hline \multicolumn{7}{|l|}{ Well-being } \\
\hline Anxiety & 2.36 & .63 & 2.44 & .54 & -.48 & -.14 \\
\hline Depression & 1.57 & .47 & 1.50 & .33 & .58 & .18 \\
\hline Stress & 3.45 & .54 & 3.41 & .56 & .29 & .07 \\
\hline Burnout & 3.66 & .94 & 3.67 & .91 & .09 & -.01 \\
\hline
\end{tabular}

Note. $\mathrm{MBEB}=$ Treatment $(n=29)$, WLC $=$ Waitlist Control $(n=29)$; ER = Emotion Regulation; No test statistic was significant at $p<.05$. 
Table 7.

Descriptive Statistics and Tests of Differences between Groups at Post-intervention

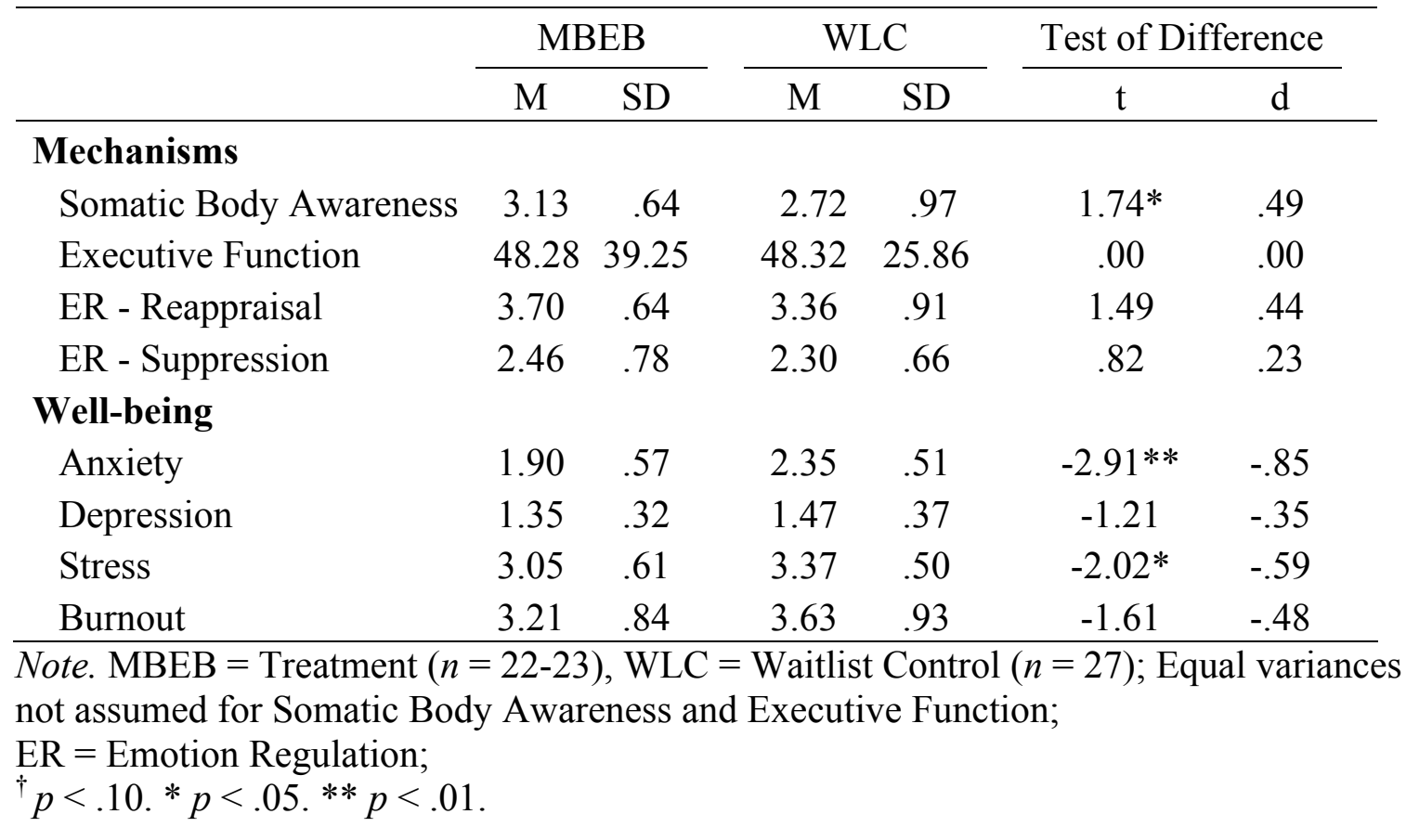

Table 8 .

Descriptive Statistics and Tests of Differences between Groups at 4-month Follow-up

\begin{tabular}{|c|c|c|c|c|c|c|}
\hline & \multicolumn{2}{|c|}{ MBEB } & \multicolumn{2}{|c|}{ WLC } & \multicolumn{2}{|c|}{ Test of Difference } \\
\hline & M & $\mathrm{SD}$ & $M$ & SD & $\mathrm{t}$ & $\mathrm{d}$ \\
\hline \multicolumn{7}{|l|}{ Mechanisms } \\
\hline Somatic Body Awareness & 2.98 & .67 & 3.11 & .79 & -.60 & -.18 \\
\hline Executive Function & 46.99 & 32.19 & 44.38 & 19.84 & .30 & .10 \\
\hline ER - Reappraisal & 3.55 & .71 & 3.28 & .89 & 1.16 & .34 \\
\hline ER - Suppression & 2.42 & .93 & 2.19 & .78 & .95 & .27 \\
\hline \multicolumn{7}{|l|}{ Well-being } \\
\hline Anxiety & 1.94 & .50 & 2.49 & .70 & $-3.03 * *$ & -.89 \\
\hline Depression & 1.37 & .50 & 1.57 & .40 & -1.46 & -.43 \\
\hline Stress & 3.17 & .74 & 3.47 & .52 & -1.65 & -.50 \\
\hline Burnout & 3.08 & .93 & 3.76 & .93 & $-2.51 *$ & -.74 \\
\hline
\end{tabular}

Note. $\mathrm{MBEB}=$ Treatment $(n=22-23), \mathrm{WLC}=$ Waitlist Control $(n=24-25)$;

$\mathrm{ER}=$ Emotion Regulation; ${ }^{\dagger} p<.10 .{ }^{*} p<.05 .{ }^{* *} p<.01$. 
Table 9.

Imputed Descriptive Statistics and Tests of Differences between Groups at Postintervention

\begin{tabular}{|c|c|c|c|c|c|c|}
\hline & \multicolumn{2}{|c|}{ MBEB } & \multicolumn{2}{|c|}{ WLC } & \multicolumn{2}{|c|}{ Test of Difference } \\
\hline & M & SD & M & SD & $\mathrm{t}$ & $\mathrm{d}$ \\
\hline \multicolumn{7}{|l|}{ Mechanisms } \\
\hline Somatic Body Awareness & 3.11 & .71 & 2.74 & .96 & $1.74 *$ & .45 \\
\hline Executive Function & 49.58 & 37.85 & 48.57 & 25.32 & .10 & .03 \\
\hline ER - Reappraisal & 3.66 & .71 & 3.36 & .92 & 1.49 & .37 \\
\hline ER - Suppression & 2.50 & .79 & 2.29 & .67 & .82 & .29 \\
\hline \multicolumn{7}{|l|}{ Well-being } \\
\hline Anxiety & 1.94 & .62 & 2.33 & .54 & $-2.27 *$ & -.68 \\
\hline Depression & 1.42 & .39 & 1.47 & .37 & -1.21 & -.13 \\
\hline Stress & 3.07 & .61 & 3.36 & .50 & $-2.02 *$ & -.53 \\
\hline Burnout & 3.32 & .84 & 3.61 & .93 & -1.61 & -.33 \\
\hline
\end{tabular}

Note. $\mathrm{MBEB}=$ Treatment $(n=29), \mathrm{WLC}=$ Waitlist Control $(n=29)$;

Equal variances not assumed for Somatic Body Awareness and Executive Function; $\mathrm{ER}=$ Emotion Regulation; ${ }^{\dagger} p<.10 .{ }^{*} p<.05 .{ }^{*} * p<.01$.

Table 10.

Imputed Descriptive Statistics and Tests of Differences between Groups at 4-month Follow-up

\begin{tabular}{|c|c|c|c|c|c|c|}
\hline & \multicolumn{2}{|c|}{ MBEB } & \multicolumn{2}{|c|}{ WLC } & \multicolumn{2}{|c|}{ Test of Difference } \\
\hline & $\mathrm{M}$ & SD & $\mathrm{M}$ & $\mathrm{SD}$ & $\mathrm{t}$ & $\mathrm{d}$ \\
\hline \multicolumn{7}{|l|}{ Mechanisms } \\
\hline Somatic Body Awareness & 2.99 & .69 & 3.15 & .81 & -.60 & -.22 \\
\hline Executive Function & 46.55 & 30.97 & 44.32 & 19.44 & .28 & .09 \\
\hline ER - Reappraisal & 3.60 & .71 & 3.30 & .89 & 1.16 & .38 \\
\hline ER - Suppression & 2.40 & .90 & 2.20 & .83 & .95 & .24 \\
\hline \multicolumn{7}{|l|}{ Well-being } \\
\hline Anxiety & 2.06 & .61 & 2.49 & .68 & $-2.21 *$ & -.68 \\
\hline Depression & 1.42 & .51 & 1.54 & .40 & -1.46 & -.27 \\
\hline Stress & 3.18 & .74 & 3.41 & .58 & -1.65 & -.35 \\
\hline Burnout & 3.15 & .95 & 3.67 & .94 & $-2.51 *$ & -.56 \\
\hline
\end{tabular}

Note. $\mathrm{MBEB}=$ Treatment $(n=29), \mathrm{WLC}=$ Waitlist Control $(n=29)$;

$\mathrm{ER}=$ Emotion Regulation; ${ }^{\dagger} p<.10 .{ }^{*} p<.05 .{ }^{* *} p<.01$. 
Table 11.

Regressions of Intervention Group Predicting Mechanisms at Post-intervention and 4month Follow-up

\begin{tabular}{|c|c|c|c|c|c|c|c|c|}
\hline & \multicolumn{4}{|c|}{ Post-intervention } & \multicolumn{4}{|c|}{ 4-month Follow-up } \\
\hline & $\mathrm{B}$ & $\mathrm{SE}$ & $\beta$ & $\mathrm{R}^{2}$ & $\mathrm{~B}$ & $\mathrm{SE}$ & $\beta$ & $\mathrm{R}^{2}$ \\
\hline Somatic Body Awareness & .50 & .22 & $.29 *$ & .29 & .07 & .18 & .05 & .34 \\
\hline Executive Function & -1.15 & 9.56 & -.02 & .23 & 1.81 & 7.94 & .03 & .18 \\
\hline ER - Reappraisal & .44 & .18 & $.27 *$ & .38 & .30 & .17 & $.18^{\dagger}$ & .56 \\
\hline ER - Suppression & .07 & .18 & .05 & .29 & .07 & .17 & .04 & .47 \\
\hline
\end{tabular}

Note. All regressions include the mean-centered baseline of the outcome as a covariate; $\mathrm{B}=$ the unstandardized beta estimate, $\beta=$ the standardized beta estimate;

$\mathrm{ER}=$ Emotion Regulation; ${ }^{\dagger} p<.10 .{ }^{*} p<.05$.

Table 12.

Imputed Regressions of Intervention Group Predicting Mechanisms at Post-intervention and 4-month Follow-up

\begin{tabular}{|c|c|c|c|c|c|c|c|c|}
\hline & \multicolumn{4}{|c|}{ Post-intervention } & \multicolumn{4}{|c|}{ 4-month Follow-up } \\
\hline & $\mathrm{B}$ & $\mathrm{SE}$ & $\beta$ & $\mathrm{R}^{2}$ & $\mathrm{~B}$ & $\mathrm{SE}$ & $\beta$ & $\mathrm{R}^{2}$ \\
\hline Somatic Body Awareness & .45 & .21 & $.26^{\dagger}$ & .21 & -.09 & .18 & -.06 & .18 \\
\hline Executive Function & -.71 & 9.01 & -.01 & .22 & 1.01 & 7.44 & .02 & .17 \\
\hline ER - Reappraisal & .30 & .19 & .18 & .25 & .29 & .17 & .18 & .39 \\
\hline ER - Suppression & .18 & .18 & .12 & .19 & .15 & .20 & .09 & .26 \\
\hline
\end{tabular}

Note. All regressions include the mean-centered baseline of the outcome as a covariate; $\mathrm{B}=$ the unstandardized beta estimate, $\beta=$ the standardized beta estimate;

$\mathrm{ER}=$ Emotion Regulation; ${ }^{\dagger} p<.10$. 
MINDFULNESS AND MECHANISMS OF STRESS REDUCTION

Table 13.

Intervention Group Predicting Anxiety Mediated by Somatic Body Awareness

\begin{tabular}{lcccccccc}
\hline Path & Effect & SE & $\begin{array}{c}\text { St. } \\
\text { Effect }\end{array}$ & $\begin{array}{c}\mathrm{t}- \\
\text { value }\end{array}$ & $\begin{array}{c}\mathrm{p}- \\
\text { value }\end{array}$ & BootLLCI & BootULCI & $\begin{array}{c}\text { Effect } \\
\text { Size }\end{array}$ \\
\hline Total effect (c) & -.55 & .16 & -.42 & -3.42 & .001 & & & -.82 \\
Direct effect (c') & -.48 & .16 & -.36 & -2.97 & .004 & & & -.72 \\
Group (a) & .40 & .22 & .24 & 1.82 & .07 & & & \\
$\begin{array}{l}\text { Somatic Body } \\
\text { Awareness (b) }\end{array}$ & -.17 & .16 & -.22 & -1.76 & .08 & & & \\
\hline $\begin{array}{l}\text { Total indirect } \\
\text { effect (ab) }\end{array}$ & -.06 & .07 & -.05 & & & -.25 & .05 & -.10 \\
\hline
\end{tabular}

Note. Percentile bootstrapping used; effect sizes calculated by dividing estimates by SD of outcome.

Table 14.

Intervention Group Predicting Depression Mediated by Somatic Body Awareness

\begin{tabular}{lcccccccc}
\hline Path & Effect & SE & $\begin{array}{c}\text { St. } \\
\text { Effect }\end{array}$ & $\begin{array}{c}\mathrm{t}- \\
\text { value }\end{array}$ & $\begin{array}{c}\mathrm{p}- \\
\text { value }\end{array}$ & BootLLCI & BootULCI & $\begin{array}{c}\text { Effect } \\
\text { Size }\end{array}$ \\
\hline Total effect (c) & -.19 & .12 & -.22 & -1.65 & .10 & & & -.43 \\
Direct effect (c') & -.14 & .12 & -.15 & -1.17 & .25 & & & -.30 \\
Group (a) & .40 & .22 & .24 & 1.82 & .07 & & & \\
Somatic Body & -.14 & .07 & -.26 & -2.02 & .048 & & & \\
Awareness (b) & -.06 & .04 & -.06 & & & -.16 & .01 & -.13 \\
\hline $\begin{array}{l}\text { Total indirect } \\
\text { effect (ab) }\end{array}$ & & & & & & & & \\
\hline
\end{tabular}

Note. Percentile bootstrapping used; effect sizes calculated by dividing estimates by SD of outcome.

Table 15

Intervention Group Predicting Stress Mediated by Somatic Body Awareness

\begin{tabular}{lcccccccc}
\hline Path & Effect & SE & $\begin{array}{c}\text { St. } \\
\text { Effect }\end{array}$ & $\begin{array}{c}\mathrm{t}- \\
\text { value }\end{array}$ & $\begin{array}{c}\mathrm{p}- \\
\text { value }\end{array}$ & BootLLCI & BootULCI & $\begin{array}{c}\text { Effect } \\
\text { Size }\end{array}$ \\
\hline Total effect (c) & -.30 & .17 & -.24 & -1.82 & .07 & & & -.47 \\
$\begin{array}{l}\text { Direct effect } \\
\text { (c') }\end{array}$ & -.23 & .17 & -.18 & -1.36 & .18 & & & -.35 \\
$\begin{array}{l}\text { Group (a) } \\
\text { Somatic Body }\end{array}$ & .40 & .22 & .24 & 1.82 & .07 & & & \\
Awareness (b) & -.19 & .10 & -.25 & -1.90 & .06 & & & \\
\hline $\begin{array}{l}\text { Total indirect } \\
\text { effect (ab) }\end{array}$ & -.08 & .08 & -.06 & & & -.27 & .02 & -.12 \\
\hline
\end{tabular}

Note. Percentile bootstrapping used; effect sizes calculated by dividing estimates by SD of outcome. 
MINDFULNESS AND MECHANISMS OF STRESS REDUCTION

Table 16.

Intervention Group Predicting Burnout Mediated by Somatic Body Awareness

\begin{tabular}{|c|c|c|c|c|c|c|c|c|}
\hline Path & Effect & $\mathrm{SE}$ & $\begin{array}{c}\text { St. } \\
\text { Effect }\end{array}$ & $\begin{array}{c}\text { t- } \\
\text { value }\end{array}$ & $\begin{array}{c}\mathrm{p}- \\
\text { value }\end{array}$ & BootLLCI & BootULCI & $\begin{array}{c}\text { Effect } \\
\text { Size }\end{array}$ \\
\hline Total effect (c) & -.69 & .24 & -.35 & -2.83 & .006 & & & -.71 \\
\hline Direct effect (c’) & -.65 & .25 & -.34 & -2.59 & .01 & & & -.67 \\
\hline Group (a) & .40 & .22 & .24 & 1.82 & .07 & & & \\
\hline $\begin{array}{l}\text { Somatic Body } \\
\text { Awareness (b) }\end{array}$ & -.09 & .15 & -.08 & -.61 & .55 & & & \\
\hline $\begin{array}{l}\text { Total indirect } \\
\text { effect }(\mathrm{ab})\end{array}$ & -.04 & .11 & -.02 & & & -.29 & .18 & -.04 \\
\hline
\end{tabular}

Note. Percentile bootstrapping used; effect sizes calculated by dividing estimates by SD of outcome.

Table 17.

Intervention Group Predicting Anxiety Mediated by Executive Function

\begin{tabular}{lccccccc}
\hline Path & Effect & SE & $\begin{array}{c}\text { St. } \\
\text { Effect }\end{array}$ & $\begin{array}{c}\text { t- } \\
\text { value }\end{array}$ & $\begin{array}{c}\text { p- } \\
\text { value }\end{array}$ & BootLLCI & $\begin{array}{c}\text { BootULCI } \\
\text { Effect } \\
\text { Size }\end{array}$ \\
\hline Total effect (c) & -.57 & .20 & -.41 & -2.82 & .007 & & -.82 \\
Direct effect (c') & -.57 & .20 & -.41 & -2.82 & .008 & & -.82 \\
Group (a) & -.04 & 10.72 & .00 & .00 & .99 & & \\
$\begin{array}{l}\text { Executive } \\
\text { Function (b) }\end{array}$ & .00 & .00 & .14 & .94 & .35 & & \\
\hline $\begin{array}{l}\text { Total indirect } \\
\text { effect (ab) }\end{array}$ & .00 & .05 & .00 & & & -.10 & .09 \\
\hline
\end{tabular}

Note. Percentile bootstrapping used; effect sizes calculated by dividing estimates by SD of outcome.

Table 18.

Intervention Group Predicting Depression Mediated by Executive Function

\begin{tabular}{lcccccccc}
\hline Path & Effect & SE & $\begin{array}{c}\text { St. } \\
\text { Effect }\end{array}$ & $\begin{array}{c}\mathrm{t}- \\
\text { value }\end{array}$ & $\begin{array}{c}\mathrm{p}- \\
\text { value }\end{array}$ & BootLLCI & BootULCI & $\begin{array}{c}\text { Effect } \\
\text { Size }\end{array}$ \\
\hline Total effect (c) & -.15 & .15 & -.16 & -1.00 & .32 & & -.33 \\
Direct effect (c') & -.15 & .15 & -.16 & -1.00 & .33 & & -.32 \\
Group (a) & -.04 & 10.72 & .00 & .00 & .99 & & \\
Executive & .00 & .00 & .09 & .59 & .56 & & & \\
Function (b) & .00 & .03 & .00 & & & -.07 & .04 & -.01 \\
\hline $\begin{array}{l}\text { Total indirect } \\
\text { effect (ab) }\end{array}$ & .00 & & & & & \\
\hline
\end{tabular}

Note. Percentile bootstrapping used; effect sizes calculated by dividing estimates by SD of outcome. 
MINDFULNESS AND MECHANISMS OF STRESS REDUCTION

Table 19.

Intervention Group Predicting Stress Mediated by Executive Function

\begin{tabular}{|c|c|c|c|c|c|c|c|c|}
\hline Path & Effect & SE & $\begin{array}{c}\text { St. } \\
\text { Effect }\end{array}$ & $\begin{array}{c}\mathrm{t}- \\
\text { value }\end{array}$ & $\begin{array}{c}\mathrm{p}- \\
\text { value }\end{array}$ & BootLLCI & BootULCI & $\begin{array}{c}\text { Effect } \\
\text { Size }\end{array}$ \\
\hline Total effect (c) & -.35 & .21 & -.25 & -1.63 & .11 & & & -.52 \\
\hline Direct effect (c') & -.35 & .22 & -.25 & -1.61 & .12 & & & -.50 \\
\hline Group (a) & -.04 & 10.72 & .00 & .00 & .99 & & & \\
\hline $\begin{array}{l}\text { Executive } \\
\text { Function (b) }\end{array}$ & .00 & .00 & -.05 & -.29 & .77 & & & \\
\hline $\begin{array}{l}\text { Total indirect } \\
\text { effect }(\mathrm{ab})\end{array}$ & .00 & .05 & .00 & & & -.15 & .06 & -.02 \\
\hline
\end{tabular}

Note. Percentile bootstrapping used; effect sizes calculated by dividing estimates by SD of outcome.

Table 20 .

Intervention Group Predicting Burnout Mediated by Executive Function

\begin{tabular}{lcccccccc}
\hline Path & Effect & SE & $\begin{array}{c}\text { St. } \\
\text { Effect }\end{array}$ & $\begin{array}{c}\mathrm{t}- \\
\text { value }\end{array}$ & $\begin{array}{c}\mathrm{p}- \\
\text { value }\end{array}$ & BootLLCI & BootULCI & $\begin{array}{c}\text { Effect } \\
\text { Size }\end{array}$ \\
\hline Total effect (c) & -.51 & .29 & -.28 & -1.79 & .08 & & -.57 \\
Direct effect (c') & -.51 & .29 & -.28 & -1.79 & .08 & & -.55 \\
Group (a) & -.04 & 10.72 & .00 & .00 & .99 & & \\
Executive & .00 & .00 & .17 & 1.09 & .29 & & & \\
Function (b) & .00 & .08 & .00 & & & -.21 & .13 & -.02 \\
\hline $\begin{array}{l}\text { Total indirect } \\
\text { effect (ab) }\end{array}$ & & & & & & \\
\hline
\end{tabular}

Note. Percentile bootstrapping used; effect sizes calculated by dividing estimates by SD of outcome.

Table 21.

Intervention Group Predicting Anxiety Mediated by Reappraisal

\begin{tabular}{|c|c|c|c|c|c|c|c|c|}
\hline Path & Effect & $\mathrm{SE}$ & $\begin{array}{c}\text { St. } \\
\text { Effect }\end{array}$ & $\begin{array}{c}\text { t- } \\
\text { value }\end{array}$ & $\begin{array}{c}\mathrm{p}- \\
\text { value }\end{array}$ & BootLLCI & BootULCI & $\begin{array}{c}\text { Effect } \\
\text { Size }\end{array}$ \\
\hline Total effect (c) & -.55 & .16 & -.42 & -3.42 & .001 & & & -.82 \\
\hline Direct effect (c') & -.44 & .15 & -.33 & -2.93 & .005 & & & -.66 \\
\hline Group (a) & .34 & .21 & .21 & 1.61 & .11 & & & \\
\hline $\begin{array}{l}\text { ER - Reappraisal } \\
\text { (b) }\end{array}$ & -.32 & .09 & -.39 & -3.40 & .001 & & & \\
\hline $\begin{array}{l}\text { Total indirect } \\
\text { effect }(\mathrm{ab})\end{array}$ & -.11 & .08 & -.08 & & & -.27 & .03 & -.16 \\
\hline
\end{tabular}

Note. Percentile bootstrapping used; effect sizes calculated by dividing estimates by SD of outcome. 
MINDFULNESS AND MECHANISMS OF STRESS REDUCTION

Table 22 .

Intervention Group Predicting Depression Mediated by Reappraisal

\begin{tabular}{lcccccccc}
\hline Path & Effect & SE & $\begin{array}{c}\text { St. } \\
\text { Effect }\end{array}$ & $\begin{array}{c}\mathrm{t}- \\
\text { value }\end{array}$ & $\begin{array}{c}\mathrm{p}- \\
\text { value }\end{array}$ & BootLLCI & BootULCI & $\begin{array}{c}\text { Effect } \\
\text { Size }\end{array}$ \\
\hline Total effect (c) & -.19 & .12 & -.22 & -1.65 & .10 & & & -.43 \\
Direct effect (c') & -.13 & .11 & -.15 & -1.16 & .25 & & & -.29 \\
Group (a) & .34 & .21 & .21 & 1.61 & .11 & & & \\
ER - Reappraisal (b) & -.18 & .07 & -.33 & -2.56 & .01 & & & -.14 \\
\hline $\begin{array}{l}\text { Total indirect effect } \\
\text { (ab) }\end{array}$ & -.06 & .05 & -.07 & & & -.17 & .01 & \\
\hline Note. Percentile bootstrapping used; effect sizes calculated by dividing estimates by SD of outcome.
\end{tabular}

Table 23.

Intervention Group Predicting Stress Mediated by Reappraisal

\begin{tabular}{lcccccccc}
\hline Path & Effect & SE & $\begin{array}{c}\text { St. } \\
\text { Effect }\end{array}$ & $\begin{array}{c}\mathrm{t}- \\
\text { value }\end{array}$ & $\begin{array}{c}\mathrm{p}- \\
\text { value }\end{array}$ & BootLLCI & BootULCI & $\begin{array}{c}\text { Effect } \\
\text { Size }\end{array}$ \\
\hline Total effect (c) & -.30 & .17 & -.24 & -1.82 & .07 & & & -.48 \\
Direct effect (c') & -.24 & .17 & -.19 & -1.45 & .15 & & & -.38 \\
Group (a) & .34 & .21 & .21 & 1.61 & .11 & & & \\
ER - Reappraisal (b) & -.18 & .10 & -.22 & -1.69 & .09 & & & \\
\hline $\begin{array}{l}\text { Total indirect effect } \\
\text { (ab) }\end{array}$ & -.06 & .07 & -.05 & & & -.23 & .03 & -.10 \\
\hline
\end{tabular}

Note. Percentile bootstrapping used; effect sizes calculated by dividing estimates by SD of outcome.

Table 24

Intervention Group Predicting Burnout Mediated by Reappraisal

\begin{tabular}{lcccccccc}
\hline Path & Effect & SE & $\begin{array}{c}\text { St. } \\
\text { Effect }\end{array}$ & $\begin{array}{c}\mathrm{t}- \\
\text { value }\end{array}$ & $\begin{array}{c}\mathrm{p}- \\
\text { value }\end{array}$ & BootLLCI & BootULCI & $\begin{array}{c}\text { Effect } \\
\text { Size }\end{array}$ \\
\hline Total effect (c) & -.69 & .24 & -.35 & -2.83 & .006 & & & -.70 \\
Direct effect (c') & -.52 & .23 & -.27 & -2.29 & .03 & & & -.53 \\
Group (a) & .34 & .21 & .21 & 1.61 & .11 & & & \\
ER - Reappraisal (b) & -.51 & .14 & -.42 & -3.66 & .0006 & & & -.17 \\
\hline $\begin{array}{l}\text { Total indirect effect } \\
\text { (ab) }\end{array}$ & -.17 & .13 & -.09 & & & -.46 & .04 & \\
\hline Note. Percentile bootstrapping used; effect sizes calculated by dividing estimates by SD of outcome.
\end{tabular}


MINDFULNESS AND MECHANISMS OF STRESS REDUCTION

Table 25 .

Intervention Group Predicting Anxiety Mediated by Suppression

\begin{tabular}{lcccccccc}
\hline Path & Effect & SE & $\begin{array}{c}\text { St. } \\
\text { Effect }\end{array}$ & $\begin{array}{c}\mathrm{t}- \\
\text { value }\end{array}$ & $\begin{array}{c}\mathrm{p}- \\
\text { value }\end{array}$ & BootLLCI & BootULCI & $\begin{array}{c}\text { Effect } \\
\text { Size }\end{array}$ \\
\hline Total effect (c) & -.55 & .16 & -.42 & -3.42 & .001 & & & -.82 \\
Direct effect (c') & -.55 & .16 & -.42 & -3.37 & .001 & & & -.82 \\
Group (a) & .17 & .19 & .12 & .89 & .38 & & & \\
ER - Suppression (b) & .00 & .12 & .00 & .02 & .98 & & & \\
\hline $\begin{array}{l}\text { Total indirect effect } \\
\text { (ab) }\end{array}$ & .00 & .04 & .00 & & & -.09 & .07 & -.01
\end{tabular}

Note. Percentile bootstrapping used; effect sizes calculated by dividing estimates by SD of outcome.

Table 26.

Intervention Group Predicting Depression Mediated by Suppression

\begin{tabular}{lcccccccc}
\hline Path & Effect & SE & $\begin{array}{c}\text { St. } \\
\text { Effect }\end{array}$ & $\begin{array}{c}\mathrm{t}- \\
\text { value }\end{array}$ & $\begin{array}{c}\mathrm{p}- \\
\text { value }\end{array}$ & BootLLCI & BootULCI & $\begin{array}{c}\text { Effect } \\
\text { Size }\end{array}$ \\
\hline Total effect (c) & -.19 & .12 & -.22 & -1.65 & .10 & & -.43 \\
Direct effect (c') & -.22 & .11 & -.25 & -1.93 & .06 & & -.49 \\
Group (a) & .17 & .19 & .12 & .89 & .38 & & \\
ER - Suppression (b) & .17 & .08 & .26 & 2.07 & .04 & & & \\
\hline Total indirect effect & .03 & .05 & .03 & & & -.05 & .15 & .06 \\
(ab) & & & & & & \\
\hline
\end{tabular}

Note. Percentile bootstrapping used; effect sizes calculated by dividing estimates by SD of outcome.

Table 27.

Intervention Group Predicting Stress Mediated by Suppression

\begin{tabular}{lcccccccc}
\hline Path & Effect & SE & $\begin{array}{c}\text { St. } \\
\text { Effect }\end{array}$ & $\begin{array}{c}\mathrm{t}- \\
\text { value }\end{array}$ & $\begin{array}{c}\mathrm{p}- \\
\text { value }\end{array}$ & BootLLCI & BootULCI & $\begin{array}{c}\text { Effect } \\
\text { Size }\end{array}$ \\
\hline Total effect (c) & -.30 & .17 & -.24 & -1.82 & .07 & & -.46 \\
Direct effect (c') & -.30 & .17 & -.24 & -1.79 & .08 & & -.47 \\
Group (a) & .17 & .19 & .12 & .89 & .38 & & \\
ER - Suppression (b) & .00 & .12 & .00 & .03 & .98 & & & .01 \\
\hline Total indirect effect & .00 & .04 & .00 & & & \multirow{2}{*}{-.07} & .09 & .07 \\
(ab) & & & & & & \\
\hline
\end{tabular}

Note. Percentile bootstrapping used; effect sizes calculated by dividing estimates by SD of outcome. 
MINDFULNESS AND MECHANISMS OF STRESS REDUCTION

Table 28.

Intervention Group Predicting Burnout Mediated by Suppression

\begin{tabular}{lcccccccc}
\hline Path & Effect & SE & $\begin{array}{c}\text { St. } \\
\text { Effect }\end{array}$ & $\begin{array}{c}\mathrm{t}- \\
\text { value }\end{array}$ & $\begin{array}{c}\mathrm{p}- \\
\text { value }\end{array}$ & BootLLCI & BootULCI & $\begin{array}{c}\text { Effect } \\
\text { Size }\end{array}$ \\
\hline Total effect (c) & -.69 & .24 & -.35 & -2.83 & .006 & & & -.71 \\
Direct effect (c') & -.73 & .24 & -.37 & -3.00 & .004 & & & -.74 \\
Group (a) & .17 & .19 & .12 & .89 & .38 & & & \\
ER - Suppression (b) & .24 & .17 & .17 & 1.40 & .17 & & & .03 \\
\hline $\begin{array}{l}\text { Total indirect effect } \\
\text { (ab) }\end{array}$ & .04 & .08 & .02 & & & -.11 & .22 & .03 \\
\hline Note. Percentile bootstrapping used; effect sizes calculated by dividing estimates by SD of outcome.
\end{tabular}

Table 29.

Imputed Intervention Group Predicting Anxiety Mediated by Somatic Body Awareness

\begin{tabular}{lcccccccc}
\hline Path & Effect & SE & $\begin{array}{c}\text { St. } \\
\text { Effect }\end{array}$ & $\begin{array}{c}\mathrm{t}- \\
\text { value }\end{array}$ & $\begin{array}{c}\mathrm{p}- \\
\text { value }\end{array}$ & BootLLCI & BootULCI & $\begin{array}{c}\text { Effect } \\
\text { Size }\end{array}$ \\
\hline Total effect (c) & -.42 & .17 & -.32 & -2.55 & .03 & & & -.63 \\
Direct effect (c') & -.40 & .17 & -.30 & -2.31 & .04 & & & -.59 \\
Group (a) & .37 & .22 & .22 & 1.68 & .13 & & & \\
Somatic Body & -.08 & .10 & -.10 & -.78 & .51 & & & \\
Awareness (b) & -.03 & .06 & -.02 & & & -.16 & .07 & -.04 \\
\hline $\begin{array}{l}\text { Total indirect effect } \\
\text { (ab) }\end{array}$ & & & & & & & \\
\hline
\end{tabular}

Note. Percentile bootstrapping used; effect sizes calculated by dividing estimates by SD of outcome.

Table 30 .

Imputed Intervention Group Predicting Depression Mediated by Somatic Body Awareness

\begin{tabular}{lcccccccc}
\hline Path & Effect & SE & $\begin{array}{c}\text { St. } \\
\text { Effect }\end{array}$ & $\begin{array}{c}\mathrm{t}- \\
\text { value }\end{array}$ & $\begin{array}{c}\mathrm{p}- \\
\text { value }\end{array}$ & BootLLCI & BootULCI & $\begin{array}{c}\text { Effect } \\
\text { Size }\end{array}$ \\
\hline Total effect (c) & -.12 & .12 & -.13 & -.97 & .36 & & -.25 \\
Direct effect (c') & -.08 & .12 & -.09 & -.64 & .54 & & -.17 \\
Group (a) & .37 & .22 & .22 & 1.68 & .13 & & \\
Somatic Body & -.10 & .07 & -.18 & -1.37 & .22 & & & \\
Awareness (b) & -.04 & .04 & -.04 & & & -.12 & .01 & -.09 \\
\hline $\begin{array}{l}\text { Total indirect effect } \\
\text { (ab) }\end{array}$ & & & & & & \\
\hline
\end{tabular}

Note. Percentile bootstrapping used; effect sizes calculated by dividing estimates by SD of outcome. 
MINDFULNESS AND MECHANISMS OF STRESS REDUCTION

Table 31.

Imputed Intervention Group Predicting Stress Mediated by Somatic Body Awareness

\begin{tabular}{lcccccccc}
\hline Path & Effect & SE & $\begin{array}{c}\text { St. } \\
\text { Effect }\end{array}$ & $\begin{array}{c}\mathrm{t}- \\
\text { value }\end{array}$ & $\begin{array}{c}\mathrm{p}- \\
\text { value }\end{array}$ & BootLLCI & BootULCI & $\begin{array}{c}\text { Effect } \\
\text { Size }\end{array}$ \\
\hline Total effect (c) & -.23 & .18 & -.18 & -1.34 & .20 & & & -.35 \\
Direct effect (c') & -.19 & .18 & -.14 & -1.03 & .34 & & & -.28 \\
Group (a) & .37 & .22 & .22 & 1.68 & .13 & & & \\
Somatic Body & -.12 & .11 & -.16 & -1.19 & .32 & & & \\
Awareness (b) & -.04 & .06 & -.04 & & & -.18 & .04 & -.07 \\
\hline $\begin{array}{l}\text { Total indirect effect } \\
\text { (ab) }\end{array}$ & & & & & & & & \\
\hline
\end{tabular}

Note. Percentile bootstrapping used; effect sizes calculated by dividing estimates by SD of outcome.

Table 32.

Imputed Intervention Group Predicting Burnout Mediated by Somatic Body Awareness

\begin{tabular}{lcccccccc}
\hline Path & Effect & SE & $\begin{array}{c}\text { St. } \\
\text { Effect }\end{array}$ & $\begin{array}{c}\mathrm{t}- \\
\text { value }\end{array}$ & $\begin{array}{c}\mathrm{p}- \\
\text { value }\end{array}$ & BootLLCI & BootULCI & $\begin{array}{c}\text { Effect } \\
\text { Size }\end{array}$ \\
\hline Total effect (c) & -.52 & .25 & -.27 & -2.10 & .05 & & -.54 \\
Direct effect (c') & -.50 & .26 & -.26 & -1.95 & .07 & & -.51 \\
Group (a) & .37 & .22 & .22 & 1.68 & .13 & & \\
Somatic Body & -.05 & .15 & -.05 & -.35 & .64 & & \\
Awareness (b) & -.02 & .08 & -.01 & & & -.20 & .13 & -.02 \\
\hline $\begin{array}{l}\text { Total indirect effect } \\
\text { (ab) }\end{array}$ & & & & & \\
\hline
\end{tabular}

Note. Percentile bootstrapping used; effect sizes calculated by dividing estimates by SD of outcome.

Table 33.

Imputed Intervention Group Predicting Anxiety Mediated by Executive Function

\begin{tabular}{|c|c|c|c|c|c|c|c|c|}
\hline Path & Effect & $\mathrm{SE}$ & $\begin{array}{c}\text { St. } \\
\text { Effect }\end{array}$ & $\begin{array}{c}\text { t- } \\
\text { value }\end{array}$ & $\begin{array}{c}\text { p- } \\
\text { value }\end{array}$ & BootLLCI & BootULCI & $\begin{array}{l}\text { Effect } \\
\text { Size }\end{array}$ \\
\hline Total effect (c) & -.48 & .20 & -.35 & -2.45 & .045 & & & -.69 \\
\hline Direct effect (c') & -.48 & .20 & -.35 & -2.46 & .04 & & & -.70 \\
\hline Group (a) & 1.01 & 10.05 & .02 & .10 & .92 & & & \\
\hline $\begin{array}{l}\text { Executive Function } \\
\text { (b) }\end{array}$ & .00 & .00 & .12 & .87 & .39 & & & \\
\hline $\begin{array}{l}\text { Total indirect effect } \\
(\mathrm{ab})\end{array}$ & .00 & .04 & .00 & & & -.08 & .10 & .01 \\
\hline
\end{tabular}

Note. Percentile bootstrapping used; effect sizes calculated by dividing estimates by SD of outcome. 
MINDFULNESS AND MECHANISMS OF STRESS REDUCTION

Table 34.

Imputed Intervention Group Predicting Depression Mediated by Executive Function

\begin{tabular}{lcccccccc}
\hline Path & Effect & SE & $\begin{array}{c}\text { St. } \\
\text { Effect }\end{array}$ & $\begin{array}{c}\mathrm{t}- \\
\text { value }\end{array}$ & $\begin{array}{c}\mathrm{p}- \\
\text { value }\end{array}$ & BootLLCI & BootULCI & $\begin{array}{c}\text { Effect } \\
\text { Size }\end{array}$ \\
\hline Total effect (c) & -.09 & .14 & -.10 & -.63 & .55 & & & -.19 \\
Direct effect (c') & -.09 & .14 & -.10 & -.64 & .54 & & & -.19 \\
Group (a) & 1.01 & 10.05 & .02 & .10 & .92 & & & \\
$\begin{array}{l}\text { Executive Function } \\
\text { (b) }\end{array}$ & .00 & .00 & .09 & .60 & .59 & & & \\
\hline $\begin{array}{l}\text { Total indirect effect } \\
\text { (ab) }\end{array}$ & .00 & .02 & .00 & & & -.06 & .04 & -.01 \\
\hline
\end{tabular}

Note. Percentile bootstrapping used; effect sizes calculated by dividing estimates by SD of outcome.

Table 35 .

Imputed Intervention Group Predicting Stress Mediated by Executive Function

\begin{tabular}{lcccccccc}
\hline Path & Effect & SE & $\begin{array}{c}\text { St. } \\
\text { Effect }\end{array}$ & $\begin{array}{c}\mathrm{t}- \\
\text { value }\end{array}$ & $\begin{array}{c}\mathrm{p}- \\
\text { value }\end{array}$ & BootLLCI & BootULCI & $\begin{array}{c}\text { Effect } \\
\text { Size }\end{array}$ \\
\hline Total effect (c) & -.34 & .21 & -.24 & -1.63 & .12 & & & -.34 \\
Direct effect (c') & -.34 & .21 & -.24 & -1.61 & .13 & & & -.34 \\
Group (a) & 1.01 & 10.05 & .02 & .10 & .92 & & & \\
$\begin{array}{l}\text { Executive Function } \\
\text { (b) }\end{array}$ & .00 & .00 & -.05 & -.31 & .76 & & & \\
\hline $\begin{array}{l}\text { Total indirect effect } \\
\text { (ab) }\end{array}$ & -.01 & .04 & .00 & & & -.12 & .06 & -.01 \\
\hline
\end{tabular}

Note. Percentile bootstrapping used; effect sizes calculated by dividing estimates by SD of outcome.

Table 36.

Imputed Intervention Group Predicting Burnout Mediated by Executive Function

\begin{tabular}{|c|c|c|c|c|c|c|c|c|}
\hline Path & Effect & SE & $\begin{array}{c}\text { St. } \\
\text { Effect }\end{array}$ & $\begin{array}{c}\text { t- } \\
\text { value }\end{array}$ & $\begin{array}{c}\mathrm{p}- \\
\text { value }\end{array}$ & BootLLCI & BootULCI & $\begin{array}{c}\text { Effect } \\
\text { Size }\end{array}$ \\
\hline Total effect (c) & -.40 & .28 & -.21 & -1.41 & .19 & & & -.26 \\
\hline Direct effect (c') & -.40 & .28 & -.21 & -1.43 & .19 & & & -.26 \\
\hline Group (a) & 1.01 & 10.05 & .02 & .10 & .92 & & & \\
\hline $\begin{array}{l}\text { Executive Function } \\
\text { (b) }\end{array}$ & .00 & .00 & .16 & 1.09 & .30 & & & \\
\hline $\begin{array}{l}\text { Total indirect effect } \\
(\mathrm{ab})\end{array}$ & -.01 & .07 & .00 & & & -.17 & .12 & -.01 \\
\hline
\end{tabular}

Note. Percentile bootstrapping used; effect sizes calculated by dividing estimates by SD of outcome. 
MINDFULNESS AND MECHANISMS OF STRESS REDUCTION

Table 37.

Imputed Intervention Group Predicting Anxiety Mediated by Reappraisal

\begin{tabular}{lcccccccc}
\hline Path & Effect & SE & $\begin{array}{c}\text { St. } \\
\text { Effect }\end{array}$ & $\begin{array}{c}\mathrm{t}- \\
\text { value }\end{array}$ & $\begin{array}{c}\mathrm{p}- \\
\text { value }\end{array}$ & BootLLCI & BootULCI & $\begin{array}{c}\text { Effect } \\
\text { Size }\end{array}$ \\
\hline Total effect (c) & -.43 & .17 & -.32 & -2.55 & .03 & & & -.63 \\
Direct effect (c') & -.35 & .17 & -.27 & -2.16 & .06 & & & -.52 \\
Group (a) & .30 & .21 & .18 & 1.41 & .19 & & & \\
ER - Reappraisal (b) & -.25 & .10 & -.30 & -2.42 & .04 & & & \\
\hline $\begin{array}{l}\text { Total indirect effect } \\
\text { (ab) }\end{array}$ & -.07 & .06 & -.05 & & & -.21 & \multirow{2}{*}{.03} & -.11 \\
\hline
\end{tabular}

Note. Percentile bootstrapping used; effect sizes calculated by dividing estimates by SD of outcome.

Table 38.

Imputed Intervention Group Predicting Depression Mediated by Reappraisal

\begin{tabular}{lcccccccc}
\hline Path & Effect & SE & $\begin{array}{c}\text { St. } \\
\text { Effect }\end{array}$ & $\begin{array}{c}\mathrm{t}- \\
\text { value }\end{array}$ & $\begin{array}{c}\mathrm{p}- \\
\text { value }\end{array}$ & BootLLCI & BootULCI & $\begin{array}{c}\text { Effect } \\
\text { Size }\end{array}$ \\
\hline Total effect (c) & -.11 & .12 & -.13 & -.97 & .36 & & & -.25 \\
Direct effect (c') & -.07 & .12 & -.08 & -.64 & .54 & & & -.16 \\
Group (a) & .30 & .21 & .18 & 1.41 & .19 & & & \\
ER - Reappraisal (b) & -.15 & .07 & -.26 & -2.00 & .13 & & & \\
\hline Total indirect effect & -.04 & .04 & -.05 & & & -.14 & .02 & -.09 \\
(ab) & & & & & & & & \\
\hline
\end{tabular}

Note. Percentile bootstrapping used; effect sizes calculated by dividing estimates by SD of outcome.

Table 39.

Imputed Intervention Group Predicting Stress Mediated by Reappraisal

\begin{tabular}{lcccccccc}
\hline Path & Effect & SE & $\begin{array}{c}\text { St. } \\
\text { Effect }\end{array}$ & $\begin{array}{c}\mathrm{t}- \\
\text { value }\end{array}$ & $\begin{array}{c}\mathrm{p}- \\
\text { value }\end{array}$ & BootLLCI & BootULCI & $\begin{array}{c}\text { Effect } \\
\text { Size }\end{array}$ \\
\hline Total effect (c) & -.23 & .18 & -.18 & -1.34 & .20 & & & -.35 \\
Direct effect (c') & -.20 & .18 & -.15 & -1.14 & .28 & & & -.30 \\
Group (a) & .30 & .21 & .18 & 1.41 & .19 & & & \\
ER - Reappraisal (b) & -.10 & .11 & -.12 & -.90 & .44 & & & \\
\hline $\begin{array}{l}\text { Total indirect effect } \\
\text { (ab) }\end{array}$ & -.03 & .05 & -.02 & & & -.15 & .05 & -.05 \\
\hline
\end{tabular}

Note. Percentile bootstrapping used; effect sizes calculated by dividing estimates by SD of outcome. 
MINDFULNESS AND MECHANISMS OF STRESS REDUCTION

Table 40.

Imputed Intervention Group Predicting Burnout Mediated by Reappraisal

\begin{tabular}{lcccccccc}
\hline Path & Effect & SE & $\begin{array}{c}\text { St. } \\
\text { Effect }\end{array}$ & $\begin{array}{c}\mathrm{t}- \\
\text { value }\end{array}$ & $\begin{array}{c}\mathrm{p}- \\
\text { value }\end{array}$ & BootLLCI & BootULCI & $\begin{array}{c}\text { Effect } \\
\text { Size }\end{array}$ \\
\hline Total effect (c) & -.52 & .25 & -.27 & -2.10 & .05 & & & -.28 \\
Direct effect (c') & -.41 & .24 & -.21 & -1.70 & .12 & & & -.22 \\
Group (a) & .30 & .21 & .18 & 1.41 & .19 & & & \\
ER - Reappraisal (b) & -.36 & .15 & -.31 & -2.47 & .03 & & & \\
\hline $\begin{array}{l}\text { Total indirect effect } \\
\text { (ab) }\end{array}$ & -.11 & .10 & -.06 & & & -.33 & \multirow{2}{*}{.04} & -.06
\end{tabular}

Note. Percentile bootstrapping used; effect sizes calculated by dividing estimates by SD of outcome.

Table 41.

Imputed Intervention Group Predicting Anxiety Mediated by Suppression

\begin{tabular}{lcccccccc}
\hline Path & Effect & SE & $\begin{array}{c}\text { St. } \\
\text { Effect }\end{array}$ & $\begin{array}{c}\mathrm{t}- \\
\text { value }\end{array}$ & $\begin{array}{c}\mathrm{p}- \\
\text { value }\end{array}$ & BootLLCI & BootULCI & $\begin{array}{c}\text { Effect } \\
\text { Size }\end{array}$ \\
\hline Total effect (c) & -.43 & .17 & -.32 & -2.55 & .03 & & & -.63 \\
Direct effect (c') & -.42 & .17 & -.32 & -2.47 & .03 & & & -.62 \\
Group (a) & .21 & .19 & .15 & 1.10 & .30 & & & \\
ER - Suppression (b) & -.02 & .12 & -.02 & -.20 & .69 & & & \\
\hline $\begin{array}{l}\text { Total indirect effect } \\
\text { (ab) }\end{array}$ & -.01 & .04 & -.01 & & & -.09 & .05 & -.01 \\
\hline
\end{tabular}

Note. Percentile bootstrapping used; effect sizes calculated by dividing estimates by SD of outcome.

Table 42

Imputed Intervention Group Predicting Depression Mediated by Suppression

\begin{tabular}{lcccccccc}
\hline Path & Effect & SE & $\begin{array}{c}\text { St. } \\
\text { Effect }\end{array}$ & $\begin{array}{c}\mathrm{t}- \\
\text { value }\end{array}$ & $\begin{array}{c}\mathrm{p}- \\
\text { value }\end{array}$ & BootLLCI & BootULCI & $\begin{array}{c}\text { Effect } \\
\text { Size }\end{array}$ \\
\hline Total effect (c) & -.12 & .12 & -.13 & -.97 & .36 & & & -.25 \\
Direct effect (c') & -.14 & .12 & -.15 & -1.12 & .30 & & & -.29 \\
Group (a) & .21 & .19 & .15 & 1.10 & .30 & & & \\
ER - Suppression (b) & .09 & .08 & .14 & 1.02 & .34 & & & \\
\hline $\begin{array}{l}\text { Total indirect effect } \\
\text { (ab) }\end{array}$ & .02 & .03 & .02 & & & -.04 & .10 & .04 \\
\hline
\end{tabular}

Note. Percentile bootstrapping used; effect sizes calculated by dividing estimates by SD of outcome. 
MINDFULNESS AND MECHANISMS OF STRESS REDUCTION

Table 43.

Imputed Intervention Group Predicting Stress Mediated by Suppression

\begin{tabular}{lcccccccc}
\hline Path & Effect & SE & $\begin{array}{c}\text { St. } \\
\text { Effect }\end{array}$ & $\begin{array}{c}\mathrm{t}- \\
\text { value }\end{array}$ & $\begin{array}{c}\mathrm{p}- \\
\text { value }\end{array}$ & BootLLCI & BootULCI & $\begin{array}{c}\text { Effect } \\
\text { Size }\end{array}$ \\
\hline Total effect (c) & -.23 & .18 & -.18 & -1.34 & .20 & & & -.35 \\
Direct effect (c') & -.23 & .18 & -.18 & -1.31 & .22 & & & -.35 \\
Group (a) & .21 & .19 & .15 & 1.10 & .30 & & & \\
$\begin{array}{l}\text { ER - Suppression } \\
\text { (b) }\end{array}$ & .00 & .12 & .00 & -.01 & .79 & & & \\
\hline $\begin{array}{l}\text { Total indirect effect } \\
\text { (ab) }\end{array}$ & .00 & .04 & .00 & & & -.07 & .08 & .00 \\
\hline
\end{tabular}

Note. Percentile bootstrapping used; effect sizes calculated by dividing estimates by SD of outcome.

Table 44.

Imputed Intervention Group Predicting Burnout Mediated by Suppression

\begin{tabular}{lcccccccc}
\hline Path & Effect & SE & $\begin{array}{c}\text { St. } \\
\text { Effect }\end{array}$ & $\begin{array}{c}\mathrm{t}- \\
\text { value }\end{array}$ & $\begin{array}{c}\mathrm{p}- \\
\text { value }\end{array}$ & BootLLCI & BootULCI & $\begin{array}{c}\text { Effect } \\
\text { Size }\end{array}$ \\
\hline Total effect (c) & -.52 & .25 & -.27 & -2.10 & .05 & & & -.18 \\
Direct effect (c') & -.56 & .25 & -.29 & -2.23 & .04 & & & -.18 \\
Group (a) & .21 & .19 & .15 & 1.10 & .30 & & & \\
$\begin{array}{l}\text { ER - Suppression } \\
\text { b) }\end{array}$ & .18 & .17 & .13 & 1.04 & .41 & & & \\
\hline $\begin{array}{l}\text { Total indirect effect } \\
\text { (ab) }\end{array}$ & .03 & .06 & .02 & & & -.09 & .17 & .00 \\
\hline
\end{tabular}

Note. Percentile bootstrapping used; effect sizes calculated by dividing estimates by SD of outcome. 


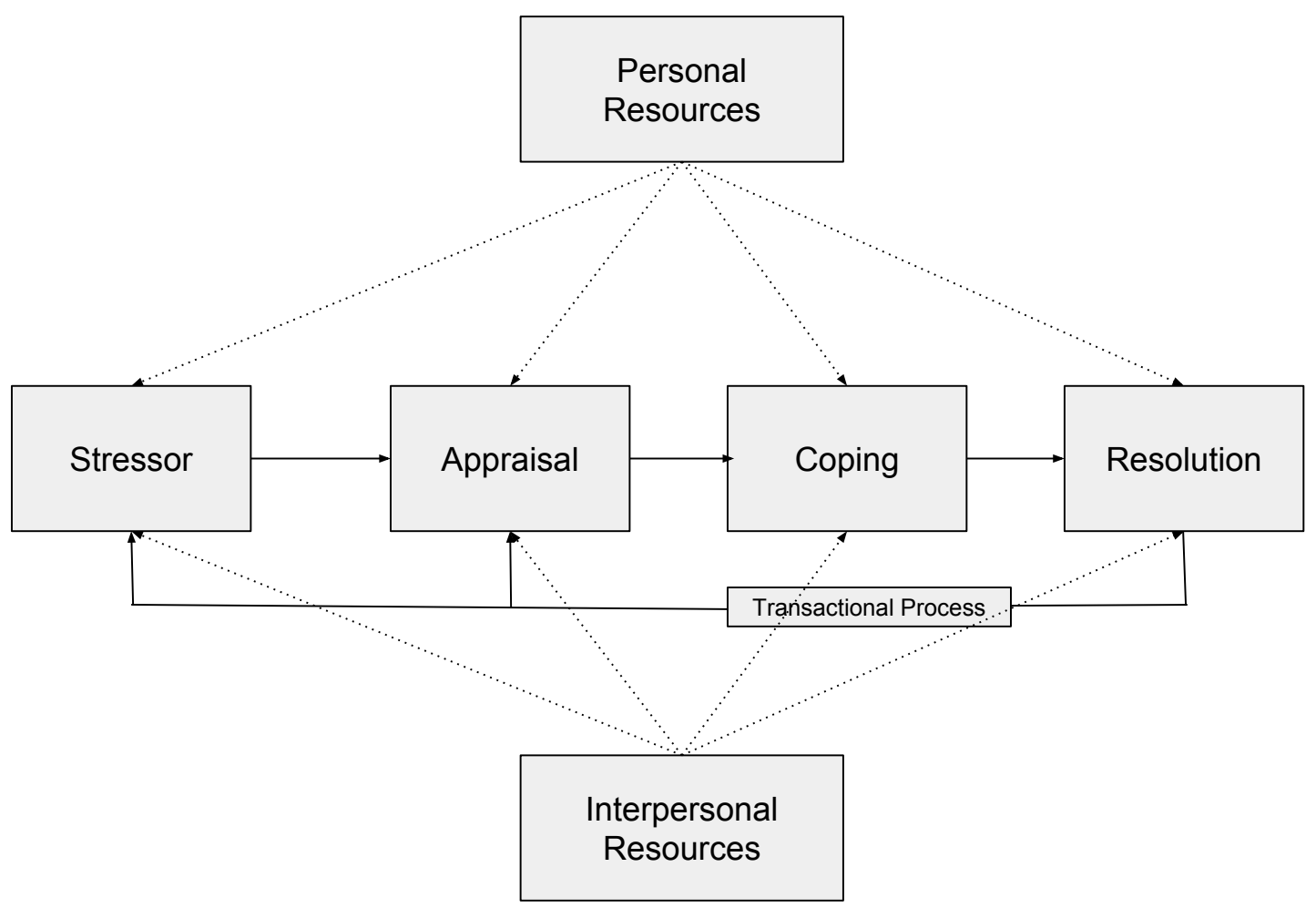

Figure 1. Model of the coping process. Model depicts the process by which a stressor is appraised as exceeding resources, which in turn begins a coping episode. Coping occurs by drawing on a multitude of strategies and resources, both personal and interpersonal. The coping episode ends with resolution, however the resolution of the episode feeds back to earlier stages and influences future stress-coping processes. 
Appraisal Processes

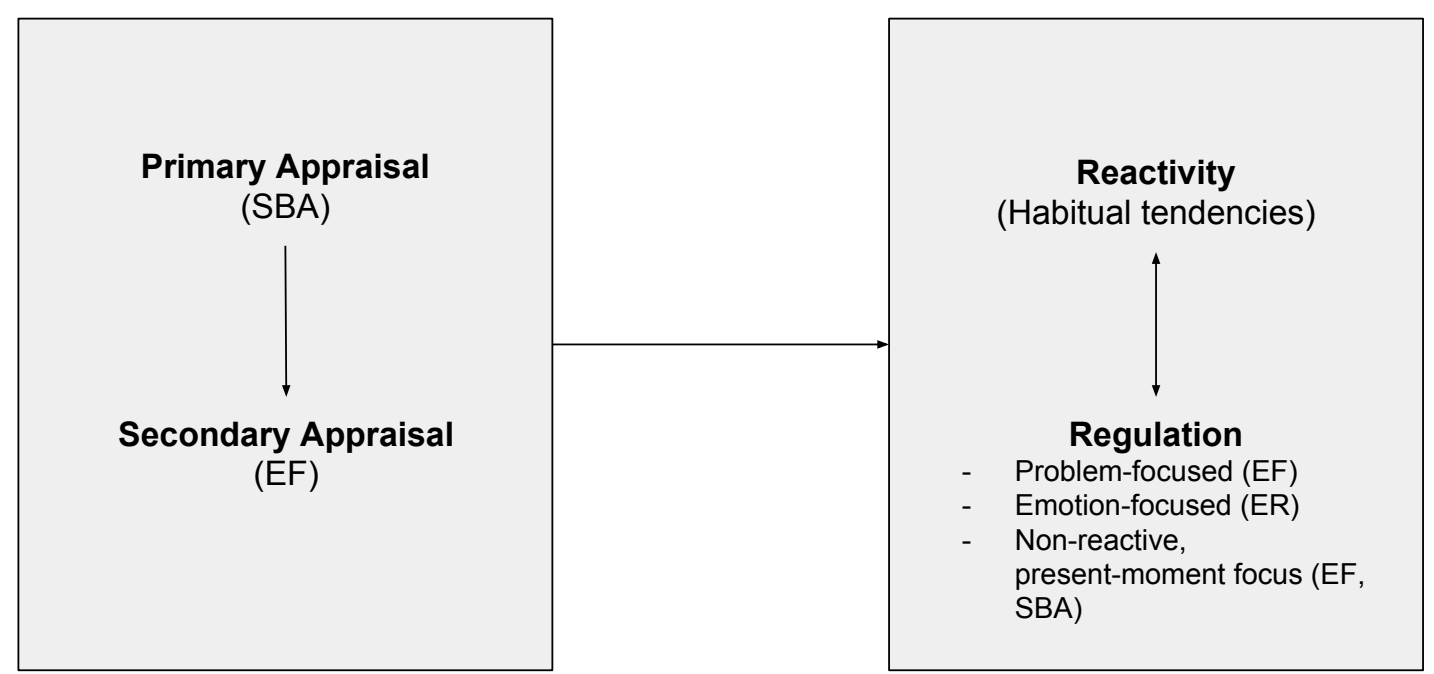

Coping Processes

Reactivity

Figure 2. Coping resources as situated within the coping process. Detailed depiction of how Somatic Body Awareness (SBA), Executive Function (EF), and Emotion Regulation (ER) function within the coping process described in Figure 1. 


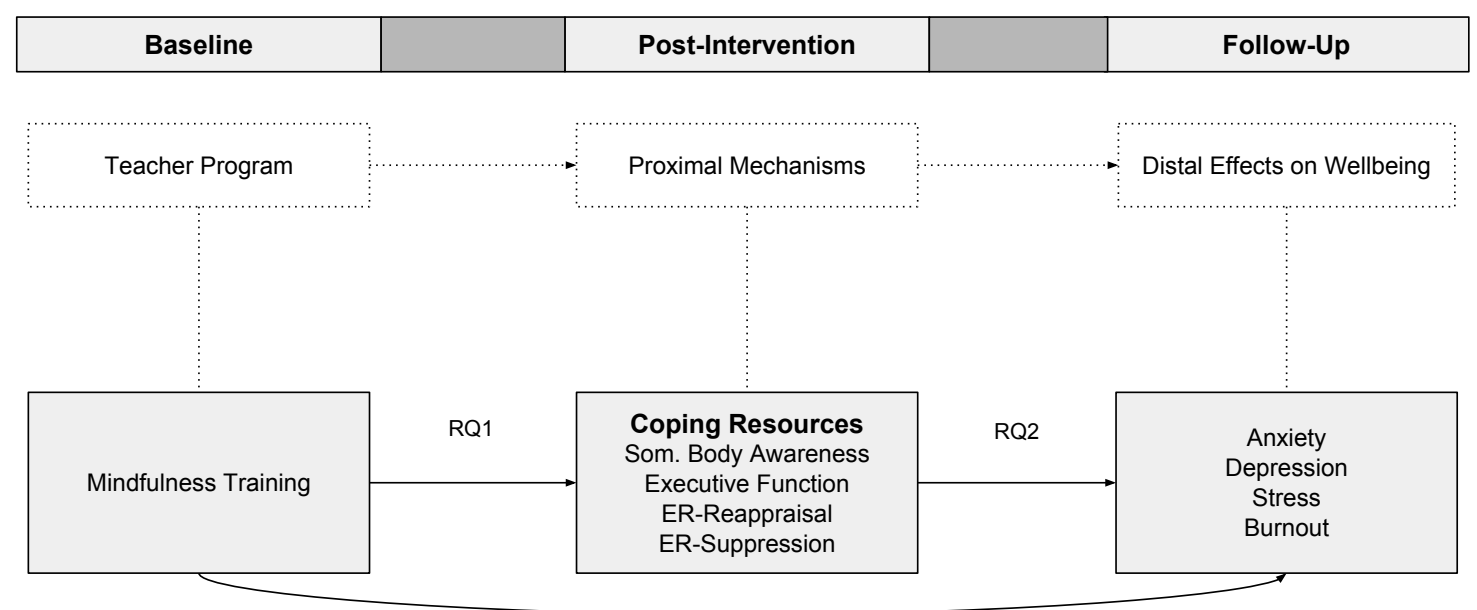

Figure 3. Comprehensive theory of change model. Model describes how mindfulness training is hypothesized to develop coping resources in teachers, which in turn leads to improved health and well-being over time. Additionally, the direct arrow from mindfulness training to the well-being outcomes indicates that direct effects from mindfulness to the distal well-being outcomes are also assumed. 

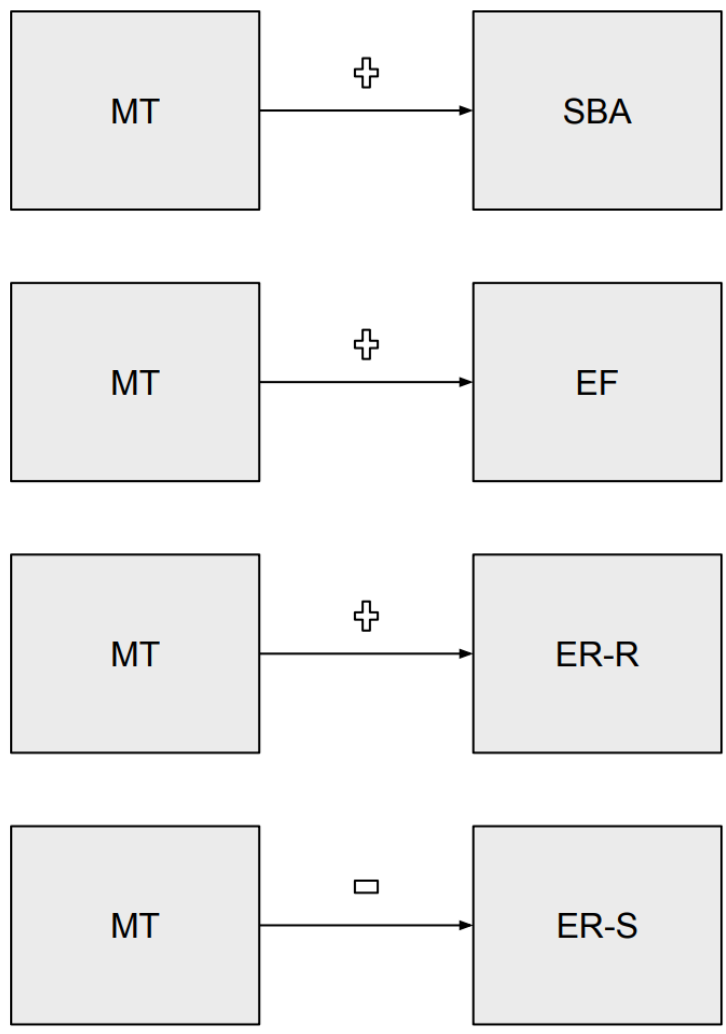

Figure 4. Conceptual models for research question one. $\mathrm{MT}=$ Mindfulness Training; $\mathrm{SBA}=$ Somatic Body Awareness; EF = Executive Function; ER-R = Emotion Regulation Reappraisal; and ER-S = Emotion Regulation Suppression 

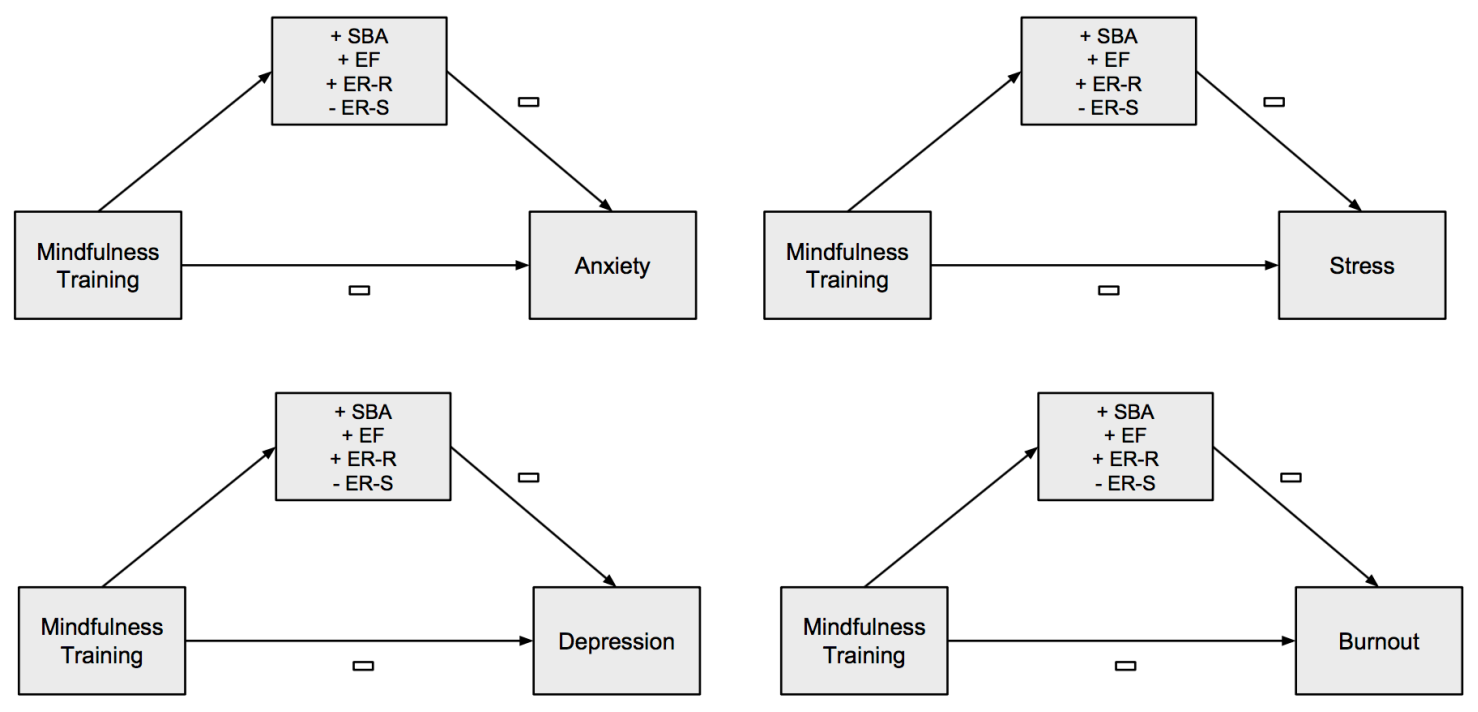

Figure 5. Conceptual models for research question two. SBA = Somatic Body Awareness; EF = Executive Function; ER-R = Emotion Regulation Reappraisal; and ER-S = Emotion Regulation Suppression 


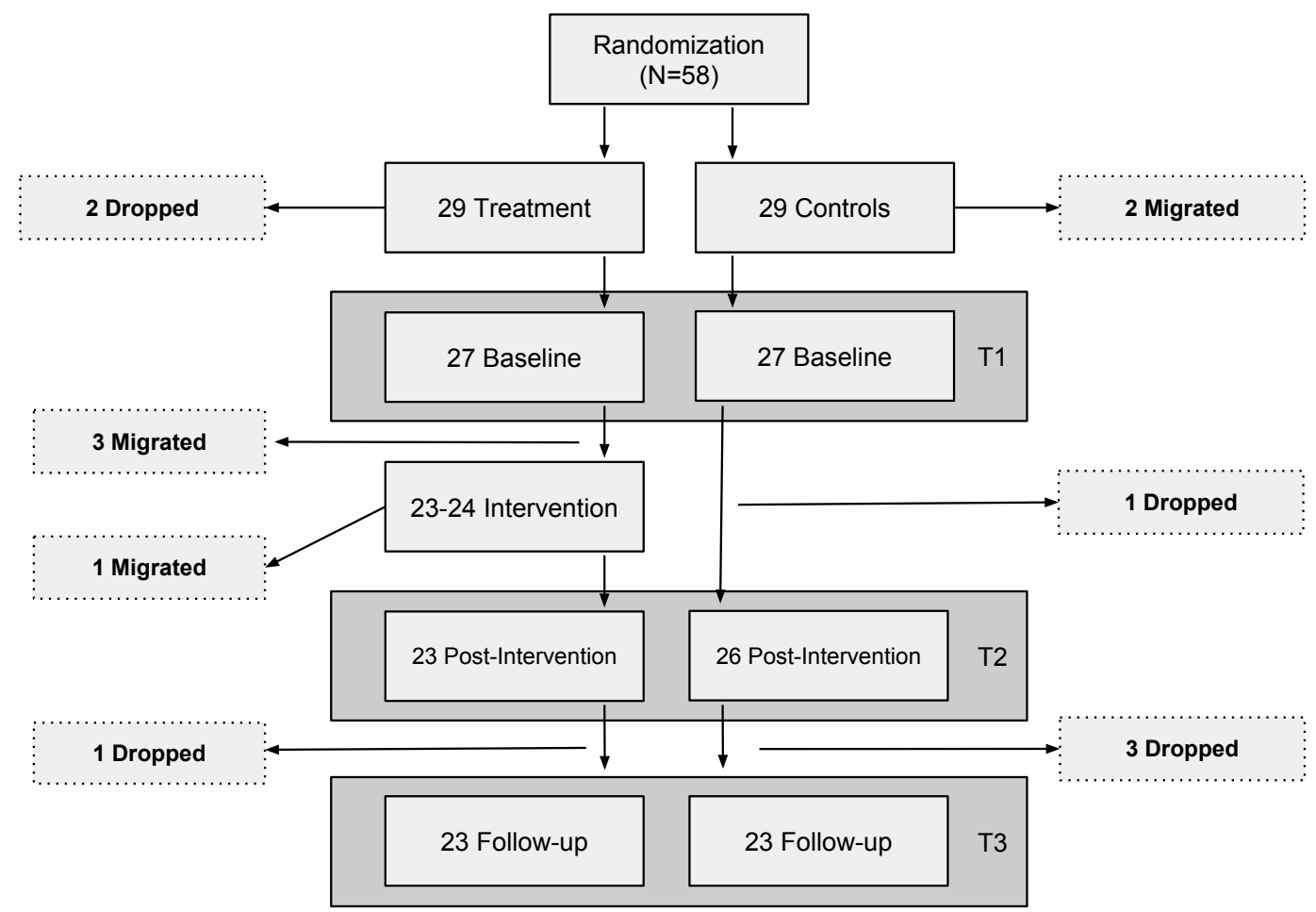

Figure 6. Consort diagram of teachers' attrition and migration throughout the study. $\mathrm{T} 1=$ Baseline, $\mathrm{T} 2$ = Post-intervention, $\mathrm{T} 3=4$-month follow-up. 


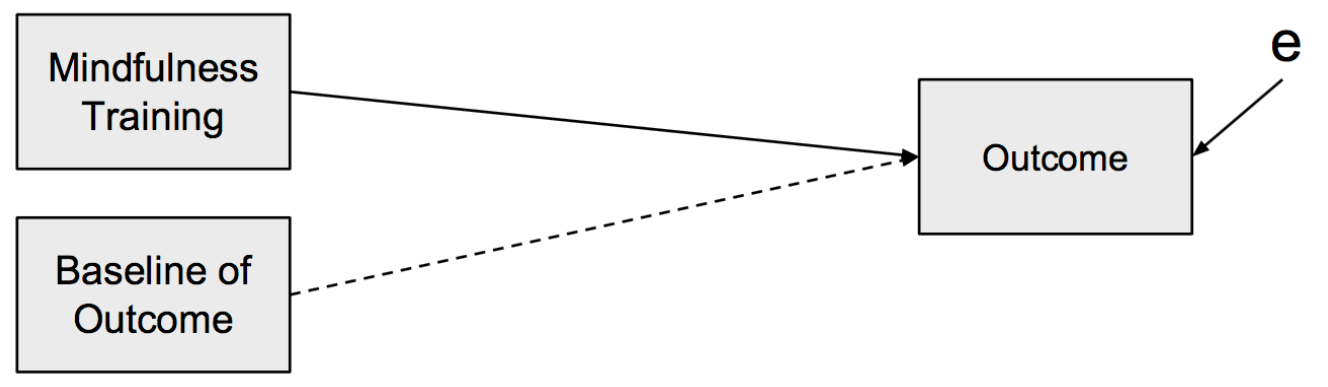

Figure 7. Statistical model for research question one. 


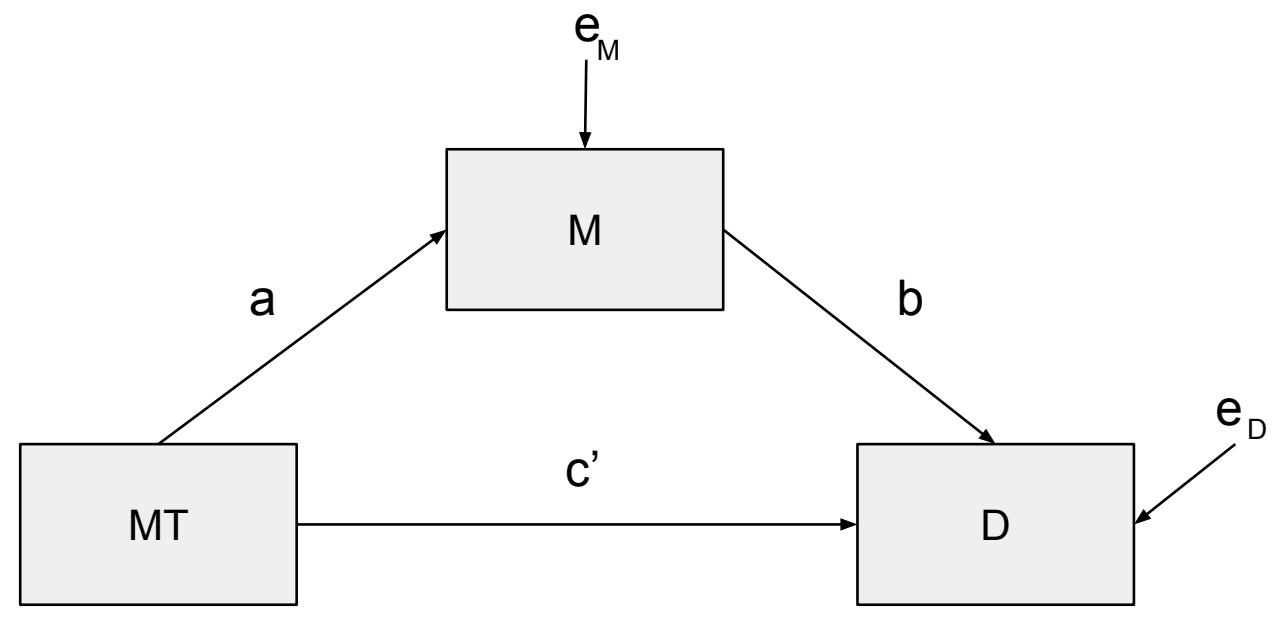

Figure 8. Statistical model for research question two. $\mathrm{MT}=$ Mindfulness Training; $\mathrm{M}=$ Mediator; $\mathrm{D}=$ Dependent variable. 


\section{References}

Aldwin, C. M. (2007). Stress, coping, and development: An integrative approach (2nd ed.). New York: Guilford.

Anderson, S., \& Teicher, M. (2008). Stress, sensitive periods and maturational events in adolsecent depression. Trends in Neurosciences, 21(4), 183-191.

Bargh, J. A., \& Williams, L. E. (2007). On the nonconscious of emotion regulation. In J. Gross (Ed.), Handbook of emotion regulation (pp. 429-445). New York: Guilford Press.

Beck, A. T., Steer, R. A., \& Carbin, M. G. (1988). Psychometric properties of the Beck Depression Inventory: Twenty-five years of evaluation. Clinical Psychology Review, 8(1), 77-100.

Bishop, S., Lau, M., Shapiro, S., Carlson, L., Anderson, N., Carmody, J., ... Devins, G. (2004). Mindfulness: A proposed operational definition. Clinical Psychology: Science and Practice, 11(3), 230-241.

Bjornsdotter, M., Loken, L., Olausson, H., Vallbo, A., \& Wessberg, J. (2009). Somatotopic organization of gentle touch processing in the posterior insular cortex. Journal of Neuroscience, 29, 9314-9320.

Bloom, H. S. (2005). Randomizing groups to evaluate place-based programs. Learning more from social experiments: Evolving analytic approaches, 115-172. Russell Sage Foundation.

Brandtstädter, J., \& Renner, G. (1990). Tenacious goal pursuit and flexible goal adjustment: Explication and age-related analysis of assimilative and accommodative strategies of coping. Psychology and Aging, 5(1), 58-67. 
Brown, K., \& Ryan, R. (2003). The benefits of being present: Mindfulness and its role in psychological well-being. Journal of Personality and Social Psychology, 84(4), $822-848$.

Brown, K. W., Goodman, R. J., \& Inzlicht, M. (2013). Dispositional mindfulness and the attenuation of neural responses to emotional stimuli. Social Cognitive and Affective Neuroscience, 8(1), 93-99.

Bush, G., Luu, P., \& Posner, M. (2000). Cognitive and emotional influences in anterior cingulate cortex. Trends in Cognitive Sciences, 4(6), 215-222.

Carmody, J., \& Baer, R. (2008). Relationships between mindfulness practice and levels of mindfulness, medical and psychological symptoms and well-being in a mindfulness-based stress reduction program. Journal of Behavioral Medicine, $31(1), 23-33$.

Chambers, R., Lo, B., \& Allen, N. (2008). The impact of intensive mindfulness training on attentional control, cognitive style, and affect. Cognitive Therapy and Research, 32(3), 303-322.

Chan, D., \& Woollacott, M. (2007). Effects of level of meditation experience on attentional focus: Is the efficiency of executive or orientation networks improved? The Journal of Alternative and Complementary Medicine, 13(6), 651-657.

Chang, M. (2009). An appraisal perspective of teacher burnout: Examining the emotional work of teachers. Educational Psychology Review, 21(3), 193-218.

Chiesa, A., Calati, R., \& Serretti, A. (2011). Does mindfulness training improve cognitive abilities? A systematic review of neuropsychological findings. Clinical Psychology Review, 31(3), 449-464. 
Cohen, J. (1988). Statistical power analysis for the behavioral sciences (2nd ed.). Hillsdale, NJ: Erlbaum.

Compas, B. E., Connor-Smith, J. K., Saltzman, H., Thomsen, A. H., \& Wadsworth, M. E. (2001). Coping with stress during childhood and adolescence: problems, progress, and potential in theory and research. Psychological Bulletin, 127(1), 87-127.

Compas, B. E., Connor, J., Osowiecki, D., \& Welch, A. (1997). Effortful and involuntary responses to stress. In Coping with chronic stress (pp. 105-130). Springer, Boston, MA.

Compas, B. E., Jaser, S. S., Bettis, A. H., Watson, K. H., Gruhn, M. A., Dunbar, J. P., ... \& Thigpen, J. C. (2017). Coping, emotion regulation, and psychopathology in childhood and adolescence: A meta-analysis and narrative review. Psychological Bulletin, 143(9), 939-991.

Craig, A. (2003). Interoception: The sense of the physiological condition of the body. Current Opinion in Neurobiology, 13, 500-505.

Craig, A. (2007). interoception and emotion: A neuroanatomical perspective. In Handbook of Emotions (M. Lewis, pp. 272-290). New York, NY: Guildford Press.

Craig, A. (2009). How do you feel now? The anterior insula and human awareness. Nature Reviews Neuroscience, 10, 59-70.

Craig, A. (2013). An interoceptive neuroanatomical perspective on feelings, energy, and effort. Behavioral and Brain Sciences, 36, 685-686.

Cullen, M., \& Wallace, L. (2010). Stress management and relaxation techniques in education (SMART) training manual. In Unpublished Manuscript. Impact 
MINDFULNESS AND MECHANISMS OF STRESS REDUCTION

Foundation, Aurora, Colorado.

Davidson, R., Dunne, J., Eccles, J., Engle, A., Greenberg, M., Jennings, P., ... Vago, D. (2012). Contemplative practices and mental training: Prospects for american education. Child Development Perspectives, 6(2), 146-153.

Davidson, R. J., Pizzagalli, D., Nitschke, J., \& Putnam, K. (2002). Depression:

Perspectives from affective neuroscience. Annual Review of Psychology, 53, 545574.

Davidson, R., \& McEwen, B. (2012). Social influences on neuroplasticity: Stress and interventions to promote well-being. Nature Neuroscience, 15(5), 689-695.

Dehaene, S., Posner, M., \& Tucker, D. (1994). Localization of a neural system for error detection and compensation. Psychological Science, 5, 303-305.

Derogatis, L. (1987). The Derogatis stress profile (DSP): Quantification of psychological stress. Advanced Psychosomatic Medicine, 17, 30-54.

Devinsky, O., Morrell, M., \& Vogt, B. (1995). Contributions of anterior cingulate cortex to behavior. Brain, 118, 279-306.

Eccles, J., \& Roeser, R. (2009). Schools, academic motivation, and stage-environment fit. In Handbook of Adolescent Psychology (pp. 404-434).

Eriksen, B. A., \& Eriksen, C. W. (1974). Effects of noise letters upon identification of a target letter in a non-search task. Perception and Psychophysics, 16, 143-149.

Fan, J., Flombaum, J., McCandliss, B., Thomas, K., \& Posner, M. (2003). Cognitive and brain consequences of conflict. NeuroImage, 18, 42-57.

Fan, J., McCandliss, B. D., Sommer, T., Raz, A., \& Posner, M. I. (2002). Testing the efficiency and independence of attentional networks. Journal of Cognitive 
MINDFULNESS AND MECHANISMS OF STRESS REDUCTION

Neuroscience, 14(3), 340-347.

Farb, N., Anderson, A., Irving, J., \& Segal, Z. (2014). Mindfulness interventions and emotion regulation. Handbook of Emotion Regulation, 548-567.

Farb, N., Daubenmier, J., Price, C. J., Gard, T., Kerr, C., Dunn, B. D., ... Mehling, W. E. (2015). Interoception, contemplative practice, and health. Frontiers in Psychology, 6.

Farb, N., Segal, Z., \& Anderson, A. (2013). Mindfulness meditation training alters cortical representations of interoceptive attention. Social Cognitive and Affective Neuroscience, 8(1), 15-26.

Farb, N., Segal, Z., Mayberg, H., Bean, J., McKeon, D., Fatima, Z., \& Anderson, A. (2007). Attending to the present: Mindfulness meditation reveals distinct neural modes of self-reference. Social Cognitive and Affective Neuroscience, 2(4), 313322.

Flook, L., Goldberg, S. B., Pinger, L., Bonus, K., \& Davidson, R. J. (2013). Mindfulness for teachers: A pilot study to assess effects on stress, burnout, and teaching efficacy. Mind, Brain, and Education, 7(3), 182-195.

Fredrickson, B. L. (2001). The role of positive emotions in positive psychology: The broaden-and-build theory of positive emotions. American psychologist, 56(3), $218-226$.

Fritz, M. S. \& MacKinnon, D. P. (2007). Required sample size to detect the mediated effect, Association for Psychological Science, 18(3), 233-239.

Gold, E., Smith, A., Hopper, I., Herne, D., Tansey, G., \& Hulland, C. (2010). Mindfulness-based stress reduction (MBSR) for primary school teachers. Journal 
of Child and Family Studies, 19(2), 184-189.

Goldin, P., \& Gross, J. (2010). Effects of mindfulness-based stress reduction (MBSR) on emotion regulation in social anxiety disorder. Emotion. 10(1), 83-91.

Gross, J. (1998). The Emerging Field of Emotion Regulation: An Integrative Review. Review of General Psychology, 2(3), 271-299.

Gross, J. (2001). Emotion regulation in adulthood: Timing is everything. Current Directions in Psychological Science, 10(6), 214-219.

Gross, J., \& John, O. (2003). Individual differences in two emotion regulation processes: Implications for affect, relationships, and well-being. Journal of Personality and Social Psychology, 85(2), 348-362.

Gross, J., Richards, J., \& John, O. (2006). Emotion regulation in everyday life. In Emotion Regulation in Couples and Families: Pathways to Dysfunction and Health (pp. 13-35).

Grossman, P., Niemann, L., Schmidt, S., \& Walach, H. (2004). Mindfulness-based stress reduction and health benefits: A meta-analysis. Journal of Psychosomatic Research, 57(1), 35-43.

Gunthert, K., Cohen, L., \& Armeli, S. (1999). The role of neuroticism in daily stress and coping. Journal of Personality and Social Psychology: Personality Processes and Individual Differences, 77(5), 1087-1100.

Hansen, W. B., Collins, L. M., Malotte, C. K., Johnson, C. A., \& Fielding, J. E. (1985). Attrition in prevention research. Journal of behavioral medicine, 8(3), 261-275. Hargreaves, A. (2000). Mixed emotions: Teachers' perceptions of their interactions with students. Teaching and Teacher Education, 16(8), 811-826. 
MINDFULNESS AND MECHANISMS OF STRESS REDUCTION

Hayes, A. F. (2013). Introduction to mediation, moderation, and conditional process analysis: A regression-based approach. New York, NY: The Guilford Press.

Hayes, A. F. (2018). Introduction to mediation, moderation, and conditional process analysis: A regression-based approach ( $2^{\text {nd }}$ ed.). New York, NY: The Guilford Press.

Hölzel, B. K., Lazar, S. W., Gard, T., Schuman-Olivier, Z., Vago, David, R., \& Ott, U. (2011). How does mindfulness meditation work? Proposing mechanisms of action from a conceptual and neural perspective. Perspectives on Psychological Science, $6(6), 537-559$.

Hölzel, B., Lazar, S., Gard, T., Schuman-Olivier, Z., Vago, D., \& Ott, U. (2011). How does mindfulness meditation work? Proposing mechanisms of action from a conceptual and neural perspective. Perspectives on Psychological Science, 6(6), $537-559$.

Hölzel, B., Ott, U., Hempel, H., \& Stark, R. (2006). Wie wirkt Achtsamkeit? Eine Interviewstudie mit erfahrenen Meditierenden (How does mindfulness work? An interview study with experienced meditators). 24th Symposium of the Section for Clinical Psychology and Psychotherapy of the German Society for Psychology, Würzburg, Germany.

Inzlicht, M., \& Legault, L. (2014). No pain, no gain: How distress underlies effective self-control (and unites diverse social psychological phenomena). The Control Within: Motivation and Its Regulation, 115-132.

Inzlicht, M., Legault, L., \& Teper, R. (2014). Exploring the mechanisms of self-control improvement. Current Directions in Psychological Science, 23(4), 302-307. 
MINDFULNESS AND MECHANISMS OF STRESS REDUCTION

Jennings, P. A., Frank, J. L., Snowberg, K. E., Coccia, M. A., \& Greenberg, M. T.

(2013). Improving classroom learning environments by cultivating awareness and resilience in education (CARE): Results of a randomized controlled trial. School Psychology Quarterly, 28(4), 374-390.

Jennings, P., \& Greenberg, M. (2009). The prosocial classroom: Teacher social and emotional competence in relation to student and classroom outcomes. Review of Educational Research, 79(1), 491-525.

Jennings, P., Frank, J., Snowberg, K., Coccia, M., \& Greenberg, M. (2011). Improving classroom learning environments by cultivating awareness and resilience in education (CARE): Results of two pilot studies. Journal of Classroom Interaction, 46(1), 37-48.

Jha, A., Krompinger, J., \& Baime, M. (2007). Mindfulness training modifies subsystems of attention. Cognitive, Affective, \& Behavioral Neuroscience, 7(2), 109-119.

Jha, A. P., Stanley, E. A., Kiyonaga, A., Wong, L., \& Gelfand, L. (2010). Examining the protective effects of mindfulness training on working memory capacity and affective experience. Emotion, 10(1), 54-64.

Kabat-Zinn, J. (1990). Full catastrophe living: The program of the stress reduction clinic at the University of Massachusetts Medical Center. New York: Delta.

Kabat-Zinn, J. (1998). Meditation. Psychoncology. New York: Oxford University Press. Kabat-Zinn, J., Massion, A., Kristeller, J., Peterson, L., Fletcher, K., \& Pbert, L. (1992). Effectiveness of a meditation-based stress reduction program in the treatment of anxiety disorders. American Journal of Psychiatry, 149(7), 936-943.

Kelley, K., \& Maxwell, S. E. (2003). Sample Size for Multiple Regression: Obtaining 
MINDFULNESS AND MECHANISMS OF STRESS REDUCTION

Regression Coefficients That Are Accurate, Not Simply

Significant. Psychological Methods, 8(3), 305-321.

Kumar, S., Feldman, G., \& Hayes, A. (2008). Changes in mindfulness and emotion regulation in an exposure-based cognitive therapy for depression. Cognitive Therapy and Research, 32, 734-744.

Kyriacou, C. (2001). Teacher stress: Directions for future research. Educational Review, $53(1), 27-35$.

Lambert, R. G., McCarthy, C. J., \& Abbott-Shim, M. (2001). Classroom Appraisal of Resources and Demands: School-age version. Atlanta, GA: Head Start Quality Research Center.

Lazarus, R., \& Folkman, S. (1984). Stress, appraisal, and coping. New York: Springer.

Little, R. J. A. (1988). A test of missing completely at random for multivariate data with missing values. Journal of the American Statistical Association, 83(404), 11981202.

Lutz, A., Slagter, H., Dunne, J., \& Davidson, R. (2008). Attention regulation and monitoring in meditation. Trends in Cognitive Sciences, 12(4), 163-169.

Maslach, C., Schaufeli, W. B., \& Lieter, M. P. (2001). Job burnout. Annual Review of Psychology, 52, 397-422.

McCrae, R., \& Costa, P. (1986). Personality, coping, and coping effectiveness in an adult sample. Journal of Personality, 54(2), 385-405.

Mehling, W. E., Gopisetty, V., Daubenmier, J., Price, C. J., Hecht, F. M., \& Stewart, A. (2009). Body awareness: Construct and self-report measures. PLoS ONE, 4(5).

Miyake, A., Friedman, N., Emerson, M., Witzki, A., Howerter, A., \& Wager, T. (2000). 
The unity and diversity of executive functions and their contributions to complext "frontal lobe" tasks: A latent variable analysis. Cognitive Psychology, 41, 49-100. Montgomery, C., \& Rupp, A. A. (2005). A meta-analysis for exploring the diverse causes and effects of stress in teachers. Canadian Journal of Education, 28(3), 458-486.

Moore, A., \& Malinowski, P. (2009). Meditation, mindfulness and cognitive flexibility. Consciousness and Cognition, 18, 176-186.

Parkes, K. R. (1990). Coping, negative affectivity, and the work environment: Additive and interactive predictors of mental health. Journal of Applied Psychology, 75(4), 399-409.

Pas, E. T., Bradshaw, C. P., \& Hershfeldt, P. A. (2012). Teacher- and school-level predictors of teacher efficacy and burnout: Identifying potential areas for support. Journal of School Psychology, 50(1), 129-145.

Paulus, M. P., \& Stein, M. B. (2010). Interoception in anxiety and depression. Brain Structure and Function, 214, 451-463.

Penley, J. A., \& Tomaka, J. (2002). Associations among the Big Five, emotional responses, and coping with acute stress. Personality and Individual Differences, 32(7), 1215-1228.

Pennebaker, J. W., Kiecolt-Glaser, J. K., \& Glaser, R. (1988). Disclosure of traumas and immune function: Health implications for psychotherapy. Journal of Consulting and Clinical Psychology, 56(2), 239-245.

Perlman, D., Salomons, T., Davidson, R. J., \& Lutz, A. (2010). Differential effects on pain intensity and unpleasantness of two meditation practices. Emotion, 10(1), 65-71. 
MINDFULNESS AND MECHANISMS OF STRESS REDUCTION

Porges, S. (1993). Body Perception Questionnaire. Laboratory of Developmental Assessment: University of Maryland.

Posner, M., Rothbart, M., Sheese, B., \& Tang, Y. (2007). The anterior cingulate gyrus and the mechanism of self-regulation. Cognitive, Affective, \& Behavioral Neuroscience, 7(4), 391-395.

R Core Team (2013). R: A language and environment for statistical computing. R Foundation for Statistical Computing, Vienna, Austria. URL http://www.Rproject.org/.

Revelle, W. (2017) psych: Procedures for Personality and Psychological Research, Northwestern University, Evanston, Illinois, USA, https://CRAN.Rproject.org/package $=$ psychd Version $=1.7 .8$.

Roeser, R. W. (2014). The emergence of mindfulness-based interventions in educational settings. In T. C. U. Stuart A. Karabenick (Ed.), Motivational Interventions (Advances in Motivation and Achievement (18th ed., pp. 379-419).

Roeser, R. W., Mashburn, A. J., Skinner, E. A., Taylor, C., Choles, J. R., Rickert, N. P., ... Sorenson, J. (2018). Assessing the teacher and classroom impacts of a mindfulness program for middle school teachers: Results of a randomizedcontrolled trial. Manuscript in Preparation.

Roeser, R. W., Schonert-Reichl, K. A., Jha, A., Cullen, M., Wallace, L., Wilensky, R., ... Harrison, J. (2013). Mindfulness training and reductions in teacher stress and burnout: Results from two randomized, waitlist-control field trials. Journal of Educational Psychology, 105(3), 787-804.

Roeser, R. W., Skinner, E., Beers, J., \& Jennings, P. A. (2012). Mindfulness training and 
teachers' professional development: An emerging area of research and practice. Child Development Perspectives, 6(2), 167-173.

Rueda, M., Posner, M., \& Rothbart, M. (2004). Attentional control and self-regulation. In Handbook of Self-Regulation: Research, Theory, and Applications (pp. 284-299).

Schafer, J. L., \& Graham, J. W. (2002). Missing data: Our view of the state of the art. Psychological Methods, 7(2), 147-177.

Schussler, D. L., Jennings, P. A., Sharp, J. E., \& Frank, J. L. (2016). Improving teacher awareness and well-being through CARE: A qualitative analysis of the underlying mechanisms. Mindfulness, 7(1), 130-142.

Segal, Z., Williams, J., \& Teasdale, J. (2002). Mindfulness-based cognitive therapy for depression-A new approach to preventing relapse. (G. Press, Ed.). New York, NY.

Semple, R. (2010). Does mindfulness meditation enhance attention? A randomized controlled trial. Mindfulness, 1, 121-130.

Sizer, T. (1992). Horace's school: Redesigning the american high school. Boston, MA: Houghlin Mifflin Co.

Skinner, E., \& Beers, J. (2016). Mindfulness and teachers' coping in the classroom: A developmental model of teacher stress, coping, and everyday resilience. In Handbook on Mindfulness in Education: Emerging Theory, Research, and Programs (pp. 99-118). Springer New York.

Skinner, E. A. \& Zimmer-Gembeck, M. J. (2016). The development of coping: Stress, neurophysiology, social relationships, and resilience during childhood and adolescence. Switzerland: Springer International Publishing. 
Slagter, H., Lutz, A., Greischar, L., Francis, A., Nieuwenhuis, S., Davis, J., \& Davidson, R. (2007). Mental training affects distribution of limited brain resources. PLoS Biology, 5(6), 1228-1235.

Spielberger, C., Gorsuch, R., Lushene, R., Vagg, P., \& Jacobs, G. (1983). Manual for the state-trait anxiety inventory. Palo Alto, CA: Consulting Psychologists.

Stanton, A. L., Danoff-Burg, S., Cameron, C. L., \& Ellis, A. P. (1994). Coping through emotional approach: Problems of conceptualizaton and confounding. Journal of Personality and Social Psychology, 66(2), 350-362.

Stroop, J. R. (1935). Studies of interference in serial verbal reactions. Journal of Experimental Psychology, 18(6), 643-662.

Tang, Y., Hölzel, B., \& Posner, M. (2015). The neuroscience of mindfulness meditation. Nature Reviews Neuroscience, 16(4), 213-225.

Tang, Y., Ma, Y., Wang, J., \& Fan, Y. (2007). Short-term meditation training improves attention and self-regulation. Proceedings of the National Academy of Sciences, 104(43), 17152-17156.

Tang, Y., Yang, L., Leve, L., \& Harold, G. (2012). Improving executive function and its neurobiological mechanisms through a mindfulness-based intervention: Advances within the field of developmental neuroscience. Child Development Perspectives, $6(4), 361-366$.

Taylor, C., Harrison, J., Haimovitz, K., Oberle, E., Thompson, K., Schonert-Reichl, K. A., \& Roeser, R. W. (2016). Examining ways that a mindfulness-based intervention reduces stress in public school teachers: A mixed-methods study. Mindfulness, 7(1), 115-129. 
Teper, R., \& Inzlicht, M. (2013). Meditation, mindfulness and executive control: The importance of emotional acceptance and brain-based performance monitoring. Social Cognitive and Affective Neuroscience, 8(1), 85-92.

Teper, R., Segal, Z., \& Inzlicht, M. (2013). Inside the mindful mind: How mindfulness enhances emotion regulation through improvements in executive control. Current Directions in Psychological Science, 22(6), 449-454.

Uliaszek, A. A., Zinbarg, R. E., Mineka, S., Craske, M. G., Sutton, J. M., Griffith, J. W., ... Hammen, C. (2010). The role of neuroticism and extraversion in the stressanxiety and stress-depression relationships. Anxiety, Stress, \& Coping, 23(4), 363-381.

Vago, D. R., \& Silbersweig, D. A. (2012). Self-awareness, self-regulation, and selftranscendence (S-ART): a framework for understanding the neurobiological mechanisms of mindfulness. Frontiers in Human Neuroscience, 6, 296.

Wenk-Sormaz, H. (2005). Meditation can reduce habitual responding. Meditation and Cognition, 11(2), 42-58.

Wickelgren, W. A. (1977). Speed-accuracy tradeoff and information processing dynamics. Acta psychologica, 41(1), 67-85.

Williams, P., Suchy, Y., \& Rau, H. (2009). Individual differences in executive functioning: Implications for stress regulation. Annals of Behavioral Medicine, $37,126-140$.

Zeidan, F., Johnson, S., Diamond, B., David, Z., \& Goolkasian, P. (2010). Mindfulness meditation improves cognition: Evidence of brief mental training. Consciousness and Cognition, 19(2), 597-605. 
Zelazo, P. D., Anderson, J. E., Richler, J., Wallner-Allen, K., Beaumont, J. L., \&

Weintraub, S. (2013). II. NIH Toolbox Cognition Battery (CB): Measuring executive function and attention. Monographs of the Society for Research in Child Development, 78(4), 16-33.

Zelazo, P. D., \& Carlson, S. M. (2012). Hot and cool executive function in childhood and adolescence: Development and plasticity. Child Development Perspectives, 4, 354-360. 
APPENDIX A

\author{
Literature Review Tables
}

Table A1.

Review of the Effects of Mindfulness Training on Teachers

\begin{tabular}{|c|c|c|c|}
\hline Study & Sample & Design & Effects \\
\hline $\begin{array}{l}\text { Taylor et al., } \\
\text { (2016) }\end{array}$ & $\begin{array}{l}59 \text { elementary and } \\
\text { secondary school } \\
\text { teachers }\end{array}$ & $\begin{array}{l}\text { Mixed Method RCT } \\
\text { mindfulness training }\end{array}$ & $\begin{array}{l}\text { Reductions in stress, decreased number } \\
\text { of negative emotions used to describe a } \\
\text { stressful event, increases in positive } \\
\text { emotion words and feelings in } \\
\text { describing challenging students, } \\
\text { increases in efficacy for regulating } \\
\text { emotions, increases in measures of } \\
\text { forgiveness }\end{array}$ \\
\hline $\begin{array}{l}\text { Flook et al., } \\
\quad(2013)\end{array}$ & $\begin{array}{l}18 \text { elementary school } \\
\text { teachers }\end{array}$ & $\begin{array}{l}\text { Pilot RCT modified } \\
\text { MBSR }\end{array}$ & $\begin{array}{l}\text { Reductions in psychological symptoms } \\
\text { and burnout (emotional exhaustion), } \\
\text { increased performance on an affective } \\
\text { attentional bias computer task, } \\
\text { increases in self-compassion, and } \\
\text { increases in FFMQ describe subscale. }\end{array}$ \\
\hline $\begin{array}{l}\text { Jennings et } \\
\text { al., (2013) }\end{array}$ & $\begin{array}{l}50 \text { public school } \\
\text { teachers }\end{array}$ & $\begin{array}{l}\text { RCT Cultivating } \\
\text { Awareness and } \\
\text { Resilience in } \\
\text { Education training } \\
\text { (CARE) }\end{array}$ & $\begin{array}{l}\text { Increased reappraisal (emotion } \\
\text { regulation), decreased daily physical } \\
\text { symptoms, increases in FFMQ } \\
\text { observing and non-reactivity subscales. }\end{array}$ \\
\hline $\begin{array}{l}\text { Roeser et } \\
\text { al., (2013) }\end{array}$ & $\begin{array}{l}113 \text { Canadian and US } \\
\text { elementary and } \\
\text { secondary school } \\
\text { teachers }\end{array}$ & $\begin{array}{l}\text { RCT mindfulness } \\
\text { training }\end{array}$ & $\begin{array}{l}\text { Increased mindfulness and self- } \\
\text { compassion, increased working } \\
\text { memory capacity (OSPAN task), } \\
\text { decreased stress, burnout, depression, } \\
\text { and anxiety }\end{array}$ \\
\hline $\begin{array}{l}\text { Jennings, et } \\
\text { al., (2011) }\end{array}$ & $\begin{array}{c}31 \text { urban educators and } \\
43 \text { suburban/semi-rural } \\
\text { student teachers and } \\
\text { mentors }\end{array}$ & $\begin{array}{l}\text { Pilot studies of } \\
\text { Cultivating } \\
\text { Awareness and } \\
\text { Resilience in } \\
\text { Education training } \\
\text { (CARE) }\end{array}$ & $\begin{array}{l}\text { Decreases in time urgency, increases } \\
\text { FFMQ mindfulness }\end{array}$ \\
\hline $\begin{array}{l}\text { Gold et al., } \\
\quad(2010)\end{array}$ & $\begin{array}{l}11 \text { teachers from } \\
\text { suburban primary } \\
\text { schools }\end{array}$ & $\begin{array}{l}\text { Pre-Post Treatment } \\
\text { only MBSR }\end{array}$ & $\begin{array}{l}\text { Decreased stress and depression, } \\
\text { increased mindfulness on KIMS in } \\
\text { both the accept without judgment } \\
\text { subscale and total KIMS composite. }\end{array}$ \\
\hline $\begin{array}{l}\text { Carmody \& } \\
\text { Baer, (2008) }\end{array}$ & 174 adults & $\begin{array}{l}\text { Pre-Post Treatment } \\
\text { only MBSR }\end{array}$ & $\begin{array}{l}\text { Increased mindfulness and measures of } \\
\text { well-being. Decreases in stress and } \\
\text { psychological symptoms (such as } \\
\text { anxiety and depression) measured with } \\
\text { the Brief Symptom Inventory }\end{array}$ \\
\hline
\end{tabular}


Table A2.

Literature of the Effects of Mindfulness Training on Somatic Body Awareness

\begin{tabular}{|c|c|c|c|}
\hline Study & Sample & Design & Effects \\
\hline $\begin{array}{l}\text { Farb et al., } \\
\text { (2013) }\end{array}$ & $\begin{array}{c}31 \text { adult } \\
\text { participants }\end{array}$ & RCT MBSR program & $\begin{array}{l}\text { fMRI data indicated MT increased } \\
\text { interoceptive awareness in middle and } \\
\text { anterior areas of the insula and } \\
\text { significantly decreased dorsal medial } \\
\text { prefrontal cortex activity. These results } \\
\text { provide neuroanatomical plasticity } \\
\text { evidence to support the development of } \\
\text { somatic body awareness as well as a } \\
\text { reciprocal down-regulation of areas } \\
\text { associated with executive function } \\
\text { processes (DMPFC) }\end{array}$ \\
\hline $\begin{array}{l}\text { Farb et al., } \\
\text { (2007) }\end{array}$ & $\begin{array}{c}36 \text { adult } \\
\text { participants }\end{array}$ & $\begin{array}{l}\text { RCT MBSR program } \\
\text { comparing pre-test } \\
\text { waitlist controls to post- } \\
\text { test mindfulness } \\
\text { treatment }\end{array}$ & $\begin{array}{l}\text { fMRI results suggest two distinct forms } \\
\text { of self-reference, a time-independent } \\
\text { narrative component and present } \\
\text { moment awareness. Furthermore, } \\
\text { results indicated the MT group shifted } \\
\text { neural processes from areas associated } \\
\text { with narrative self-reference towards } \\
\text { those related to present moment } \\
\text { awareness (i.e. activation in the ventral } \\
\text { and dorsolateral prefrontal cortex, the } \\
\text { insula, and other areas). }\end{array}$ \\
\hline $\begin{array}{l}\text { Hölzel et al., } \\
\text { (2006) }\end{array}$ & $\begin{array}{l}10 \text { experienced } \\
\text { meditators }\end{array}$ & Qualitative interviews & $\begin{array}{l}\text { Seven of ten experienced meditators } \\
\text { spontaneously described improvement } \\
\text { in somatic body awareness, and } 4 \text { out } \\
\text { of ten described greater emotional } \\
\text { awareness. }\end{array}$ \\
\hline $\begin{array}{l}\text { Carmody \& } \\
\text { Baer (2008) }\end{array}$ & $\begin{array}{l}206 \text { participants } \\
\text { across } 9 \text { MBSR } \\
\text { groups, reportedly } \\
\text { with a wide-range } \\
\text { of diagnoses }\end{array}$ & $\begin{array}{l}\text { Quasi-experimental, } \\
\text { treatment only MBSR } \\
\text { group }\end{array}$ & $\begin{array}{l}\text { Significant improvements post- } \\
\text { mindfulness training on self-report } \\
\text { scores of body awareness, as measured } \\
\text { by the FFMQ observe subscale. }\end{array}$ \\
\hline
\end{tabular}


Table A3.

Literature of the Effects of Mindfulness Training on Executive Function and Emotion Regulation

\begin{tabular}{|c|c|c|c|}
\hline Study & Sample & Design & Effects \\
\hline $\begin{array}{c}\text { Chambers et } \\
\text { al., (2008) }\end{array}$ & $\begin{array}{c}20 \text { meditators, } 20 \\
\text { control. }\end{array}$ & $\begin{array}{l}\text { Quasi-experimental pre- } \\
\text { post MT comparing } \\
\text { experienced meditators and } \\
\text { controls. }\end{array}$ & $\begin{array}{l}\text { MT associated with decreases } \\
\text { in self-report rumination and } \\
\text { depressive symptoms, and } \\
\text { increased working memory } \\
\text { abilities and sustained attention } \\
\text { as measured by the Digit Span } \\
\text { Backward sub scale and the } \\
\text { Internal Switching task. } \\
\text { Evidence for increased } \\
\text { attention switching was not } \\
\text { supported. }\end{array}$ \\
\hline $\begin{array}{l}\text { Chan \& } \\
\text { Woollacott, } \\
\text { (2007) }\end{array}$ & $\begin{array}{l}50 \text { long-term practice } \\
\text { meditators and } 10 \\
\text { controls }\end{array}$ & Quasi-Experimental & $\begin{array}{l}\text { Meditation experience was } \\
\text { associated with decreased } \\
\text { interference on the Stroop task } \\
\text { and no effects were found with } \\
\text { meditation and orienting of } \\
\text { attention on a Global-Local } \\
\text { letter task. Time spent } \\
\text { meditating per day (in contrast } \\
\text { with total hours meditated in } \\
\text { lifetime) was significantly } \\
\text { negatively related to } \\
\text { interference. }\end{array}$ \\
\hline $\begin{array}{c}\text { Goldin \& } \\
\text { Gross, (2010) }\end{array}$ & $\begin{array}{c}16 \text { participants } \\
\text { diagnosed with } \\
\text { generalized anxiety } \\
\text { disorder. }\end{array}$ & $\begin{array}{l}\text { Quasi-experimental pre- } \\
\text { post MBSR treatment only } \\
\text { design. }\end{array}$ & $\begin{array}{l}\text { Post MBSR was associated } \\
\text { with decreases in social } \\
\text { anxiety, depression, } \\
\text { rumination, etc. Significant pre } \\
\text { to post decreases in negative } \\
\text { emotion were found in the } \\
\text { breath-focused attention } \\
\text { condition. Additionally, fMRI } \\
\text { data indicated increases in } \\
\text { areas of the brain associated } \\
\text { with visual attention, indicative } \\
\text { of greater use of attentional } \\
\text { resources or more effective } \\
\text { allocation of attention during } \\
\text { regulating. }\end{array}$ \\
\hline
\end{tabular}


Table A3 Continued.

\begin{tabular}{|c|c|c|c|}
\hline Study & Sample & Design & Effects \\
\hline $\begin{array}{l}\text { Jha et al., } \\
\text { (2007) }\end{array}$ & $\begin{array}{c}17 \text { MBSR participants, } \\
\text { number of retreat } \\
\text { participants not mentioned, } \\
17 \text { control. }\end{array}$ & $\begin{array}{l}\text { Experienced } \\
\text { meditator group } \\
\text { underwent a 1- } \\
\text { month intensive } \\
\text { meditation course, } \\
\text { meditation naive } \\
\text { group underwent 8- } \\
\text { week MBSR } \\
\text { program, and control } \\
\text { group }\end{array}$ & $\begin{array}{l}\text { Using the ANT, the retreat group } \\
\text { showed better conflict ability at } \\
\text { baseline. The MBSR group } \\
\text { demonstrated significantly } \\
\text { improved orienting post- } \\
\text { intervention (as compared to } \\
\text { other two groups). Retreat group } \\
\text { showed significant alerting } \\
\text { improvement post-retreat as } \\
\text { compared to others. No group } \\
\text { differences in conflict } \\
\text { monitoring at T2. }\end{array}$ \\
\hline $\begin{array}{l}\text { Lutz et al., } \\
\text { (2008) }\end{array}$ & $\begin{array}{l}17 \text { meditators, } 23 \text { matched } \\
\text { controls. }\end{array}$ & $\begin{array}{l}\text { Quasi-experimental } \\
\text { study comparing } \\
\text { experienced } \\
\text { meditators to } \\
\text { matched controls. }\end{array}$ & $\begin{array}{l}\text { Mindfulness training significantly } \\
\text { increased performance on an } \\
\text { attentional blink cognitive task, } \\
\text { indicating more effective } \\
\text { allocation of attentional resources. } \\
\text { Additionally, this relationship was } \\
\text { linear, such that those who } \\
\text { showed the highest reduction in } \\
\text { ERP activity also showed the } \\
\text { most significant increase in } \\
\text { attentional blink detection. }\end{array}$ \\
\hline $\begin{array}{l}\text { Moore \& } \\
\text { Malinowski, } \\
\text { (2009) }\end{array}$ & 25 meditators, 25 control. & $\begin{array}{l}\text { Quasi-experimental } \\
\text { comparing } \\
\text { experienced } \\
\text { meditators and } \\
\text { controls. }\end{array}$ & $\begin{array}{l}\text { Self-report mindfulness positively } \\
\text { related to inhibitory control } \\
\text { (measured by Stroop and d2- } \\
\text { concentration and endurance test) } \\
\text { and negatively related to errors on } \\
\text { both tasks. Additionally, between } \\
\text { group comparisons indicated } \\
\text { meditators had significantly better } \\
\text { Stroop interference scores and d2 } \\
\text { concentration and endurance test } \\
\text { scores (a cognitive flexibility and } \\
\text { inhibitory control task), as } \\
\text { compared to controls. }\end{array}$ \\
\hline $\begin{array}{l}\text { Perlman et } \\
\text { al., (2010) }\end{array}$ & $\begin{array}{c}9 \text { meditators with }>10,000 \\
\text { hours of meditation, } 10 \\
\text { matched controls. }\end{array}$ & $\begin{array}{l}\text { Quasi-experimental } \\
\text { long-term } \\
\text { meditators/control } \\
\text { comparison }\end{array}$ & $\begin{array}{l}\text { Group differences found in pain } \\
\text { intensity and subjective feelings } \\
\text { of pain unpleasantness. Long-term } \\
\text { practitioners found a painful } \\
\text { stimulus significantly less } \\
\text { unpleasant during open } \\
\text { monitoring meditation as } \\
\text { compared to controls. These same } \\
\text { results were not found for group } \\
\text { differences in focused attention } \\
\text { meditation. }\end{array}$ \\
\hline
\end{tabular}


Table A3 Continued.

\begin{tabular}{|c|c|c|c|}
\hline Study & Sample & Design & Effects \\
\hline $\begin{array}{l}\text { Semple, } \\
(2010)\end{array}$ & $\begin{array}{l}45 \text { community } \\
\text { members with no } \\
\text { prior meditation } \\
\text { experience }\end{array}$ & $\begin{array}{l}\text { RCT with active } \\
\text { and waitlist control } \\
\text { groups }\end{array}$ & $\begin{array}{l}\text { Significant improvement in mindfulness group } \\
\text { on a sustained vigilance target-detection task, } \\
\text { no significant differences on Stroop, Digit } \\
\text { Symbol Substitution (focused attention task) } \\
\text { as compared to active and waitlist control } \\
\text { groups. Significant decrease in state anxiety } \\
\text { for both active groups, but decrease in state } \\
\text { anxiety predicted by frequency of practice in } \\
\text { mindfulness group only. }\end{array}$ \\
\hline $\begin{array}{l}\text { Tang et } \\
\text { al., } \\
(2007)\end{array}$ & $\begin{array}{l}40 \text { undergraduate } \\
\text { Chinese students }\end{array}$ & $\begin{array}{l}\text { 5-Day IBMT } \\
\text { (Integrative Body- } \\
\text { Mind Training) } \\
\text { RCT with } \\
\text { relaxation group as } \\
\text { control }\end{array}$ & $\begin{array}{l}\text { Improvement in conflict scores on Attention } \\
\text { Network Task, decreased reports of anxiety, } \\
\text { depression, anger, and fatigue. Increased } \\
\text { reports of vigor. Decreased levels of stress- } \\
\text { related cortisol and increased } \\
\text { immunoreactivity. }\end{array}$ \\
\hline $\begin{array}{l}\text { Teper \& } \\
\text { Inzlicht, } \\
(2013)\end{array}$ & $\begin{array}{l}20 \text { experienced } \\
\text { meditators ( }>1 \text { year } \\
\text { experience) and } 18 \\
\text { non-mediators }\end{array}$ & $\begin{array}{l}\text { Experimental } \\
\text { meditator-control } \\
\text { group design. }\end{array}$ & $\begin{array}{l}\text { Experienced meditators showed greater } \\
\text { executive control (i.e. fewer Stroop errors) } \\
\text { increased ERN (Error Related Negativity) } \\
\text { amplitudes, and greater self-report mindful } \\
\text { acceptance. Additionally acceptance directly } \\
\text { predicted ERN amplitudes. }\end{array}$ \\
\hline $\begin{array}{l}\text { Wenk- } \\
\text { Sormaz, } \\
(2005)\end{array}$ & $\begin{array}{l}120 \text { undergraduates } \\
\text { for first study, } 90 \\
\text { undergraduates for } \\
\text { second study. }\end{array}$ & $\begin{array}{l}\text { Block randomized } \\
\text { experimental design } \\
\text { with meditation, } \\
\text { learning and rest } \\
\text { control groups. }\end{array}$ & $\begin{array}{l}\text { In first study, short-term meditation ( } 20 \text { min } x \\
3 \text { ) improved Stroop scores as compared to } \\
\text { controls but no differences in word stem- } \\
\text { completion scores were found. In the second } \\
\text { study, when prompted to respond atypically to } \\
\text { word stem-completion task meditation group } \\
\text { performed significantly better than control } \\
\text { groups. Both studies provide evidence that } \\
\text { mindfulness decreases habitual responding. }\end{array}$ \\
\hline $\begin{array}{l}\text { Zeidan et } \\
\text { al., } \\
(2010)\end{array}$ & 63 undergraduates & $\begin{array}{l}\text { RCT with short- } \\
\text { term (4 day) MBSR } \\
\text { training and waitlist } \\
\text { control group. }\end{array}$ & $\begin{array}{l}\text { MBSR training associated with increases in } \\
\text { several sustained attention and executive } \\
\text { function tasks including the Symbol Digit } \\
\text { Modalities Test, verbal fluency, and the N- } \\
\text { back test. }\end{array}$ \\
\hline
\end{tabular}




\section{APPENDIX B}

\section{Self-Report Measures}

\section{Somatic Body Awareness}

The following series of questions ask about your general awareness of your body. Rate your awareness of the following characteristics described below using the scale. When I am teaching in the classroom, I am able to become aware of:

\begin{tabular}{|c|c|c|c|c|c|}
\hline Questions & $\begin{array}{l}\text { Never } \\
\text { (1) }\end{array}$ & $\begin{array}{c}\text { Occasionally } \\
\text { (2) }\end{array}$ & $\begin{array}{c}\text { Sometimes } \\
\text { (3) }\end{array}$ & $\begin{array}{l}\text { Usually } \\
\text { (4) }\end{array}$ & $\begin{array}{c}\text { Always } \\
\text { (5) }\end{array}$ \\
\hline \multicolumn{6}{|l|}{ My mouth becoming dry } \\
\hline \multicolumn{6}{|l|}{ How fast I am breathing } \\
\hline \multicolumn{6}{|c|}{ Muscle tension in my body (e.g. back, neck, jaw) } \\
\hline \multicolumn{6}{|l|}{ Being exhausted } \\
\hline \multicolumn{6}{|l|}{ When I am sweating } \\
\hline \multicolumn{6}{|l|}{ The temperature of my face } \\
\hline \multicolumn{6}{|l|}{ Needing to rest } \\
\hline \multicolumn{6}{|l|}{ Having difficulty focusing } \\
\hline How hard my heart is beating & & & & & \\
\hline
\end{tabular}




\section{Emotion Regulation}

For each sentence, indicate how often each statement describes you by checking your responses using the scale to the right.

\begin{tabular}{|c|c|c|c|c|c|}
\hline Questions & $\begin{array}{c}\text { Strongly } \\
\text { Disagree } \\
(1)\end{array}$ & $\begin{array}{l}\text { Disagree } \\
\quad(2)\end{array}$ & $\begin{array}{l}\text { Unsure } \\
\text { (3) }\end{array}$ & $\begin{array}{l}\text { Agree } \\
(4)\end{array}$ & $\begin{array}{c}\text { Strongly } \\
\text { Agree } \\
(5)\end{array}$ \\
\hline \multicolumn{6}{|l|}{ Reappraisal } \\
\hline \multicolumn{6}{|c|}{ I control my emotions by changing the way I think about the situation I'm in. } \\
\hline \multicolumn{6}{|c|}{$\begin{array}{l}\text { When I want to feel less negative emotion, I change the way I'm thinking about } \\
\text { the situation. }\end{array}$} \\
\hline \multicolumn{6}{|c|}{$\begin{array}{l}\text { When I want to feel more positive emotion (such as joy or amusement), I change } \\
\text { what I'm thinking about. }\end{array}$} \\
\hline \multicolumn{6}{|l|}{ Suppression } \\
\hline \multicolumn{6}{|c|}{ When I am feeling negative emotions, I make sure not to express them. } \\
\hline \multicolumn{6}{|c|}{ I keep my emotions to myself. } \\
\hline When I am feeling & ons, I am & areful no & expre & them. & \\
\hline
\end{tabular}




\section{Anxiety}

Listed below are statements that people sometimes use to describe themselves. Please read each statement and then select the phrase that best describes the extent to which you have been feeling each one during the last two weeks (including today). Do not spend too much time on any one statement.

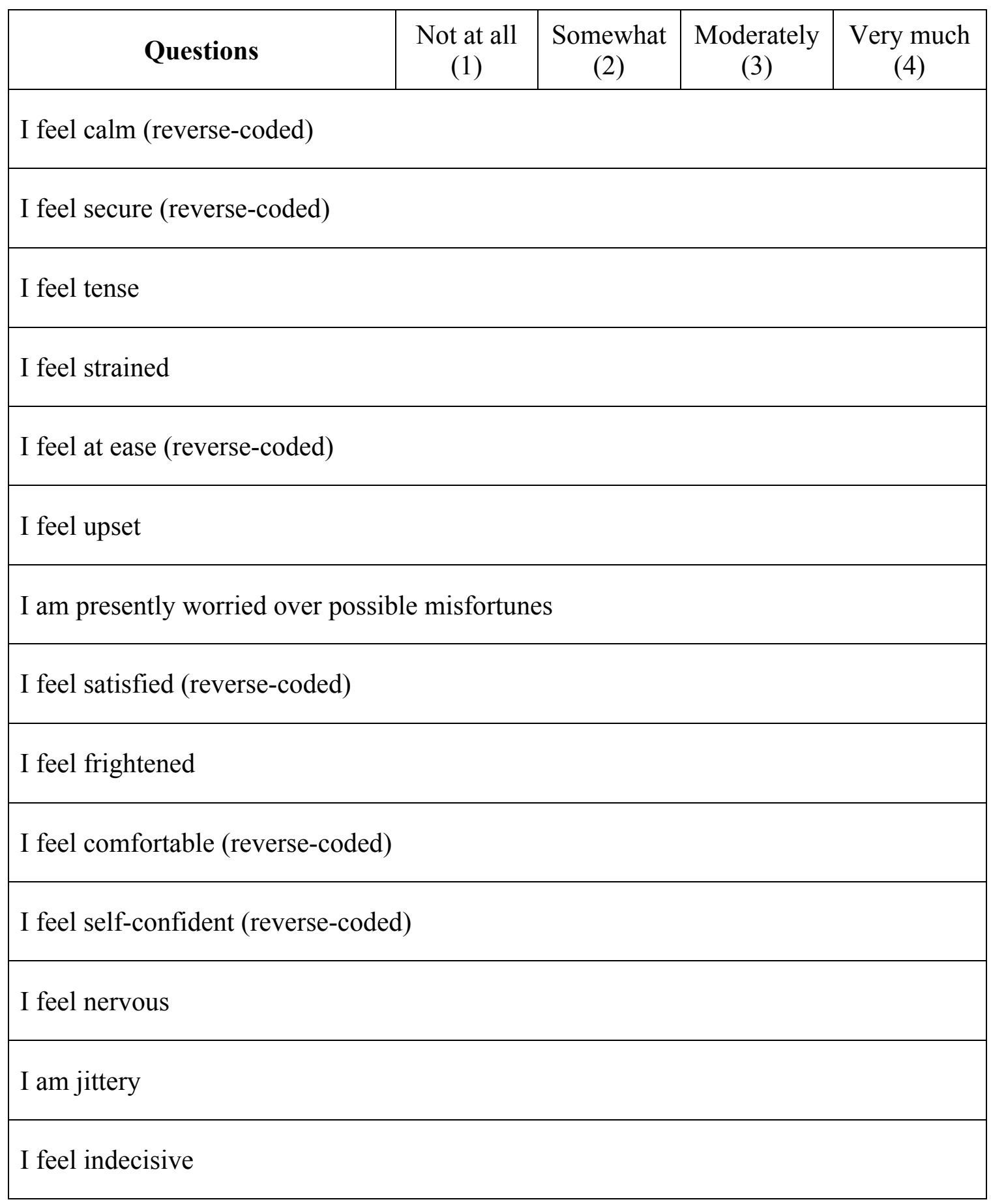




\section{Anxiety Continued}

Listed below are statements that people sometimes use to describe themselves. Please read each statement and then select the phrase that best describes the extent to which you have been feeling each one during the last two weeks (including today). Do not spend too much time on any one statement.

\begin{tabular}{|c|c|c|c|c|}
\hline Questions & $\begin{array}{l}\text { Not at all } \\
\text { (1) }\end{array}$ & $\begin{array}{c}\text { Somewhat } \\
\text { (2) }\end{array}$ & $\begin{array}{c}\text { Moderately } \\
\text { (3) }\end{array}$ & $\begin{array}{l}\text { Very much } \\
\text { (4) }\end{array}$ \\
\hline \multicolumn{5}{|l|}{ I am relaxed (reverse-coded) } \\
\hline \multicolumn{5}{|l|}{ I feel content (reverse-coded) } \\
\hline \multicolumn{5}{|l|}{ I feel worried } \\
\hline \multicolumn{5}{|l|}{ I feel confused } \\
\hline \multicolumn{5}{|l|}{ I feel steady (reverse-coded) } \\
\hline I feel pleasant (reverse-coded) & & & & \\
\hline
\end{tabular}




\section{Depression}

The following questions are about how you have been feeling lately. Please read each group of 4 statements carefully. Then pick out the one statement in each group that best describes the way you have been feeling in the PAST WEEK, INCLUDING TODAY. Please read all the statements in each group before making your choice, then check the one in each group that best describes how you have been feeling.

\section{Questions}

I do not feel sad. (1)

I feel sad. (2)

I am sad all the time and I can't snap out of it. (3)

I am so sad or unhappy that I can't stand it. (4)

I am not particularly discouraged about the future. (1)

I feel discouraged about the future. (2)

I feel I have nothing to look forward to. (3)

I feel that the future is hopeless and that things cannot improve. (4)

I do not feel like a failure. (1)

I feel I have failed more than the average person. (2)

As I look back on life, all I can see is a lot of failures. (3)

I feel that I am a complete failure as a person. (4)

I don't feel particularly guilty. (1)

I feel guilty a good part of the time. (2)

I feel quite guilty most of the time. (3)

I feel guilty all of the time. (4)

I have not lost interest in other people. (1)

I am less interested in other people than I used to be. (2)

I have lost most of my interest in other people. (3)

I have lost all of my interest in other people. (4)

I make decisions about as well as I ever could. (1)

I put off making decisions more than I used to. (2)

I have greater difficulty in making decisions than before. (3)

I can't make decisions at all anymore. (4) 


\section{Depression Continued}

The following questions are about how you have been feeling lately. Please read each group of 4 statements carefully. Then pick out the one statement in each group that best describes the way you have been feeling in the PAST WEEK, INCLUDING TODAY. Please read all the statements in each group before making your choice, then check the one in each group that best describes how you have been feeling.

\section{Questions}

I don't feel I look any worse than I used to. (1)

I am worried that I am looking old or unattractive. (2)

I feel that there are permanent changes in my appearance that make me look unattractive. (3)

I believe that I look ugly. (4)

I can work about as well as before. (1)

It takes an extra effort to get started at doing something. (2)

I have to push myself very hard to do anything. (3)

I can't do any work at all. (4)

I don't get more tired than usual. (1)

I get tired more easily than I used to. (2)

I get tired from doing almost anything. (3)

I am too tired to do anything. (4)

My appetite is no worse than usual. (1)

My appetite is not as good as it used to be. (2)

My appetite is much worse now. (3)

I have no appetite at all. (4) 


\section{Teacher Occupational Stress}

Please indicate how much you disagree or agree with each statement. Remember, there are no right or wrong answers but only your opinions. All of your responses are kept strictly confidential. (Please check a response for each statement).

\begin{tabular}{|c|c|c|c|c|c|}
\hline Questions & $\begin{array}{c}\text { Strongly } \\
\text { Disagree } \\
(1)\end{array}$ & $\begin{array}{c}\text { Disagree } \\
\text { (2) }\end{array}$ & $\begin{array}{c}\text { Unsure } \\
\text { (3) }\end{array}$ & $\begin{array}{l}\text { Agree } \\
(4)\end{array}$ & $\begin{array}{c}\text { Strongly } \\
\text { Agree } \\
(5)\end{array}$ \\
\hline \multicolumn{6}{|c|}{ I find dealing with student motivational and disciplinary problems to be very stressful } \\
\hline \multicolumn{6}{|c|}{$\begin{array}{l}\text { Having to participate in school activities outside of normal working hours is stressful } \\
\text { for me. }\end{array}$} \\
\hline \multicolumn{6}{|c|}{ I find trying to be attentive to the needs of fellow teachers is very stressful. } \\
\hline \multicolumn{6}{|c|}{ There is a lot of stress at work just keeping up with changing professional standards. } \\
\hline \multicolumn{6}{|c|}{ Job worries distract me when I am at home. } \\
\hline \multicolumn{6}{|c|}{ Stress at work makes me irritable at home. } \\
\hline \multicolumn{6}{|c|}{ Complying with state, federal, and school rules and policies is very stressful. } \\
\hline
\end{tabular}




\section{Burnout}

Thinking about the school year SO FAR, how often do you: (please check a response for each statement)

\begin{tabular}{|c|c|c|c|c|c|c|c|}
\hline Questions & $\begin{array}{c}\text { Never } \\
(1)\end{array}$ & $\begin{array}{c}\text { A few } \\
\text { times } \\
(2)\end{array}$ & $\begin{array}{c}\text { Once a } \\
\text { month or } \\
\text { less (3) }\end{array}$ & $\begin{array}{c}\text { A few } \\
\text { times a } \\
\text { month (4) }\end{array}$ & $\begin{array}{c}\text { Once a } \\
\text { week } \\
(5)\end{array}$ & $\begin{array}{c}\text { A few } \\
\text { times } \\
\text { a week } \\
(6)\end{array}$ & $\begin{array}{c}\text { Every } \\
\text { day } \\
(7)\end{array}$ \\
\hline
\end{tabular}

Feel emotionally drained from your work?

Feel used up at the end of the workday?

Feel fatigued when you get up in the morning and have to face another day on the job?

Feel that working with people all day is really a strain?

Deal very effectively with the problems of your students? (reverse-coded)

Feel burned out from your work?

Feel like you are positively influencing other people's lives through your work? (reverse-coded)

Worry that this job is hardening you emotionally?

Feel very energetic at work? (reverse-coded)

Feel frustrated by your job?

Feel you're working too hard on your job?

Feel working with people directly puts too much stress on you?

Create a relaxed atmosphere with your students? (reverse-coded)

Feel exhilarated after working closely with your students? (reverse-coded) 


\section{Burnout Continued}

Thinking about the school year SO FAR, how often do you: (please check a response for each statement)

\begin{tabular}{|l|c|c|c|c|c|c|c|}
\hline Questions & $\begin{array}{c}\text { Never } \\
(1)\end{array}$ & $\begin{array}{c}\text { A few } \\
\text { times } \\
(2)\end{array}$ & $\begin{array}{c}\text { Once a } \\
\text { month or } \\
\text { less (3) }\end{array}$ & $\begin{array}{c}\text { A few } \\
\text { times a } \\
\text { month (4) }\end{array}$ & $\begin{array}{c}\text { Once a } \\
\text { week } \\
(5)\end{array}$ & $\begin{array}{c}\text { A few } \\
\text { times a } \\
\text { week } \\
(6)\end{array}$ & $\begin{array}{c}\text { Every } \\
\text { day } \\
(7)\end{array}$ \\
\hline Feel you have accomplished many worthwhile things in this job? (reverse-coded) \\
\hline Feel like you're at the end of your rope? \\
Deal with emotional problems in the classroom very calmly? (reverse-coded) \\
Feel students blame you for some of their problems? \\
\hline
\end{tabular}

